University of Rhode Island

DigitalCommons@URI

Open Access Dissertations

2017

\title{
Experimental and Numerical Investigation of Sandwich Structures Subject to Blast Loading
}

Jefferson Townsend Wright

University of Rhode Island, jeffersonwright@gmail.com

Follow this and additional works at: https://digitalcommons.uri.edu/oa_diss

\section{Recommended Citation}

Wright, Jefferson Townsend, "Experimental and Numerical Investigation of Sandwich Structures Subject to Blast Loading" (2017). Open Access Dissertations. Paper 576.

https://digitalcommons.uri.edu/oa_diss/576

This Dissertation is brought to you for free and open access by DigitalCommons@URI. It has been accepted for inclusion in Open Access Dissertations by an authorized administrator of DigitalCommons@URI. For more information, please contact digitalcommons-group@uri.edu. 
EXPERIMENTAL AND NUMERICAL INVESTIGATION OF SANDWICH STRUCTURES SUBJECT TO BLAST LOADING

BY

JEFFERSON TOWNSEND WRIGHT

\begin{abstract}
A DISSERTATION SUBMITTED IN PARTIAL FULFILLMENT OF THE
REQUIREMENTS FOR THE DEGREE OF DOCTOR OF PHILOSOPHY
\end{abstract}

IN

MECHANICAL, INDUSTRIAL AND SYSTEMS ENGINEERING

UNIVERSITY OF RHODE ISLAND 


\section{DOCTOR OF PHILOSOPHY DISSERTATION}

OF

JEFFERSON TOWNSEND WRIGHT

\section{APPROVED:}

Dissertation Committee:

Major Professor Arun Shukla

Hongyan Yuan

Richard Brown

Nasser H. Zawia

DEAN OF THE GRADUATE SCHOOL

UNIVERSITY OF RHODE ISLAND 


\begin{abstract}
Sandwich panels have shown improved air blast performance over more traditional monolithic armor however it is an area of continuous research in order to optimize the beneficial shock mitigative properties of the sandwich structure. To that end a series of shock experiments on various sandwich panels via shock tube with high speed photography and numerical analyses via finite element method were performed to determine their efficacy for shock mitigation. Originally corrugated steel core sandwich panels were investigated varying face sheet thickness, corrugation thickness, boundary conditions, and foam infill. The hierarchy of foam infilling within the core was then iterated on and lastly, the corrugated core was replaced with an open cell foam core entrained with various Newtonian and non-Newtonian fluids to determine their behavior under shock loading. These results found that foam infilling had the greatest impact upon shock performance although the benefit decreased with increased face or corrugation thickness (increasing stiffness). When selectively filling the foam hierarchy within the core it was found that back filled (soft/hard) arrangements to be the most effective but using the foam alternately to attenuate the shock wave was not effective. Lastly, the various non-Newtonian fluid fillings were found to have detrimental effect on the performance of the sandwich structures while often being weighty.
\end{abstract}




\section{ACKNOWLEDGEMENTS}

I thank my advisor Dr. Arun Shukla for first taking me in as a research assistant and later as a graduate student and for providing his assistance, guidance, and advice throughout my time at the laboratory. He is a model professor, scientist and person to whom I will forever be grateful.

I would also like to thank Dr. Hongyan Yuan, Dr. Richard Brown, Dr. Taggart, and Dr. Tsiatas, for serving on my review committee.

I would especially like to thank the other members of the Dynamic Photomechanics Laboratory for their assistance and support during my research. To my fellow graduate students Nathaniel Gardner, Erheng Wang, Puneet Kumar, Ryan Sekac, Sandeep Abotula, Nicholas Heeder, Sachin Gupta, Dan Gracia Alex Escher, Emad Makki, Helio Matos, Payam Farh, Craig Tilton, Michael Pinto, Shyamal Kishore, Daniel Clarkin, Nicholas Denardo, Frank LiVolsi, Chris Shillings, and Abayomi N. Yussuf - my thanks and gratitude. I would also like to thank our visiting professors Murat Yazici and Idris Karen whom I had the pleasure of working with until their forced return to Turkey. In addition, I would like to thank Joe Gomez, Dave Ferriera, Jim Byrnes, Rob D'Ambrosca, Jen Cerullo, Nancy Dubee, Sally Marinelli, A. J Bothun, Donna Mattera and the rest of the mechanical engineering department faculty and staff.

To my ever supportive and encouraging family: my mother Lorraine, father Jefferson, brother Benjamin, and wife Allison thank you - no words can express my appreciation.

I would like to acknowledge the financial support provided by the US Department of Homeland Security under Award Number: 2009-ST-061-TS0011. 


\section{PREFACE}

In this dissertation the manuscript format is in use. The first manuscript "Experimental and Numerical Study of Foam Filled Corrugated Core Steel Sandwich Structures Subjected to Blast Loading" is published and in the format of the Journal of Composite Structures. The second manuscript "Preferentially Filled Foam Core Corrugated Steel Sandwich Structures for Improved Blast Performance" is published and in the format of the Journal of Applied Mechanics. The third paper "Experimental Investigation of Sandwich Panels with non-Newtonian Fluid Cores to Shock" is not yet published and is in the format of the Journal of Composites Science and Technology. 


\section{TABLE OF CONTENTS}

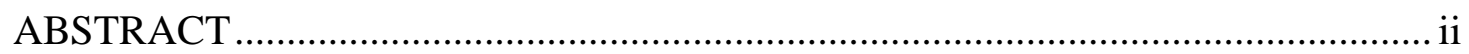

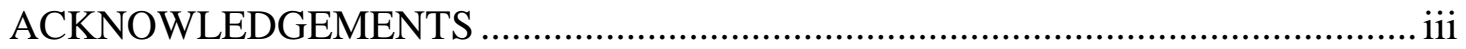

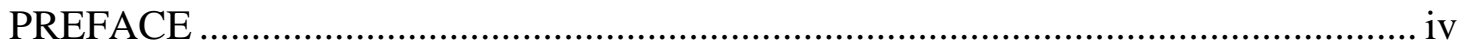

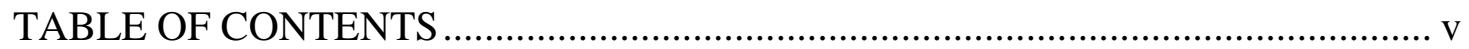

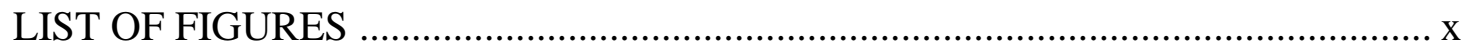

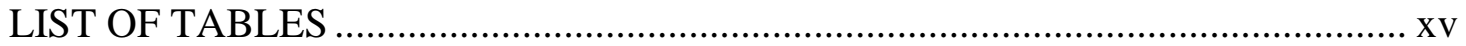

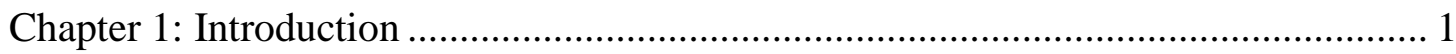

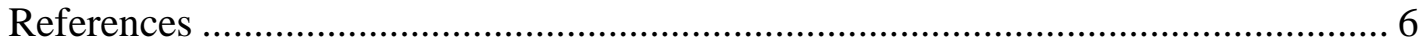

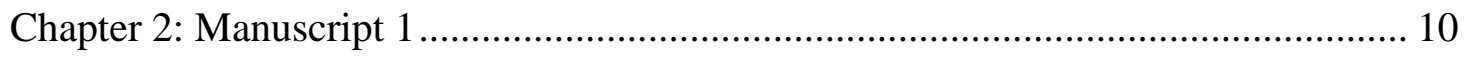

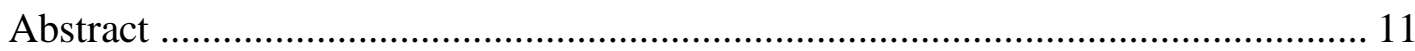

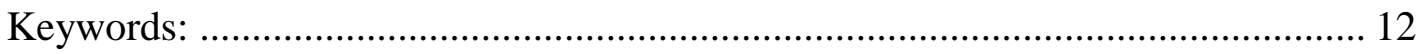

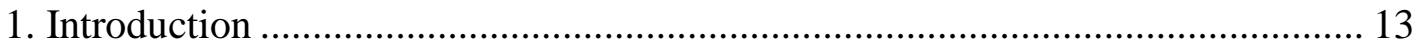

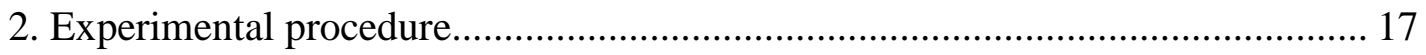

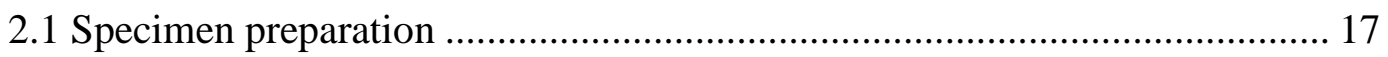

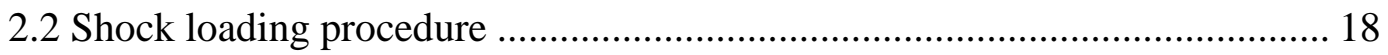

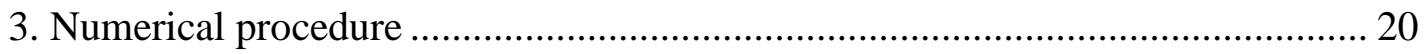

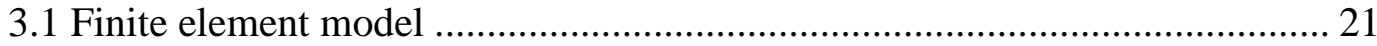

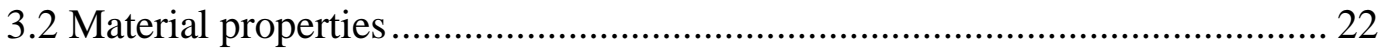


4. Experimental results and discussion

4.1 Empty corrugated steel core sandwich specimen response ......................... 24

4.2 Foam Core Sandwich Panels ...................................................................... 25

4.3 Foam Filled Corrugated Steel Core Sandwich Panels ................................. 27

4.4. Comparison of experimental mid span deflections of the sandwich panels .. 28

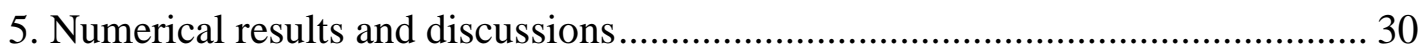

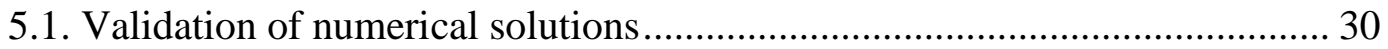

5.2 Investigation of face sheet thickness, corrugated core sheet thickness, and boundary conditions on blast performance ............................................... 33

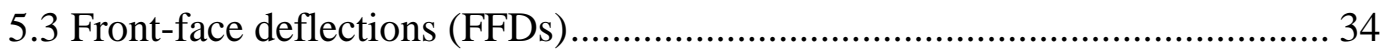

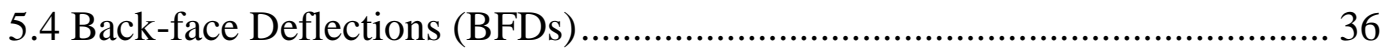

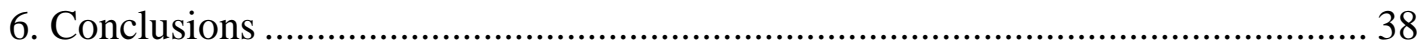

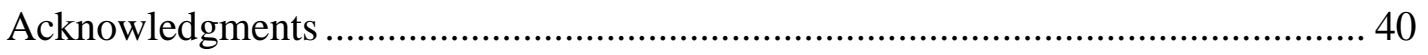

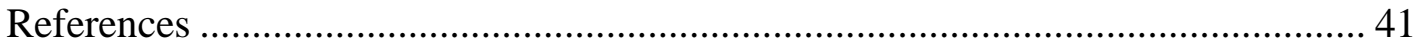

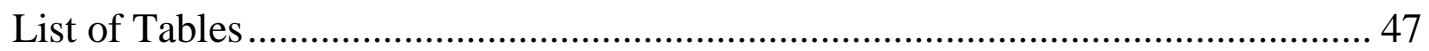

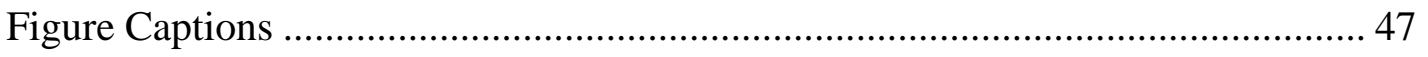

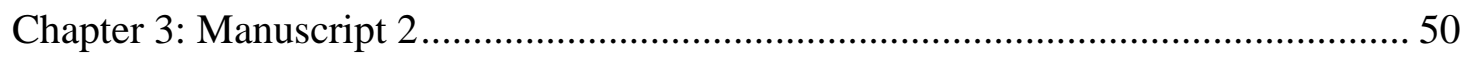

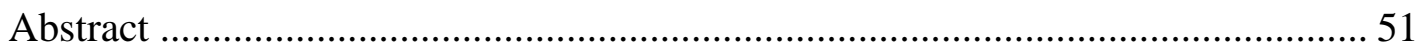

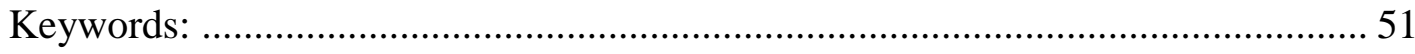

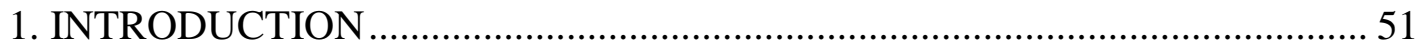




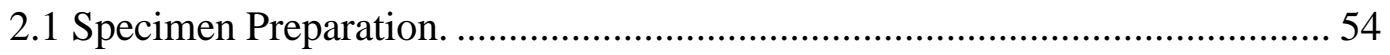

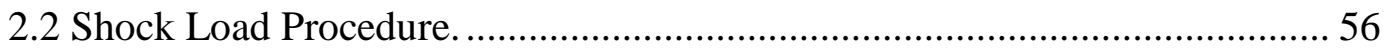

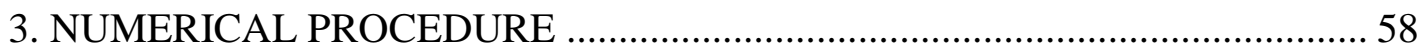

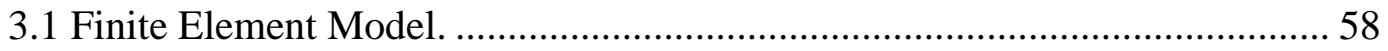

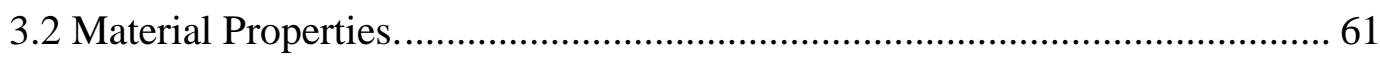

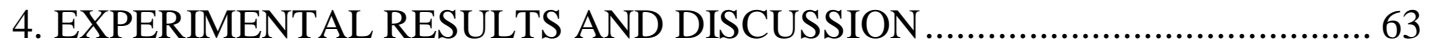

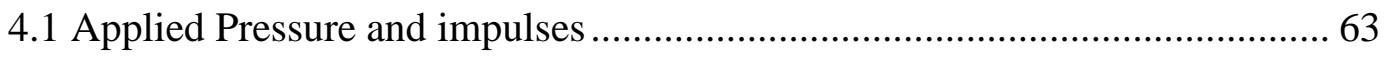

4.2 High Speed Photography and Experimental Results................................ 64

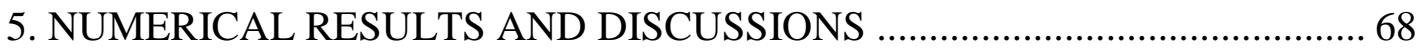

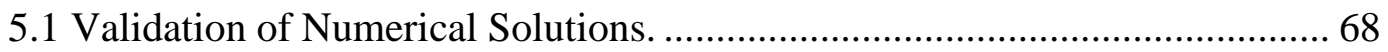

5.2 Investigation of filling hierarchy effect by FEM. ..................................... 70

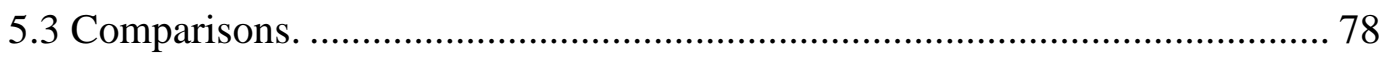

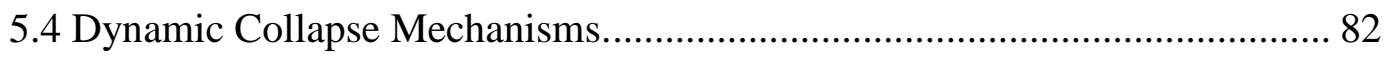

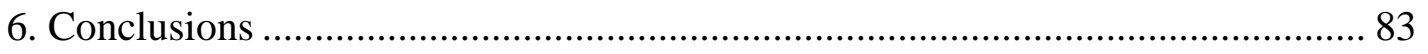

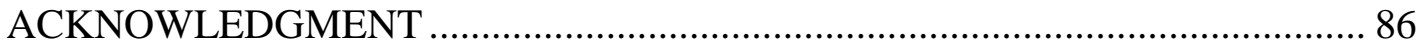

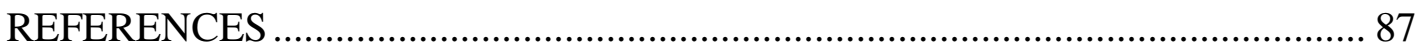

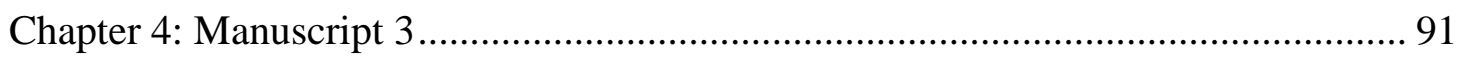

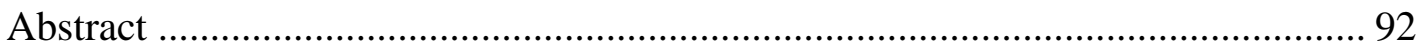

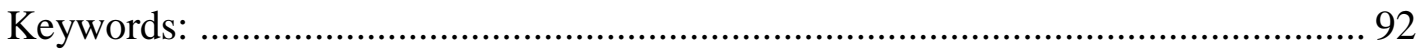


1. Introduction

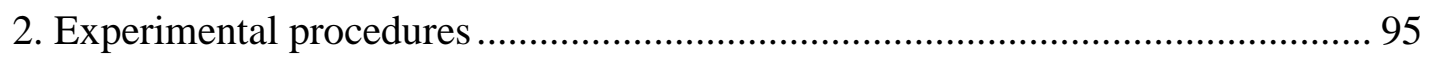

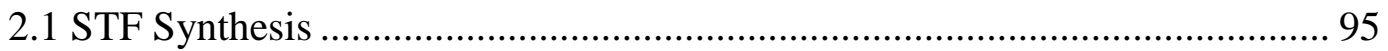

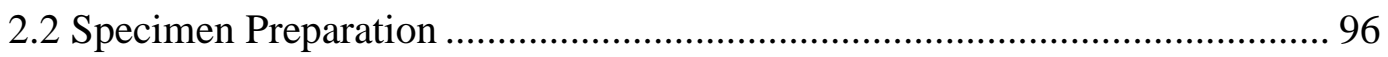

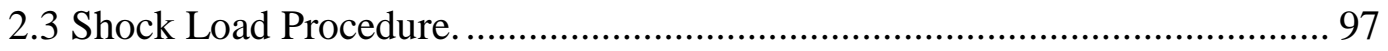

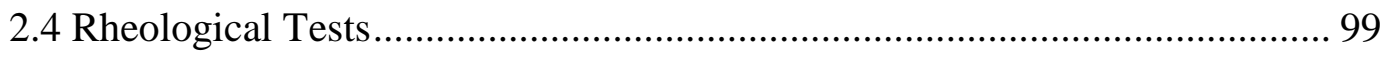

3. Experimental Results and Discussion ................................................... 100

3.1 Applied Pressure and Impulses ...................................................... 100

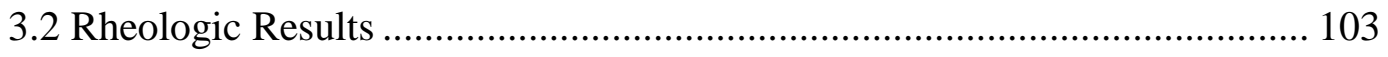

3.2.1 Viscoelastic Response of Silicone Oil .......................................... 103

3.2.2 Fumed Silica and PEG 200 ........................................................... 105

3.2.3 Calcium Carbide and PEG 200 .................................................... 105

3.2.4 Corn Starch and Water .............................................................. 106

3.3 High Speed Photography and Experimental Results.............................. 107

3.3.1 Back Face Deflections................................................................ 109

3.3.2 Front Face Deflections ............................................................ 110

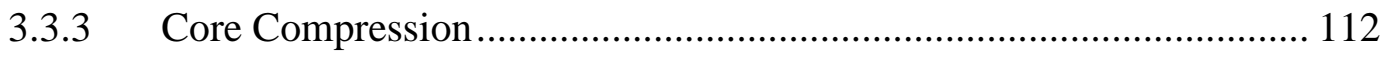

3.3.4 Post Mortem Analysis ........................................................ 116

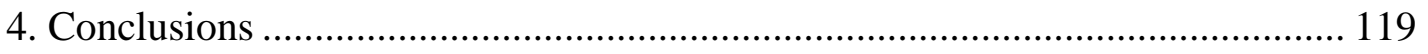

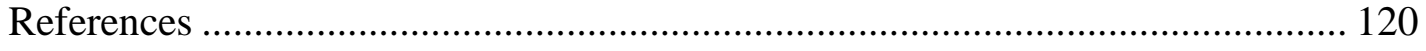


Chapter 5: Conclusions

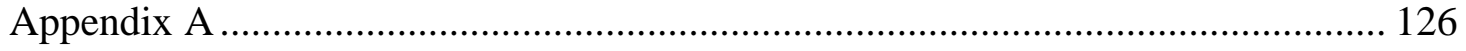




\section{LIST OF FIGURES}

Fig. 1 (a) Corrugated core sheet dimensions. (b) Assembly procedure of corrugated steel core sandwich structures. (c) Final sandwich panel side view.

Fig. 2 Schematic of the sandwich panels. (a) Empty corrugated steel core sandwich panel. (b) Foam filled corrugated steel core sandwich panel. (c) Foam core sandwich

panel. 18

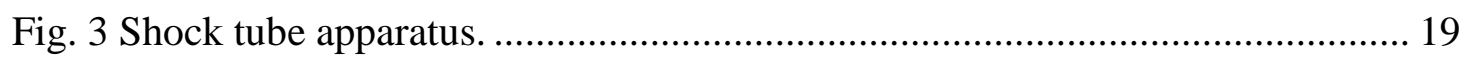

Fig. 4 Typical experimental pressure profile. ………………………………....... 19

Fig. 5 Experimental setup for real-time side-view deflection measurements............. 20

Fig. 6 (a) FEM model. (b) Pressure distribution function over loaded area. ............... 22

Fig. 7 Quasi static and high-strain rate compression response of Polyurethane foam. 23

Fig. 8 High-speed images of unfilled corrugated steel core sandwich panel during

shock loading.

Fig. 9 Experimental results for empty corrugated steel core sandwich panels under shock loading. (a) Front-face and back-face out of plane velocities. (b) Front-Face Deflection (FFD), Back-Face Deflection (BFD), core compression, and strain rate of the core.

Fig. 10 High-speed images of foam core sandwich specimen during shock loading. . 26 Fig. 11 Experimental results for foam core sandwich panels under shock loading: Front Face Deflection (FFD), Back Face Deflection (BFD), core compression, and strain rate of the core.

Fig. 12 High-speed images of fully foam filled corrugated core sandwich specimen during shock loading. 
Fig. 13 Experimental results for foam fillet corrugated steel core sandwich panels under shock loading. (a) Front face and back face out of plane velocities. (b) Front Face Deflection (FFD), Back Face Deflection (BFD), core compression, and strain rate of the core.

Fig. 14 Experiments results of (a) average Back-Face Deflections (BFDs), (b) average Front-Face Deflections (FFDs) for all the three configurations 30 Fig. 15 Corrugated steel core sandwich panel FFD and BFD variation by foam filling.

Fig. 16 Validation of FEM simulations with the experimental results for single face sheet, empty corrugated core sandwich panels, foam core sandwich panels and foam filled sandwich panels.

Fig. 17 Boundary conditions used in FEM simulations

Fig. 18 Specific front-face deflections of empty corrugated steel core (E) and foam filled corrugated steel core (FF) sandwich panels depend on Face Sheet Thickness (FST), Corrugated Sheet Thickness (CST), Boundary Conditions (BC) which are Simple Supported (SS) and Encastre Supported (ES).

Fig. 19 Specific back-face deflections of empty corrugated steel core (E) and foam filled corrugated steel core (FF) sandwich panels depend on Face Sheet Thickness (FST), Corrugated Sheet Thickness (CST), Boundary Conditions (BC) which are Simple Supported (SS) and Encastre Supported (ES).

Fig. 1 Corrugated core with interstitial layering arrangment and $(b)$ Illustration of six

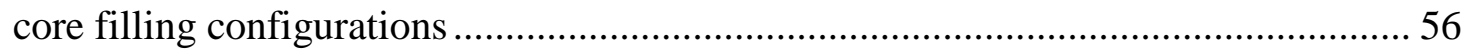
Fig. 2 Typical experimental pressure profile .................................................... 57 
Fig. 3 High-speed camera side-view deflection measurement.

Fig. 4 (a) Assembly of Sandwich Structure as a Finite Element Model for F3F4F5 filled corrugated steel core sandwich panel. (b) Pressure distribution on applied surface 60

Fig. 5 (a) Blast pressures subjected to specimen in shock tube experiments and $(b)$ Specific Impulses subjected to shock tube experiments 60

Fig. 6 Quasi static and high-strain rate compression properties of the PU foam. 62

Fig. 7 High-speed images of the foam filled corrugated core sandwich specimens .... 67

Fig. 8 Shock tube experimental results depend on filling hierarchy of the sandwich

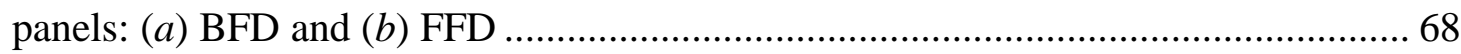

Fig. 9 FEM and experimental empty corrugated steel core sandwich specimen: $(a)$ FFD and $(b)$ BFD

Fig. 10 FEM and experimental foam filled corrugated steel core sandwich specimen:

(a) FFD and (b) BFD 69

Fig. 11 Categorization of analyzed models by type of configuration ..... 71

Fig. 12 Front filled panel configurations' deflection over time: (a) FFD and (b) BFD72

Fig. 13 Back filled panel configurations' deflection over time: (a) FFD and (b) BFD73 Fig. 14 Middle filled panel configurations' deflection over time: $(a)$ FFD and (b) BFD

Fig. 15 Both sides filled panel configurations' deflection over time: $(a)$ FFD and $(b)$ BFD 75

Fig. 16 Alternately filled panel configurations' deflection over time: $(a)$ FFD and $(b)$ BFD 76 
Fig. 17 Boundary conditions used in FEM simulations.

Fig. 18 Comparison of filling hierarcy with respect equivalent number of filled layers:

(a) four filled layers FFD, (b) four filled layers BFD, $(c)$ three filled layers FFD, $(d)$ three filled layers BFD, $(e)$ two filled layers FFD, $(f)$ two filled layers BFD, $(g)$ one

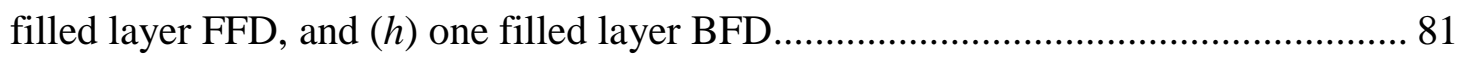

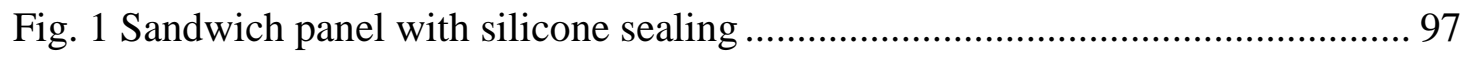

Fig. 2 Typical experimental pressure profile .................................................... 98

Fig. 3 (a) Shock Tube at the DPML Facility (b) Diagram of the Muzzle of the Shock

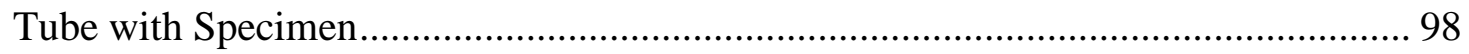

Fig. 4 High-Speed Photography System with Speckle Pattern [11] ......................... 99

Fig. 5 Blast pressures specimen subjected to in shock tube experiments ................. 101

Fig. 6 Average Impulses imparted on the fluid filled panels by infill .................... 102

Fig. 7 The complex moduli of glycerin (Newtonian Fluid) and silicone oil (non-

Newtonian viscoelastic) over a range of frequencies........................................ 104

Fig. 8 Effect of shear rate on the viscosity of silicone oil and glycerin ................... 104

Fig. 9 Effect of shear rate on the viscosity of Fumed Silica and PEG 200 .............. 105

Fig. 10 Effect of shear rate on the viscosity of Calcium Carbonate and PEG 200 .... 106

Fig. 11 Effect of shear rate on the viscosity of corn starch and water ..................... 107

Fig. 12 High-speed images of the sandwich specimens .................................... 108

Fig. 13 BFD of sandwich panels exposed to shock wave ................................... 110

Fig. 14 FFD of sandwich panels exposed to shock wave .................................... 111

Fig. 15 Core compression of air filled sandwich panels .................................... 113

Fig. 16 Core compression of glycerin filled sandwich panels ............................. 114 
Fig. 17 Core compression of silicon oil filled sandwich panels

Fig. 18 Core compression of oobleck filled sandwich panels

Fig. 19 Core compression of water filled sandwich panels

Fig. 20 Damage pattern 1 specimens (a) air filled specimen (b) side view without debonding (c) side view with debonding and tearing of silicon barrier.

Fig. 21 Damage pattern 2 specimens (a) oobleck filled specimen (b) side view with debonding and shear cracking (c) side view with debonding and core extraction..... 118 


\section{LIST OF TABLES}

Table 1 Johnson Cook parameters for low carbon steel used in FEM analysis [42]... 23

Table 2 Predictability of the model for the deflection of the panel configurations. .... 31

Table 3 Investigated parameters in FEM simulations of empty and foam filled

corrugated steel core sandwich panels. ........................................................ 34

Table 4 Calculated masses of FEM models for the empty corrugated steel core

sandwich panels.

Table 1 Low carbon steel Johnson Cook Parameters in FEM analysis [31].............. 61

Table 2 Predictability of the Model for the Deflection of the Panel Configurations .. 61

Table 1 Density of the Foam Infills with Correlating Average Impulses ................. 102

Table 2 Density and quasi static viscosity of liquids ....................................... 103 


\section{Chapter 1: Introduction}

The search for light weight blast mitigative armor to protect structures from high-intensity dynamic loads, created by explosions, has stimulated interest in the mechanical response of sandwich armor. With the fast development of modern military technology, monolithic plates are continuing to fall behind the desired levels of blast protection. Sandwich structures (structures with two similar face plates with a core in between which often has differing geometry or material than the face plates) with cellular solid cores, such as metallic foams and honeycomb structures, have shown superior weight specific stiffness and strength properties compared to their monolithic counterparts in blast resistant structural applications. Their cellular microstructure allows them to undergo large deformation at nearly constant nominal stress and thus absorb more energy [1-3].

In recent years, a number of micro-architectured materials have been developed to use as cores in sandwich panels. These include pyramidal cores [4-6], diamond celled lattice cores [7], corrugated cores [8], hexagonal honeycomb cores [9], foam cores [10], and square honeycomb cores [11]. The benefits of sandwich construction depend on core topology. Core designs that afford simultaneous crushing and stretching resistance are preferred. One of the most preferred practical core topologies in blast resistant sandwich panel construction is the corrugated metallic core. These cores provide manufacturing advantages as well as high strength in both the normal and longitudinal directions of the structures [7, 12, \& 13].

Sandwich structures have various energy dissipation mechanisms, such as bending and stretching of the face sheet, as well as compression and shear of the core. 
This is especially pertinent in the case of impulsive loading, wherein the interstices in the metal cellular core can provide adequate space for the large plastic deformation, which is an efficient mechanism to dissipate the energy produced by blast impact [1417]. During blast loading, the cellular solid core can absorb more than one half of the initial kinetic energy imparted to face sheet of the sandwich plate. This is due to crushing in the early stages of deformation, prior to significant overall bending and stretching, which causes a reduction in the separation between the face sheets. The high crushing strength and energy absorption per unit mass of the core is therefore important [18-22].

Different material properties have been suggested to provide blast attenuation. Depending on the acoustic impedance of the interacting medium, the shock wave will reflect, transmit, and/or dissipate to differing degrees [23]. Zhuang et al. [24] examined the scattering effects of stress waves in layered composite materials. Their experimental results show that due to the scattering effects, shock propagation in the layered composites was dramatically slowed, and that shock speed in composites can be lower than that of either of its components. Wakabayashi et al. conducted experiments that suggest that low-density materials may provide the most effective blast mitigation [25]. In recent years, sandwich structures with strong face sheets and lightweight cores have become central structural components for blast mitigation. Polymeric foams offer unique structural, impact, thermal and acoustic properties, which make them an excellent choice as core materials to obtain low density blast resistive sandwich structures $[2,26]$. Based on these ideas, extensive research on blast 
mitigating layered sandwich structures has been performed in recent years, using foam cores with different wave impedances to minimize shock effect [27-29].

Studies on metallic sandwich panels subjected to air blasts $[8,17]$ indicate that sandwich plates with high ductility and high energy absorption capacity per unit areal mass show good performance. Liang et al. [30] and Wei et al. [31] studied the behavior of metallic sandwich cores with varying strengths and found that soft cores (those in which the core is much less stiff then the sandwich panels' faces) reduce the momentum transferred, thus providing better mitigation for blast loading. For metallic structures, energy absorption in metallic lattice cores is through large scale plasticity, shear and compressive buckling, and eventual tearing of core walls and face sheets [26].

Another possible application of structural foams is for use as a filler material inside cellular metallic core sandwich structures. It is possible to obtain a new sandwich structure by combining these two cores' shock absorption advantages and decrease the transmitted shock load due to differing acoustic impedances. Moreover, foam filling stabilizes the core cell walls against buckling and increases the strength of the core. Vaziri et al. [21] studied two different types of PVC foam filled stainless steel honeycomb and folded core sandwich plates using FEM under various restrictions. They found no clear advantage or disadvantage implemented by foam filling for structural purpose under quasi static and impact loading.

Jhaver and Tippur [32] investigated syntactic foam filled aluminum honeycomb composites compression response by experimental and computational methods. They obtained considerable increases in elastic modulus and plateau stress 
through foam filling the honeycomb composites. Murray et al. [33] studied polymer filled aluminum honeycomb structures to investigate the filling effect on damping using numerical methods with experimental validations. It was found that high damping improvements in the filled honeycomb explained the significant strain energy in the polymeric infill due to the Poisson's mismatch between the honeycomb and the infill. Yungwirth et al. [34] showed that low modulus elastomer infill in pyramidal lattice truss metallic core increased the impact energy absorption capacity. Other studies have had success improving the impact resistance of honeycomb cores by fully or partially filling the cells of the honeycomb [35-38].

Recently, functionally graded foams (where the material properties vary continuously, or stepwise, within the material itself) have gained attention in improving energy absorbing capabilities of sandwich structures. Gardner et al. [27] found that the higher number of layers of increasing impedance improved performance (up to the maximum studied of four). The increasing material interfaces allow for blast wave scattering/dispersion of through interface variations and stepwise compression of the core. Wang et al. [29] studied stepwise graded foam core composite sandwich plates. Three layer cores arranged via acoustic impedance were used in two different configurations: low-mid-high and mid-high-low. In the first configuration, the properties of the layers gradually increased and obtained better performance than the second configuration. Work has also been done with the stepwise increasing of metallic core corrugation thickness, similar to the foams mentioned above but focusing on increasing stiffness rather than impedance. The 
findings shows that a gradual increase in core stiffness from front to back results in the most effective formation for blast mitigation similar to the foams [39-41].

Shear thickening fluids, also known as dilatants, are non-Newtonian fluids that are characterized by a nonlinear increase in viscosity with increasing shear rate. These fluids have a number of applications but recently have been actively and numerously investigated for their potential use as additives to body armor (typically fibrous body armor) as they allow for smaller more flexible armor (as the relatively slow shear rate from human activity results in low viscosity) with greater ballistic protection (when the high shear rate ballistic impact results in high viscosity which dissipates the impact). This behavior and use of shear thickening fluids has been extensively studied by Wagner [42-45]. The use of these materials in shock mitigation, however, has been sparsely investigated with a review of the literature revealing only two investigations into the topic, each with a limited focus, and reaching opposite conclusions [46, 47]. 


\section{References}

[1] Zhu F, Lu GA. Review of blast and impact of metallic and sandwich structures. Electron J Struct Eng 2007:92-101. Loading on structures:.

[2] Gibson LJ, Ashby MF. Cellular solids: structure and properties. $2^{\text {nd }}$ ed. Cambridge: Cambridge University Press; 1997.

[3] Hanssen AG, Enstock L, Langseth M. Close-range blast loading of aluminum foam panels. Int J Impact Eng 2002; 27:593-618.

[4] Dharmasena KP, Wadley HNG, Williams K, Xue Z, Hutchinson JW. Response of metallic pyramidal lattice core sandwich panels to high intensity impulsive loading in air. Int J Impact Eng 2011; 38:275-89.

[5] Dharmasena KP, Queheillalt DT, Wadley HNG, Dudt P, Chen Y, Knight D, et al. Dynamic compression of metallic sandwich structures during planar impulsive loading in water. Eur J Mech A-Solid 2010; 29 (1):56-67.

[6] Wadleya H, Dharmasena K, Chen Y, Dudt P, Knight D, Charette R, et al. Compressive response of multilayered pyramidal lattices during underwater shock loading. Int J Impact Eng 2008; 35(9):1102-14.

[7] Fleck NA, Deshpande VS. The resistance of clamped sandwich beams to shock loading. J Appl Mech-T ASME 2004; 71:386-401.

[8] Xue ZY, Hutchinson JW. A comparative study of impulse-resistant metal sandwich plates. Int J Impact Eng 2004; 30(10):1283-305.

[9] Theobald MD, Langdon GS, Nurick GN, Pillay S, Heyns A, Merrett RP. Large inelastic response of unbonded metallic foam and honeycomb core sandwich panels to blast loading. Compos Struct 2010; 92(10):2465-75.

[10] Langdon GS, von Klemperer CJ, Rowland BK, Nurick GN. The response of sandwich structures with composite face sheets and polymer foam cores to airblast loading: preliminary experiments. Eng Struct 2012; 36:104-12.

[11] Rathbun HJ, Radford DD, Xue Z, He MY, Yang J, Deshpande V, et al. Performance of metallic honeycomb-core sandwich beams under shock loading. Int J Solids Struct 2006; 43:1746-63.

[12] Valdevit L, Wei Z, Mercer C, Zok FW, Evans AG. Structural performance of near optimal sandwich panels with corrugated cores. Int J Solids Struct 2006; 43(16):4888-905. 
[13] Qiu X, Deshpande VS, Fleck NA. Finite element analysis of the dynamic response of clamped sandwich beams subject to shock loading. Eur J Mech Ap Solid 2003; 22:801-14.

[14] Cui X, Zhao L, Wang Z, Zhao H, Fang D. Dynamic response of metallic lattice sandwich structures to impulsive loading. Int J Impact Eng 2012; 43:1-5.

[15] Evans AG, Hutchinson JW, Ashby MF. Multifunctionality of cellular metal systems. Prog Mater Sci 1998; 43(3):171-221.

[16] Nurick GN, Langdon GS, Chi Y, Jacob N. Behaviour of sandwich panels subjected to intense air blast - Part 1: experiments. Compos Struct 2009; 91:43341.

[17] Xue ZY, Hutchinson JW. Preliminary assessment of sandwich plates subject to blast loads. Int J Mech Sci 2003; 45(4):687-705.

[18] Tilbrook MT, Deshpande VS, Fleck NA. Underwater blast loading of sandwich beams: regimes of behaviour. Int J Solids Struct 2009; 46:3209-21.

[19] Tilbrook MT, Deshpande VS, Fleck NA. The impulsive response of sandwich beams: analytical and numerical investigation of regimes of behaviour. J Mech Phys Solids 2006; 54:2242-80.

[20] Karagiozova D, Nurick GN, Langdon GS. Behaviour of sandwich panels subject to intense air blasts - Part 2: numerical simulation. Compos Struct 2009; 91:44250 .

[21] Vaziri A, Xue Z, Hutchinson JW. Metal sandwich plates with polymer foam filled cores. J Mech Mater Struct 2006; 1(1):95-125.

[22] Gupta S, Shukla A. Blast performance of marine foam core sandwich composites at extreme temperatures. Exp Mech 2012; 52(9):1521-34.

[23] Schimizze B, Son SF, Goel R, Vechart AP, Young L. An experimental and numerical study of blast induced shock wave mitigation in sandwich structures. Appl Acoust 2013; 74(1):1-9.

[24] Zhuang S, Ravichandran G, Grady DE. An experimental investigation of shock wave propagation in periodically layered composites. J Mech Phys Solids 2003; 51:245-65.

[25] Homae T, Wakabayashi K, Matsumura T, Nakayama Y. Reduction of explosion damage using sand or water layer. In: Proceedings of the conference of the American Physical Society topical group on shock compression of condensed matter (AIP Conf. Proc. 955), 24-29 June, 2007, Waikoloa. p. 1289-92. 
[26] Avachat S, Zhou M. Effect of face sheet thickness on dynamic response of composite sandwich plates to underwater impulsive loading. Exp Mech 2012; 52(1):83-93.

[27] Gardner N, Wang E, Shukla A. Performance of functionally graded sandwich composite beams under shock wave loading. Compos Struct 2012; 94:1755-70.

[28] Liu X, Tian X, Lu TJ, Zhou D, Liang B. Blast resistance of sandwich-walled hollow cylinders with graded metallic foam cores. Compos Struct 2012; 94:248593.

[29] Wang E, Gardner N, Shukla A. The blast resistance of sandwich composites with stepwise graded cores. Int J Solids Struct 2009; 46:3492-502.

[30] Liang YM, Spuskanyuk AV, Flores SE, Hayhurst DR, Hutchinson JW, McMeeking RM, et al. The response of metallic sandwich panels to water blast. J Appl Mech-T ASME 2007; 74(1):81-99.

[31] Wei Z, Deshpande VS, Evansa AG, Dharmasena KP, Queheillalt DT, Wadley HNG, et al. The resistance of metallic plates to localized impulse. J Mech Phys Solids 2008; 56(5):2074-91.

[32] Jhaver R, Tippur H. Characterization and modeling of compression behavior of syntactic foam-filled honeycombs. J Reinf Plast Compos 2010; 29(21): 3185-96.

[33] Murray G, Gandhi F, Hayden E. Polymer-filled honeycombs to achieve a structural material with appreciable damping. J Intell Mater Syst Struct 2012; 23(6):703-18.

[34] Yungwirth CJ, Radford DD, Aronson M, Wadley HNG. Experiment assessment of the ballistic response of composite pyramidal lattice truss structures. Compos Part B-Eng 2008; 39:556-69.

[35] Wu CL, Weeks CA, Sun CT. Improving honeycomb-core sandwich structures for impact resistance. J Adv Mater 1995; 26(4):41-7.

[36] Resewski C, Buchgraber W. Properties of new polyimide foams and polyimide foam filled honeycomb composites. Materialwiss Werkst 2003; 34(4):365-9.

[37] Vaidya UK, Ulven C, Pillay S, Ricks H. Impact damage of partially foam-filled co-injected honeycomb core sandwich composites. J Compos Mater 2003; 37(7):611-26.

[38] Vaidya UK, Kamath MV, Mahfuz H, Jeelani S. Low velocity impact response of resin infusion molded foam filled[39] Zhang, L., Hebert, R., Wright, J. T., Shukla, 
A., Kim, J.-H., 2014, Dynamic Response of Corrugated Steel Plates With Graded Cores. Int. J. Impact Eng., 65, pp. 185-194.

[40] Wright, J., Hebert, R., Maddala, D., Shukla, A., 2014, Experimental Study on the Response of Graded Corrugated Steel Armor to Shock Loading. Meccanica, 50(2), pp. 479-492.

[41] Yazici, M., Wright, J., Bertin, D., Shukla, A., 2014, Preferentially Filled Foam Core Corrugated Steel Sandwich Structures for Improved Blast Performance. J Apl Mech, 82, pp 061005-1-15

[42] Fritz, G., Maranzano, B., Wagner, N., Willenbacher, N., 2002, High Frequency Rheology of Hard Sphere Colloidal Dispersions Measured with a Torsional Resonator. J. Non-Newtonian Fluid Mech. 102, pp. 149-156.

[43] Lim, A., Lopatnikov, S., Wagner, N., Gillespie, J., 2010, An Experimental Investigation into the Kinematics of a Concentrated Hard-Sphere Colloidal Suspension during Hopkinson Bar Evaluation at High Stresses. J. Non-Newtonian Fluid Mech. 165, pp. 1342-1350.

[44] Bian, X., Litvinov, S., Ellero, M., Wagner, N., 2014, Hydrodynamic Shear Thickening of Particulate Suspension under Confinement. J. Non-Newtonian Fluid Mech. 213, pp. 39-49.

[45] Cwalina, C., Dombrowski, R., McCutcheon, C., Christiansen, E., Wagner, N., 2015, MMOD Puncture Resistance of EVA Suits with Shear Thickening Fluid (STF) - Armor $^{\text {tm }}$ Absorber Layers. Procedia Engineering. 103, pp. 97-104.

[46] Dawson, M. A., 2009, Composite Plates with a Layer of Fluid-Filled, Reticulated Foam for blast Protection of Infrastructure, Int J Impact Eng, 36, pp. 1288-1295.

[47] Harris, A., Lee, H., Tay, T., Tan, V., 2015, Shear Thickening Fluid Impregnated Ballistic Fabric Composites for Shock Wave Mitigation, Int J Impact Eng, 80, pp. 143-151. 


\title{
Chapter 2: Manuscript 1
}

Published in the Journal of Composite Structures, April 2014, 110

\section{Experimental and Numerical Study of Foam Filled Corrugated Core Steel Sandwich Structures Subjected to Blast Loading}

\author{
MURAT YAZICI ${ }^{\mathrm{a}}$, JEFFERSON WRIGHT $^{\mathrm{b}}$, DAMIEN BARTIN $^{\mathrm{b}}$, ARUN \\ SHUKLA ${ }^{b^{*}}$ \\ ${ }^{a}$ Uludag University, Engineering Faculty, Automotive Engineering Department, \\ TR16059 Bursa/TURKEY
}

${ }^{\mathrm{b}}$ University of Rhode Island, Dynamic Photomechanics Laboratory, Department of Mechanical, Industrial, and Systems Engineering, 92 Upper College Road; Kingston, 02881, RI, USA 


\begin{abstract}
The influence of foam infill on the blast resistivity of corrugated steel core sandwich panels was investigated experimentally using a shock tube facility and high speed photography and numerically through Finite Element Methods (FEM). After verifying the finite element model, numerical studies were conducted to investigate the effect of face sheet thickness $(1,3$ and $5 \mathrm{~mm})$, corrugated sheet thickness $(0.2 \mathrm{~mm}$, $0.6 \mathrm{~mm}$ and $1 \mathrm{~mm}$ ), and boundary conditions (Simple Supported and Encastre Supported on the back sides) on blast performance. Experimental and FEM results were found to be in good agreement with $\mathrm{R} 2$ values greater than 0.95 . The greatest impact on blast performance came from the addition of foam infill, which reduced both the back-face deflections and front-face deflections by more than $50 \%$ at $3 \mathrm{~ms}$ after blast loading at a weight expense of only $2.3 \%$. However, increasing face sheet thickness and corrugated sheet thickness decreased the benefit obtained from foam filling in the sandwich structure. Foam infill benefits were more prominent for Simple Supported edge case than Encastre Supported edge case.
\end{abstract}




\section{Keywords:}

Sandwich panel, Blast loading, Corrugated steel core, Polymer foam infill, FEM, Shock tube 


\section{Introduction}

A major consideration in the design of military vehicles is their resistance to explosive blast loading. With the fast development of modern military technology, monolithic plates are continuing to fall behind the desired levels of blast protection. Sandwich structures with cellular solid cores, such as metallic foams and honey-comb structures, have shown superior weight specific stiffness and strength properties compared to their monolithic counterparts in blast resistant structural applications. Their cellular microstructure allows them to undergo large deformation at nearly constant nominal stress and thus absorb more energy [1-3]. To date, the effect of foam filling on blast mitigation of corrugated core sandwich panels under shock loads has not been fully understood. In this study, shock tube experiments and FEM were used to investigate the influence of foam infill on the blast resistivity of corrugated steel core sandwich panels. In addition, monolithic face sheets and foam core sandwich panels were tested and analyzed to validate the FEM. More studies were numerically conducted to investigate the effect of face sheet thickness and corrugated sheet thickness under two different boundary conditions, namely simply supported and Encastre Supported. In order to see the effect of corrugated core rigidity, soft, medium, and hard core cases were studied numerically utilizing both filled and empty conditions under blast loading.

In recent years, a number of micro-architectured materials have been developed to use as cores in sandwich panels. These include pyramidal cores [4-6], diamond celled lattice cores [7], corrugated cores [8], hexagonal honeycomb cores [9], foam cores [10], and square honeycomb cores [11]. The benefits of sandwich 
construction depend on core topology. Core designs that afford simultaneous crushing and stretching resistance are preferred. One of the most preferred practical core topologies in blast resistant sandwich panel construction is the corrugated metallic core. These cores provide manufacturing advantages as well as high strength in both the normal and longitudinal directions of the structures $[7,12,13]$.

Sandwich structures have various energy dissipation mechanisms, such as bending and stretching of the face sheet, as well as compression and shear of the core. This is especially pertinent in the case of impulsive loading, wherein the interstices in the metal cellular core can provide adequate space for the large plastic deformation, which is an efficient mechanism to dissipate the energy produced by blast impact [1417]. During blast loading, the cellular solid core can absorb more than one half of the initial kinetic energy imparted to face sheet of the sandwich plate. This is due to crushing in the early stages of deformation, prior to significant overall bending and stretching, which causes a reduction in the separation between the face sheets. The high crushing strength and energy absorption per unit mass of the core is therefore important [18-22].

Different material properties have been suggested to provide blast attenuation. Depending on the acoustic impedance of the interacting medium, the shock wave will reflect, transmit, and/or dissipate to differing degrees [23]. Zhuang et al. [24] examined the scattering effects of stress waves in layered composite materials. Their experimental results show that due to the scattering effects, shock propagation in the layered composites was dramatically slowed, and that shock speed in composites can be lower than that of either of its components. 
Wakabayashi et al. conducted experiments that suggest that low-density materials may provide the most effective blast mitigation [25]. In recent years, sandwich structures with strong face sheets and lightweight cores have become central structural components for blast mitigation. Polymeric foams offer unique structural, impact, thermal and acoustic properties, which make them an excellent choice as core materials to obtain low density blast resistive sandwich structures [2,26]. Based on these ideas, extensive research on blast mitigating layered sandwich structures has been performed in recent years, using foam cores with different wave impedances to minimize shock effect [27-29].

Studies on metallic sandwich panels subjected to air blasts $[17,8]$ indicate that sandwich plates with high ductility and high energy absorption capacity per unit areal mass show good performance. Liang et al. [30] and Wei et al. [31] studied the behavior of metallic sandwich cores with varying strengths and found that soft cores (those in which the core is much less stiff then the sandwich panels' faces) reduce the momentum transferred, thus providing better mitigation for blast loading. For metallic structures, energy absorption in metallic lattice cores is through large scale plasticity, shear and compressive buckling, and eventual tearing of core walls and face sheets [26].

Another possible application of structural foams is for use as a filler material inside cellular metallic core sandwich structures. It is possible to obtain a new sandwich structure by combining these two cores' shock absorption advantages and decrease the transmitted shock load due to differing acoustic impedances. Moreover, foam filling stabilizes the core cell walls against buckling and increases the strength of 
the core. Vaziri et al. [21] studied two different types of PVC foam filled stainless steel honeycomb and folded core sandwich plates using FEM under various restrictions. They found no clear advantage or disadvantage implemented by foam filling for structural purpose under quasi static and impact loading.

Jhaver and Tippur [32] investigated syntactic foam filled aluminum honeycomb composites compression response by experimental and computational methods. They obtained considerable increases in elastic modulus and plateau stress through foam filling the honeycomb composites. Murray et al. [33] studied polymer filled aluminum honeycomb structures to investigate the filling effect on damping using numerical methods with experimental validations. It was found that high damping improvements in the filled honeycomb explained the significant strain energy in the polymeric infill due to the Poisson's mismatch between the honey-comb and the infill. Yungwirth et al. [34] showed that low modulus elastomer infill in pyramidal lattice truss metallic core increased the impact energy absorption capacity. Other studies have had success improving the impact resistance of honeycomb cores by fully or partially filling the cells of the honeycomb [35-38].

In this study the influence of face sheet thickness, corrugation thickness, boundary condition and foam filling on shock mitigation is explored. Encastre boundary conditions generally decreased panel deflection. The decrease was more prominent with face thickness change than with core thickness change. Generally soft core structures performed better under shock loading than strong or slapping cores with the one exception that completely foam filled panels were the best core having the least back-face deflection. Foam filling reduced the deflection of the panels in all 
cases although the degree of improvement decreased with the increase in corrugation and face sheet thickness.

\section{Experimental procedure}

\subsection{Specimen preparation}

Corrugated steel core sandwich structures used in this study were produced with low carbon steel face sheets and galvanized, low carbon steel sinusoidal corrugations in a four-layer match-up. A schematic of the sandwich panels is shown in Fig. 1.

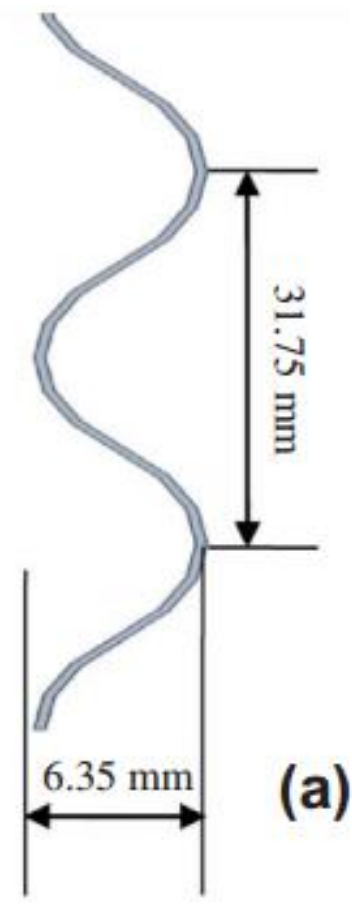

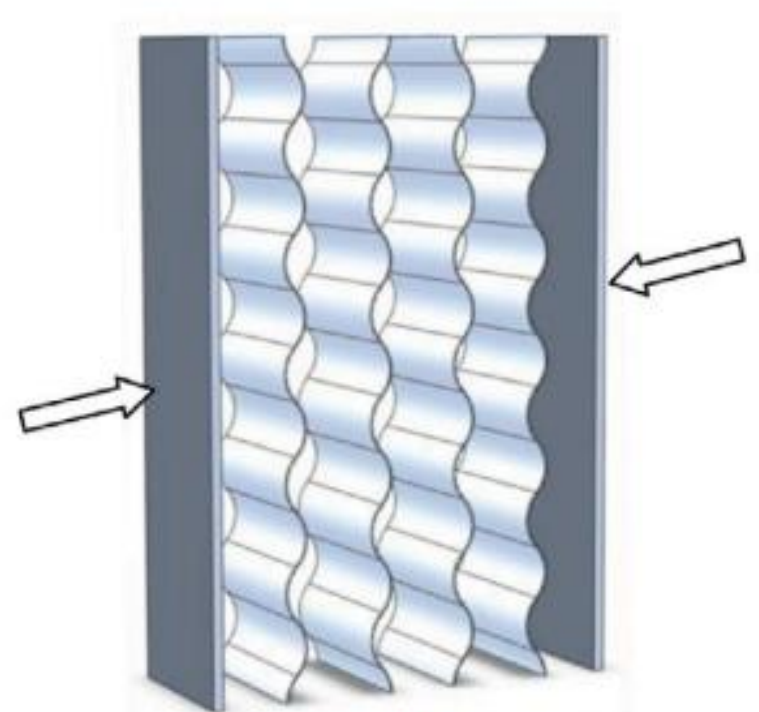

(b)

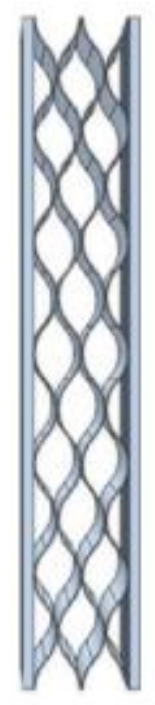

(c)

Fig. 1 (a) Corrugated core sheet dimensions. (b) Assembly procedure of corrugated steel core sandwich structures. (c) Final sandwich panel side view.

The face sheets had lateral dimensions of 50.8 × 203.2 × $3.2 \mathrm{~mm}$. The sinusoidal corrugated sheet reference dimensions are shown in Fig. 1a. Thickness of the corrugated sheet was $0.44 \mathrm{~mm}$ (29 gauge) with galvanization. The corrugation 
sheets and the face sheets were bonded to each other with epoxy adhesive G/Flex (West System Inc.). The shear strength of this material was $20 \mathrm{MPa}$. The specimens' average mass was $616.2 \mathrm{~g}, 630.4 \mathrm{~g}$, and $491.9 \mathrm{~g}$ for empty corrugated steel core sandwich panels, foam filled corrugated steel core sandwich panels, and foam core sandwich panels, respectively. All three different sandwich panel configurations (see Fig. 2) were subjected to blast loading with simply supported boundary conditions.

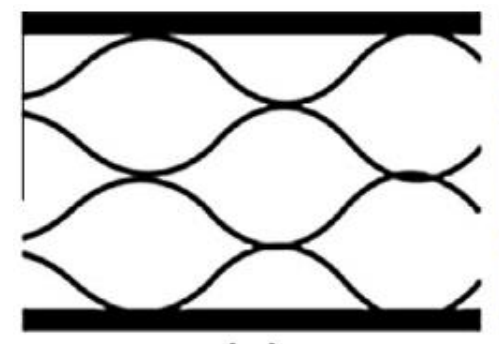

(a)

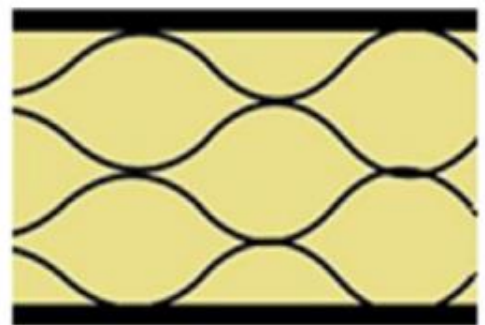

(b)

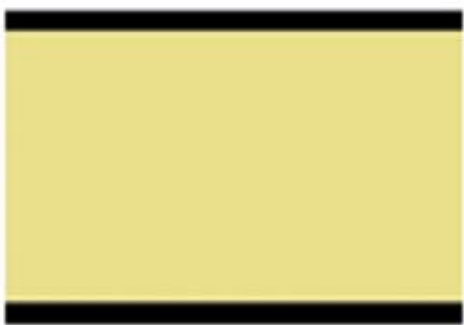

(c)

Fig. 2 Schematic of the sandwich panels. (a) Empty corrugated steel core sandwich panel. (b) Foam filled corrugated steel core sandwich panel. (c) Foam core sandwich panel.

\subsection{Shock loading procedure}

A shock tube apparatus was used to generate shock waves with planar wave

fronts. A photograph of the shock tube used in these studies can be seen in Fig. 3. A typical pressure profile generated by the shock tube and used in these experiments is shown in Fig. 4. The exit muzzle inner diameter of the shock tube was $38.1 \mathrm{~mm}$ (see Fig. 5) [39]. Two pressure transducers (PCB102A) were mounted at the end of the muzzle section to record the incident and reflected pressure profiles. The first pressure sensor was mounted $20 \mathrm{~mm}$ away from the muzzle, and the second was mounted 180 $\mathrm{mm}$ away (160 $\mathrm{mm}$ separation from the first pressure sensor). The incident peak 
pressure of the shock wave was chosen to be $1.1 \mathrm{MPa}$ and the reflected peak pressure of approximately $5.5 \mathrm{MPa}$ was obtained in the current study.

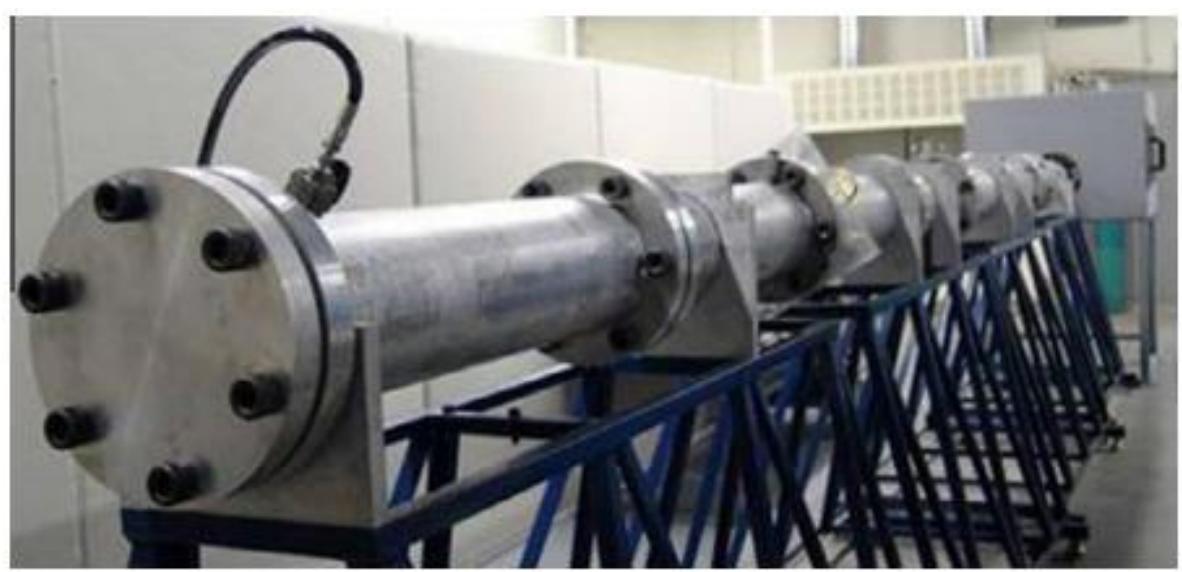

Fig. 3 Shock tube apparatus.

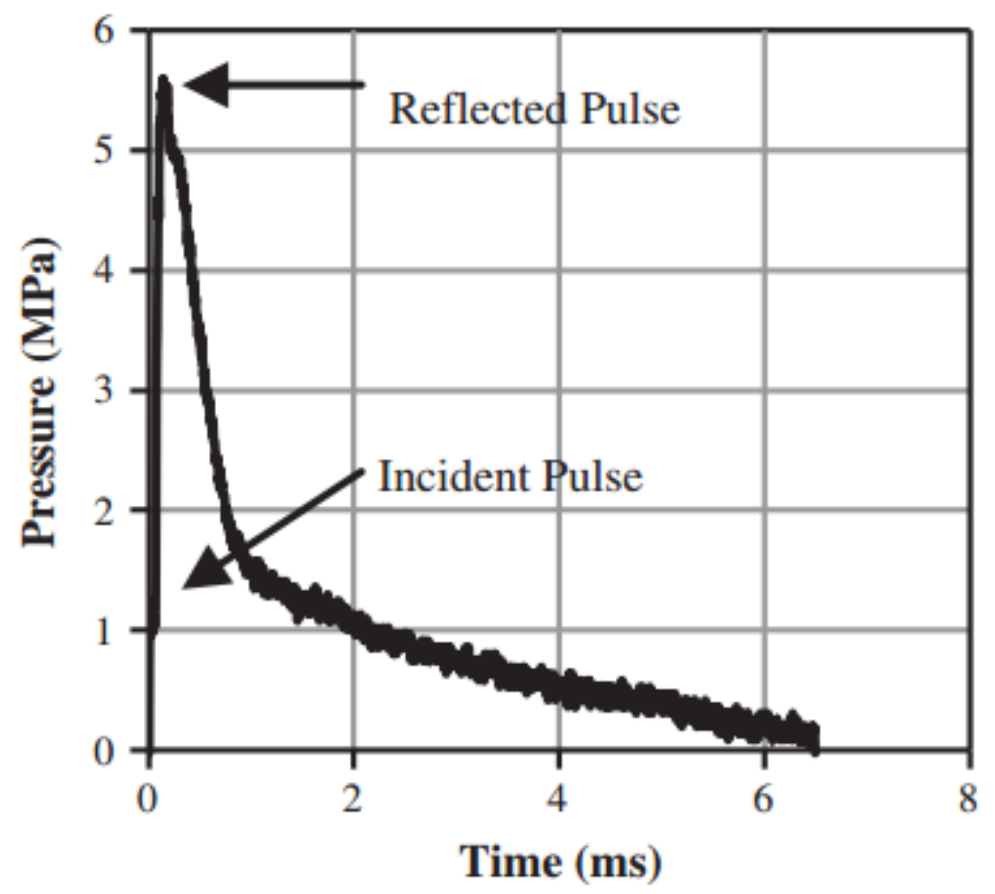

Fig. 4 Typical experimental pressure profile.

The specimen was placed onto a simply supported boundary condition fixture with a $152.4 \mathrm{~mm}$ span. The flat front face of the specimen was set normal to the axis of the shock tube with the face completely covering the muzzle. A diagram of this set 
up can be seen in Fig. 5. At least three specimens of each type were shock loaded to insure repeatability.

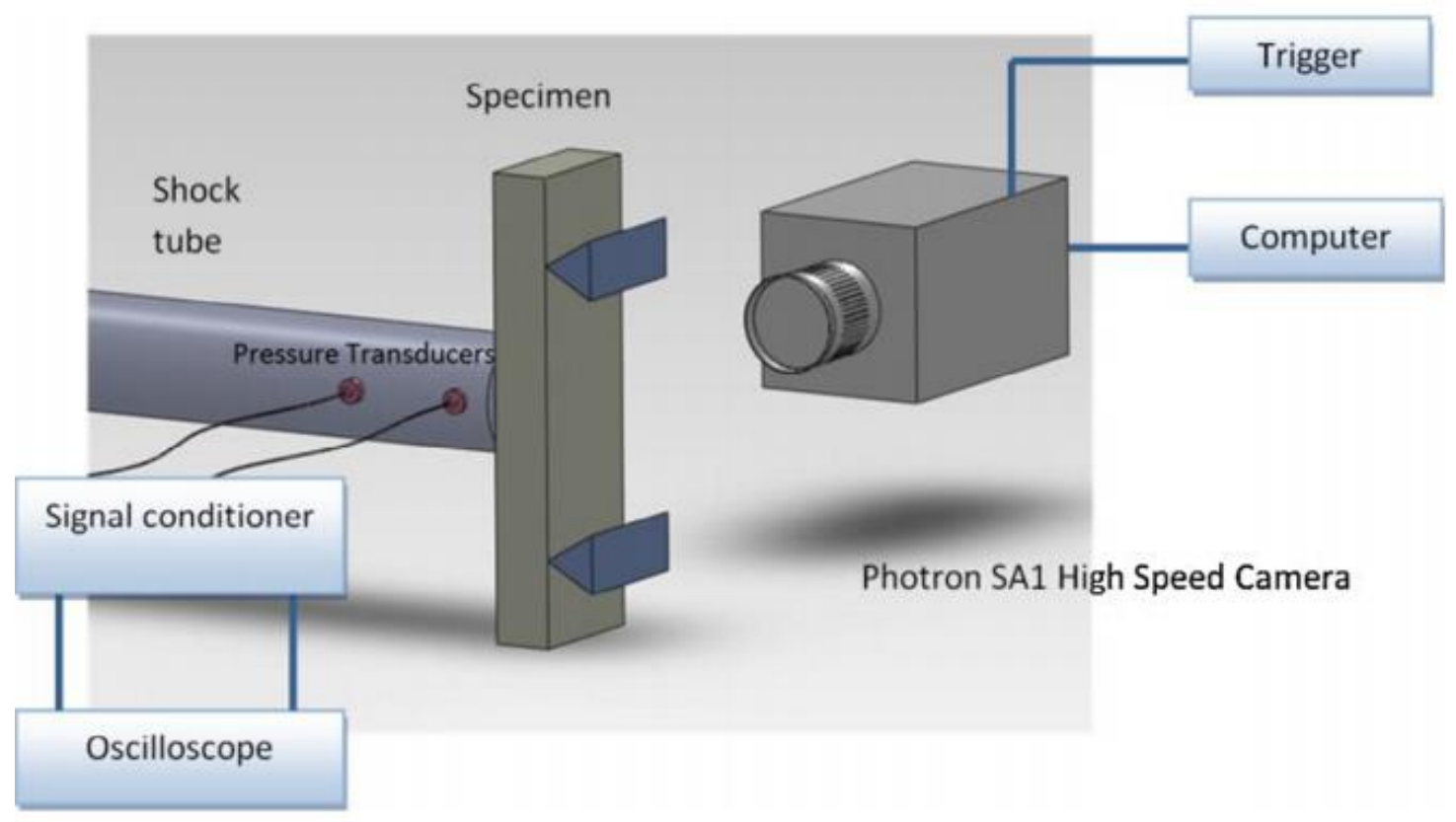

Fig. 5 Experimental setup for real-time side-view deflection measurements.

A high speed photography system was utilized to capture the motion of the specimens in order to determine their deformation and damage propagation. The lens axis of the camera was set perpendicular to the shock tube as shown in Fig. 5. A Photron SA1 high speed digital camera was used at a framing rate of 20,000 frames per second with an image resolution of $512 \times 512$ pixels over 3 ms duration.

\section{Numerical procedure}

Dynamic explicit 3D FEA analyses of the sandwich panels subjected to a blast load were performed using Abaqus/Explicit finite element software. During analysis, nonlinear deformations were accounted for and simulated for duration of $3 \mathrm{~ms}$. 


\subsection{Finite element model}

A model was created to render Simple and Encastre Supported (along the back-face's short edges) corrugated steel core sandwich panels 203 x 50.8 x 25.34 mm, subjected to blast loading. Each layer section was modeled as a homogenous sheet with a prescribed thickness. Front and back face sheets were modeled as shells from their back and top faces respectively while the corrugated layers were also modeled as shells defined by their mid planes (Fig. 6a). Interactions between the corrugated core and the front and back-face sheets were taken as surface-to-surface contacts under the penalty contact method and finite tangential sliding. The shear stress limit for failure was prescribed as $20 \mathrm{MPa}$.

This shock pressure profile was input into Abaqus as tabular data. It was applied to the specimens' front face as a non-uniform function of area as shown in Fig. 6b. This variation in shock pressure induced by the shock tube was observed experimentally and validated numerically by Kumar et al. [40]. For FEM simulations, the specimen was symmetrically aligned with the center of the shock tube, and the distance between the supports was fixed at $152.4 \mathrm{~mm}$. 


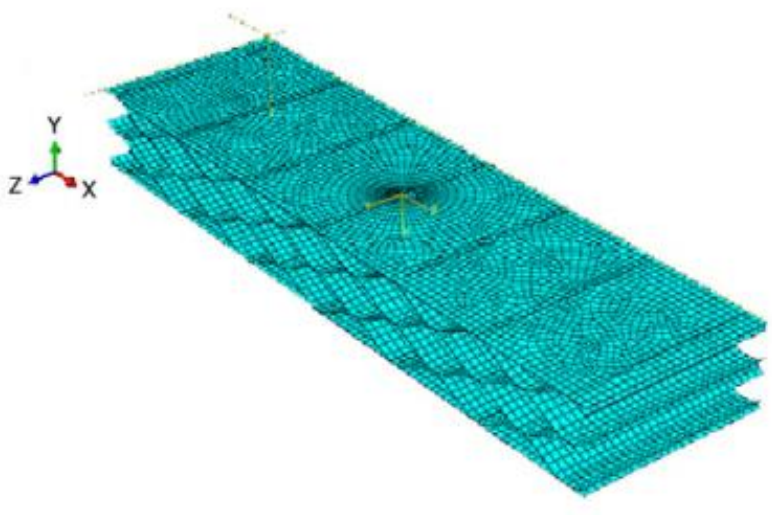

(a)

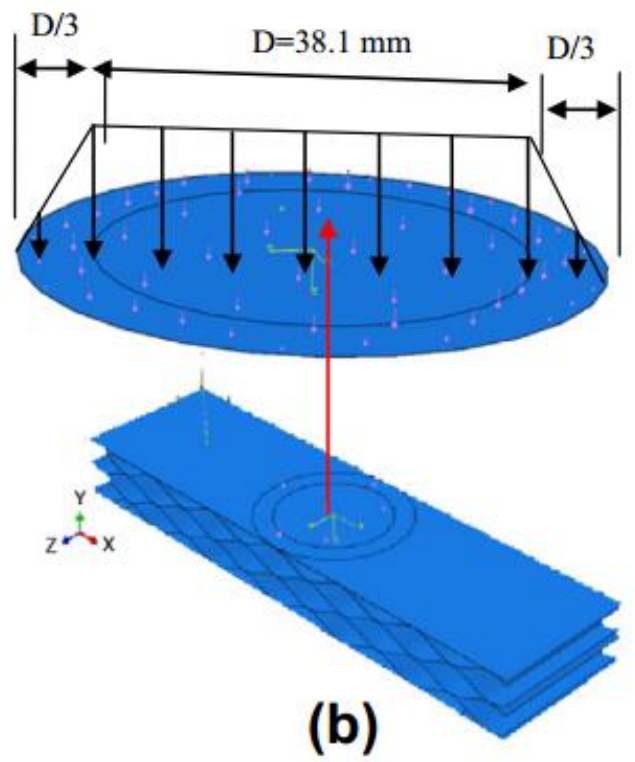

(b)

Fig. 6 (a) FEM model. (b) Pressure distribution function over loaded area.

\subsection{Material properties}

The material properties of the corrugated steel sheets and face sheets as listed in literature were used in this study. These were: modulus of elasticity $(E) 205 \mathrm{GPa}$, Poisson's ratio (v) 0.29 , density $(\rho) 7.85 \mathrm{~g} / \mathrm{cm} 3$, and one-dimensional acoustic wave impedance $3962 \times 10^{4} \mathrm{~kg} / \mathrm{m} 2 \mathrm{~s}$.

A Jonson Cook material model with strain hardening was applied in Abaqus.

The yield stress is, therefore, expressed as

$$
\bar{\sigma}=\left[A+B\left(\bar{\varepsilon}^{p l}\right)^{n}\right]\left[1+C \ln \left(\frac{\dot{\bar{\varepsilon}}^{p l}}{\dot{\varepsilon}_{0}}\right)\right]\left[1-\hat{\theta}^{m}\right]
$$

where $\bar{\sigma}$ is the yield stress at nonzero strain rate, $\bar{\varepsilon}^{\mathrm{pl}}$ is the equivalent plastic strain, $\bar{\varepsilon}_{0}$ is the quasi static strain rate, ${ }^{\frac{5}{\varepsilon}}{ }^{p l}$ is the equivalent plastic strain rate, and $A, B, C, n$ and 
$m$ are material constants [41]. $\hat{\theta}$ is the nondimensional temperature ratio and set to zero in this paper.

Johnson Cook parameters for the material used in this study are given in Table 1 and were obtained from literature [42].

Table 1 Johnson Cook parameters for low carbon steel used in FEM analysis [42].

\begin{tabular}{llllll}
\hline$A(\mathrm{MPa})$ & $B(\mathrm{MPa})$ & $n$ & $C$ & $m$ & $\dot{\varepsilon}_{0}\left(\mathrm{~s}^{-1}\right)$ \\
\hline 220 & 499.87 & 0.228 & 0.017 & 0.917 & 1 \\
\hline
\end{tabular}

The foam filled sandwich structures used general purpose humidity cured Polyurethane (PU), of density $0.0446 \mathrm{~g} / \mathrm{cm} 3$ and elasticity modulus $0.24 \mathrm{MPa}$. These materials can deform elastically to large strains, up to $90 \%$ strain in compression and are intended for finite strain applications The mechanical properties of the PU foam were obtained using quasi static compression tests, and the high strain rate (3000/s) properties were found via Split Hopkinson Pressure Bar experiments [43] and are shown in Fig. 7.

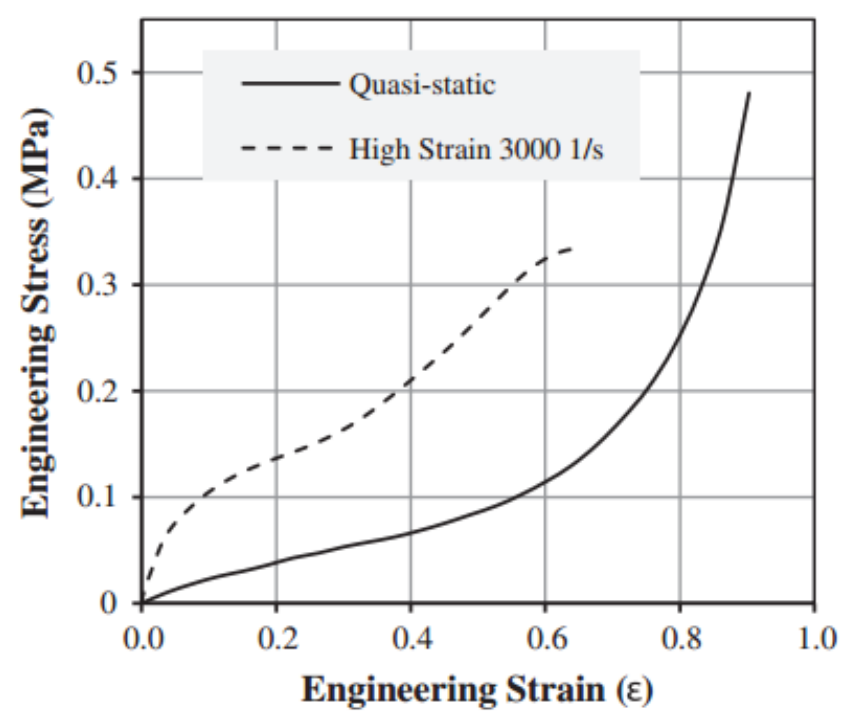

Fig. 7 Quasi static and high-strain rate compression response of Polyurethane foam. 
PU foam material shows non-linear, hyperelastic behavior and is extremely compressible. The porosity permits very large volumetric changes. PU foams under large strains were modeled as compressible hyperelastic solids, if their time dependent mechanical properties and hysteresis are ignored. For PU foams, an Ogden strain energy potential was applied using tabular data from experimentation [41]. In all FE analysis, a Poisson's ratio, $\mathrm{m}=0$ was used.

\section{Experimental results and discussion}

A series of three successful experiments was performed for each geometry to insure repeatability. The applied pressure loading as well as the results obtained were consistent in all the experiments, and are discussed below.

\subsection{Empty corrugated steel core sandwich specimen response}

The side view history of the empty specimen shows different compression behavior over the entirety of the metallic corrugated core (see Fig. 8) during loading. The beginning of the Back-Face Deflection (BFD) occurred $0.25 \mathrm{~ms}$ after the initial Front-Face Deflection (FFD) of the specimen, which implies a coupled response.

Core compression and bending/stretching stages can be clearly observed by using core compression/time curves. In Fig. 9a, front and back-face deflections, strain rates in the core and the core compression variation over time are given for the empty corrugated steel core sandwich panel. The core compression increased from rest to $1.25 \mathrm{~ms}$. After this time, compression of the core (about $10 \mathrm{~mm}$ ) remained stable without change, but the front and back faces continued to deflect. This is indicative of the sandwich panel's global bending after $1.25 \mathrm{~ms}$. The average core compression strain rate increased quickly up to $500 / \mathrm{s}$ in $0.5 \mathrm{~ms}$ and then decays to zero in an 
oscillatory fashion. During shock loading the front face accelerates rapidly (3000 g) to velocity of $17 \mathrm{~m} / \mathrm{s}$ after which the velocity gradually reduces to zero. The back-face is slower to react and achieves a velocity of $14 \mathrm{~m} / \mathrm{s}$ at around $1.25 \mathrm{~ms}$ (Fig. 9b). After this time both front and back-face have equal velocities indicating no more core compression.

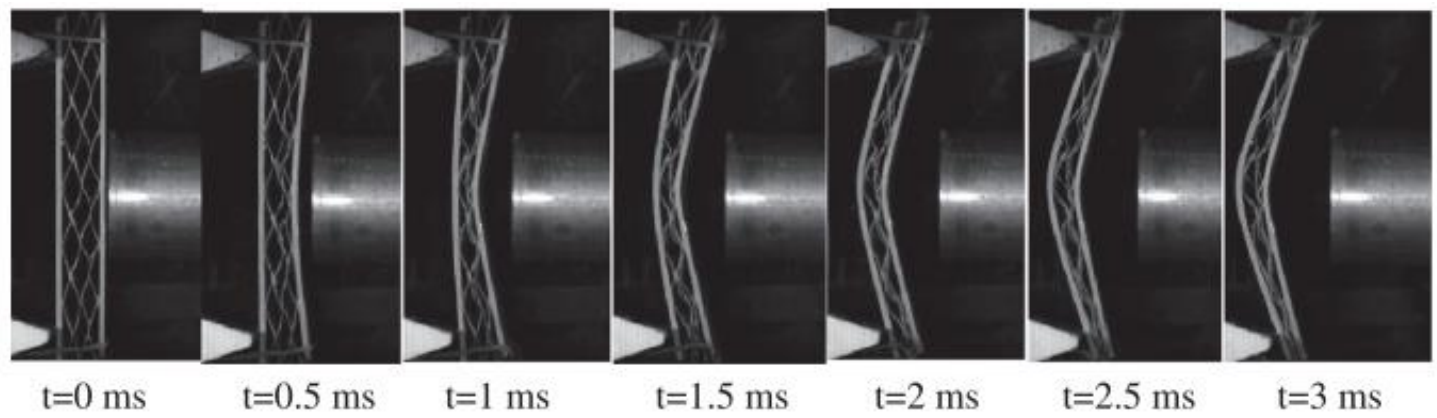

Fig. 8 High-speed images of unfilled corrugated steel core sandwich panel during shock loading.
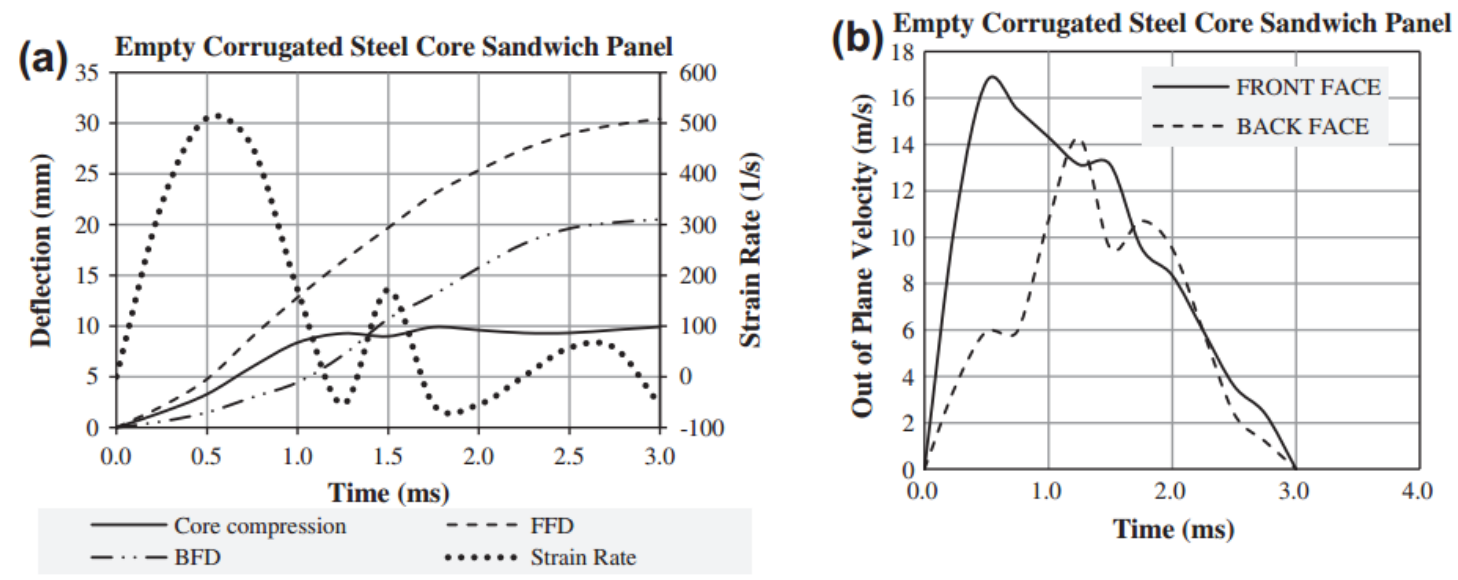

Fig. 9 Experimental results for empty corrugated steel core sandwich panels under shock loading. (a) Front-Face Deflection (FFD), Back-Face Deflection (BFD), core compression, and strain rate of the core. (b) Front-face and back-face out of plane velocities.

\subsection{Foam Core Sandwich Panels}

High-speed side view camera images, recording the deflections of foam core sandwich panels, are given in Fig. 10. After the shock wave impinged upon the 
specimen, the weak foam core did not resist the front face motion enough to decrease its velocity until $1.25 \mathrm{~ms}$. As seen in Fig. 11, the back-face started moving in synchronization with the front face after this time. This behavior is called "slapping', $[18,19]$. The core compresses very rapidly to about $10 \mathrm{~mm}$ and then maintains this compression as both faces are moving together. The foam core was subjected to very high (1263/s) strain rate loading in these experiments.

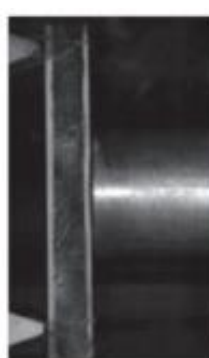

$0 \mathrm{~ms}$

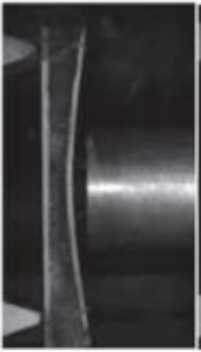

$0.5 \mathrm{~ms}$

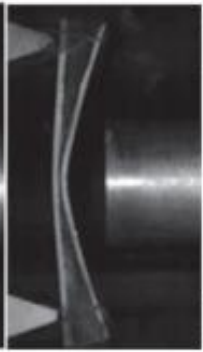

$1 \mathrm{~ms}$

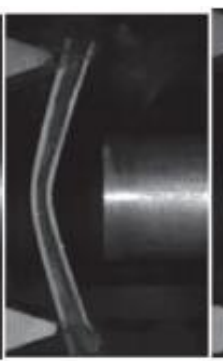

$1.5 \mathrm{~ms}$

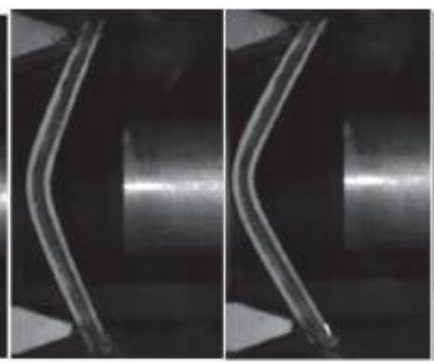

$2.5 \mathrm{~ms}$

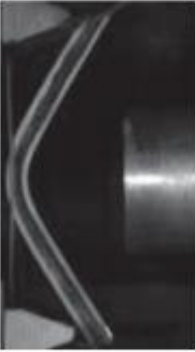

$3 \mathrm{~ms}$

Fig. 10 High-speed images of foam core sandwich specimen during shock loading.

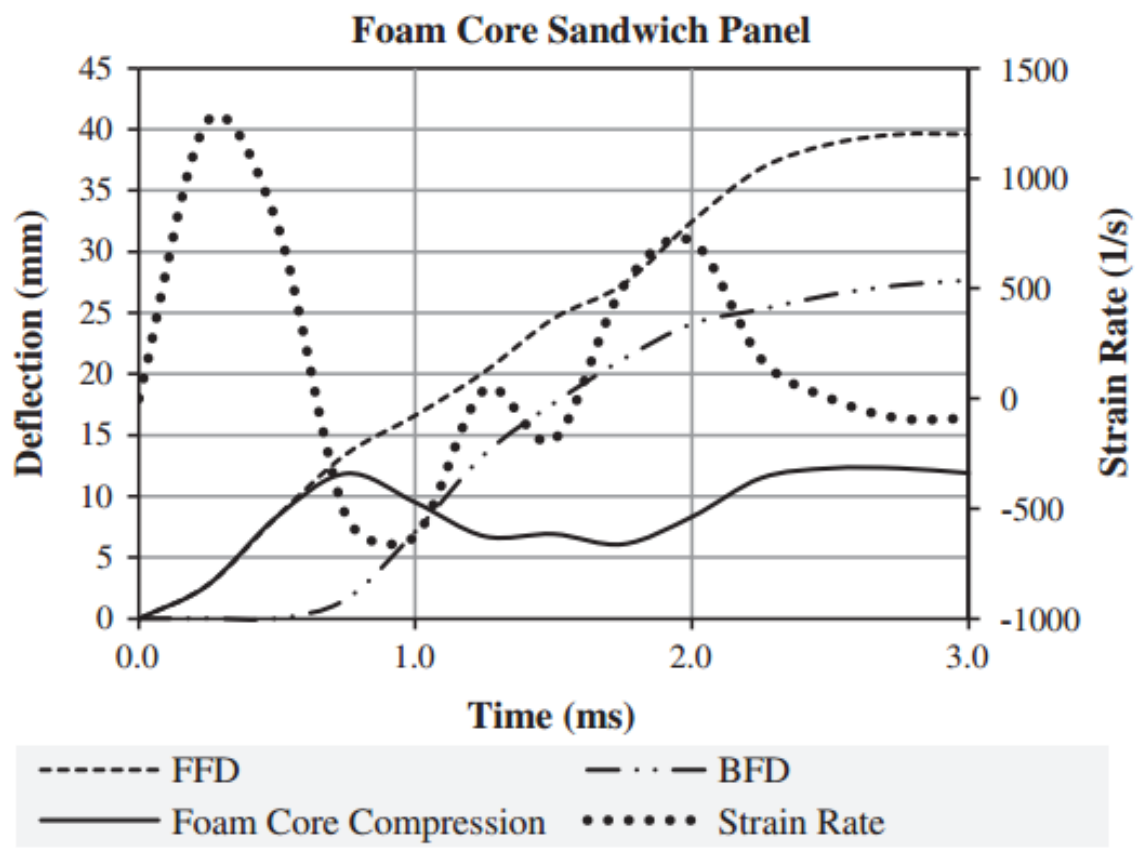

Fig. 11 Experimental results for foam core sandwich panels under shock loading: Front Face Deflection (FFD), Back Face Deflection (BFD), core compression, and strain rate of the core. 


\subsection{Foam Filled Corrugated Steel Core Sandwich Panels}

The foam filling caused large changes in specimen behavior when compared to that of the empty and foam core specimens. This behavior can be seen in Fig. 12, which shows high speed side view camera images. Core compression in the foam filled case is decreased when compared to empty and foam core sandwich panels. The BFD starts almost at the same time as the FFD. In Fig. 13a, velocity profiles of both faces are given. The slope of both the front and back-face velocities show the same magnitude, except during two durations between $0.5-1 \mathrm{~ms}$ and $2-2.5 \mathrm{~ms}$. The frontface started deflecting initially, but after only $0.25 \mathrm{~ms}$ the BFD began. During the first $0.50 \mathrm{~ms}$ the first core compression was observed, followed by a brief expansion of the core between $0.50 \mathrm{~ms}$ and about $1.00 \mathrm{~ms}$ and then a larger, secondary compression lasting until $2.00 \mathrm{~ms}$. Between $1 \mathrm{~ms}$ and $2 \mathrm{~ms}$ the FFD increased more than the BFD, thus causing an increase in the core compression. After this time, both the BFD and FFD started to decrease, and the core decompressed. This reaction occurred over much less time than the empty corrugated steel core and foam core sandwich panels. In this case, the obtained maximum strain rate in the core was much lower than that of both the empty and foam core cases, and was calculated to be 170/s around $1.25 \mathrm{~ms}$ (see Fig. 13b). The core compression percentage at this time was about 5.28\%. This means that the foam did not exhibit high strain rate behavior in the foam filled corrugated core sandwich panel under blast loading. It is observed that the foam filling increased bending rigidity and core compression strength. 


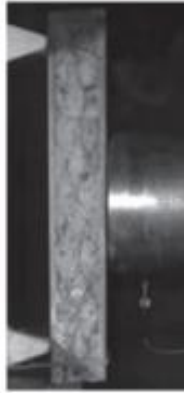

$\mathrm{t}=0 \mathrm{~ms}$

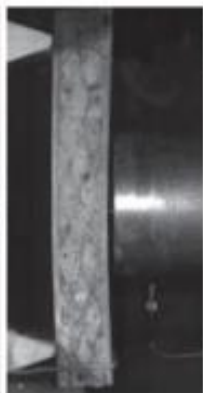

$\mathrm{t}=0.5 \mathrm{~ms}$

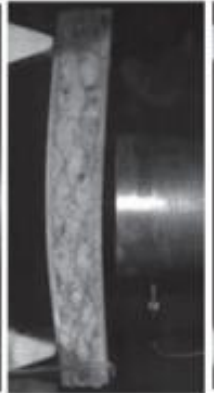

$\mathrm{t}=1 \mathrm{~ms}$

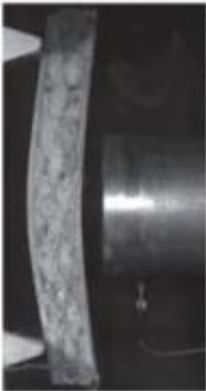

$\mathrm{t}=1.5 \mathrm{~ms}$

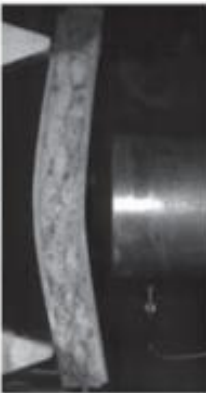

$\mathrm{t}=2 \mathrm{~ms}$

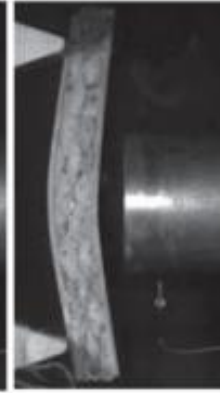

$\mathrm{t}=2.5 \mathrm{~ms}$

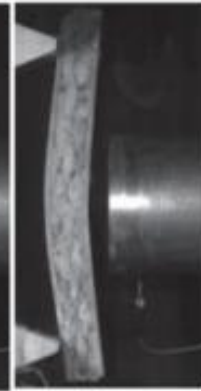

$\mathrm{t}=3 \mathrm{~ms}$

Fig. 12 High-speed images of fully foam filled corrugated core sandwich specimen during shock loading.
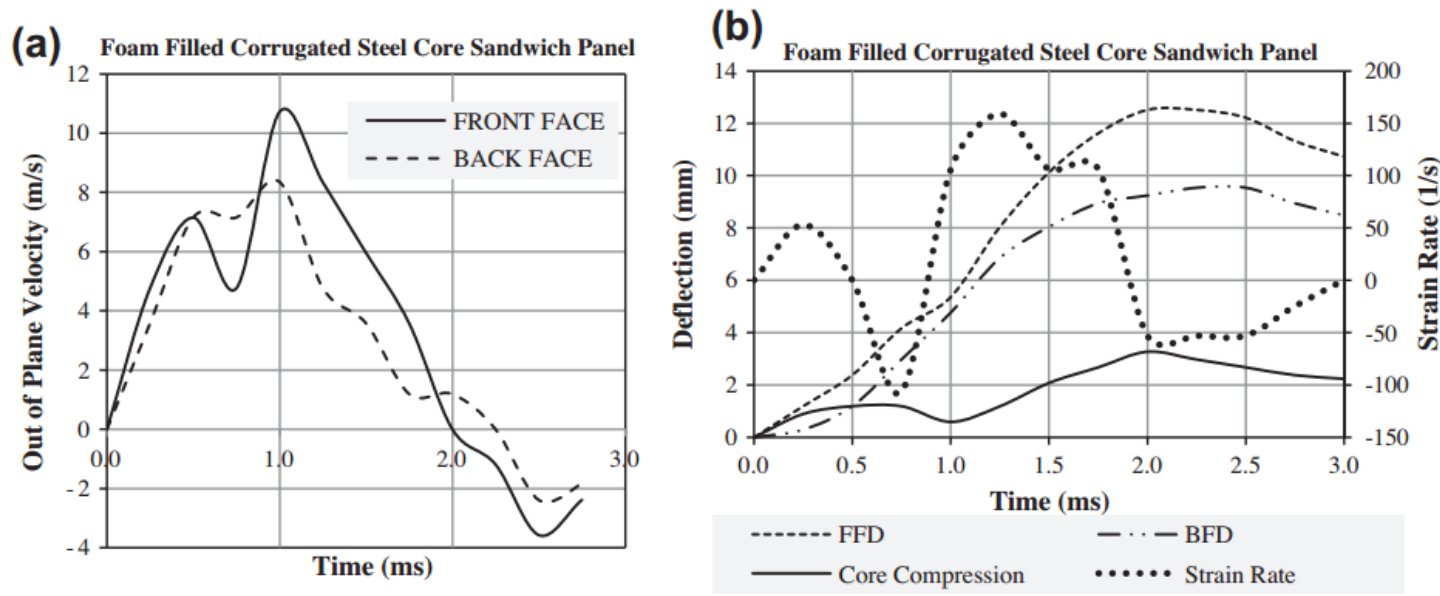

Fig. 13 Experimental results for foam fillet corrugated steel core sandwich panels under shock loading. (a) Front face and back face out of plane velocities. (b) Front Face Deflection (FFD), Back Face Deflection (BFD), core compression, and strain rate of the core.

\subsection{Comparison of experimental mid span deflections of the sandwich panels}

Fig. 14 shows back-face and front face mid span deflections for all three sandwich configurations. It is clearly seen that both FFD and BFD results of the foam filled corrugated steel core sandwich panel are smaller than the empty and foam core sandwich panels, while its mass exceeds that of the empty sandwich panel by just 2.30\%. The benefits of the corrugated steel core sandwich panel and foam core 
sandwich panels are combined by foam filling of corrugated steel core interstices. The percentage reduction of corrugated steel core sandwich panel deflections by foam filling is given in Fig. 15 for FFD and BFD with respect to time. The FFDs in foam filled corrugated structures under shock loading in comparison to unfilled corrugated structures were reduced by more than $50 \%$ as a result of foam filling . However, BFDs are affected to various degrees by foam filling. From the initial loading to $1 \mathrm{~ms}$, BFDs are increased by foam filling, but not by a constant percentage. After $1 \mathrm{~ms}$, the amplitude of loading on the back-face decreases and this results in about 50\% decrease in BFD at $3 \mathrm{~ms}$. From the 0 to $1 \mathrm{~ms}$ time duration, the corrugated steel core is the major load carrying member in the core. Around this time $(1 \mathrm{~ms})$, as shown in high speed images (see Fig. 8), the corrugated steel core cell walls incline due to bending and buckling failure. At the same time, however, the foam infill has increased the bending and buckling resistivity of the corrugated steel core unit cell walls. Due to this support the core compression strength is increased, and the transmitted load from the front face to the back-face is increased, although the foam inside the cell has not compressed to its maximum value. 

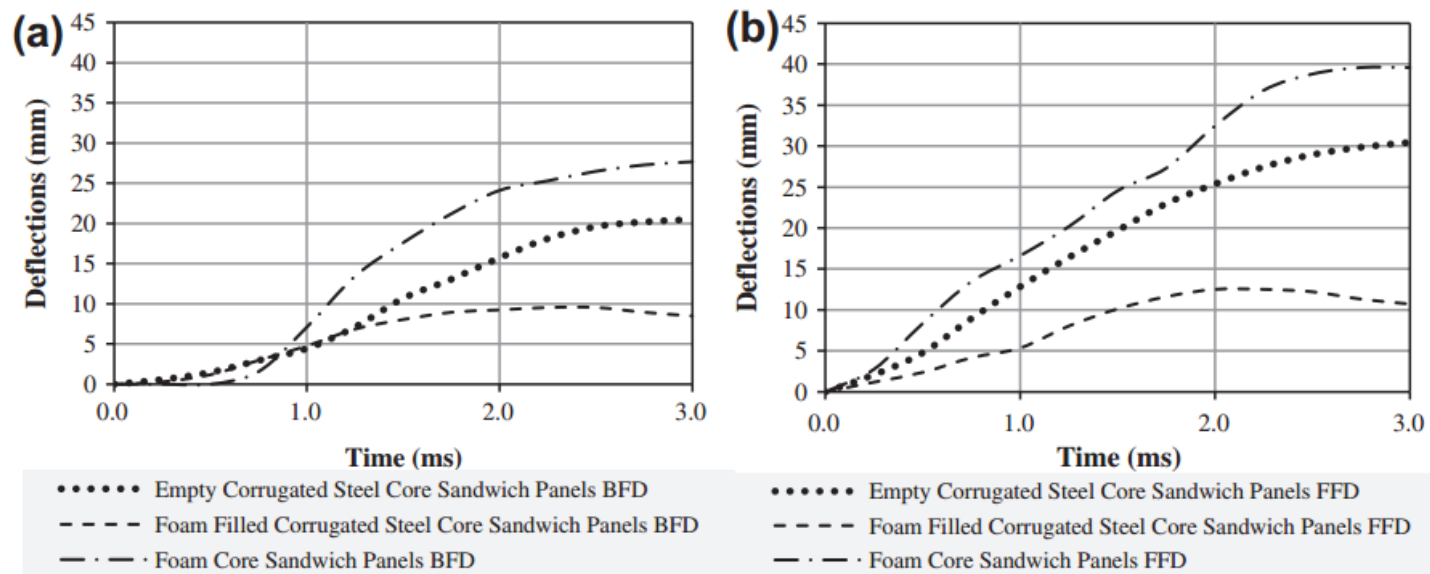

..... Empty Corrugated Steel Core Sandwich Panels FFD - - - - Foam Filled Corrugated Steel Core Sandwich Panels FFD - - - Foam Core Sandwich Panels FFD

Fig. 14 Experiments results of (a) average Back-Face Deflections (BFDs), (b) average Front-Face Deflections (FFDs) for all the three configurations.

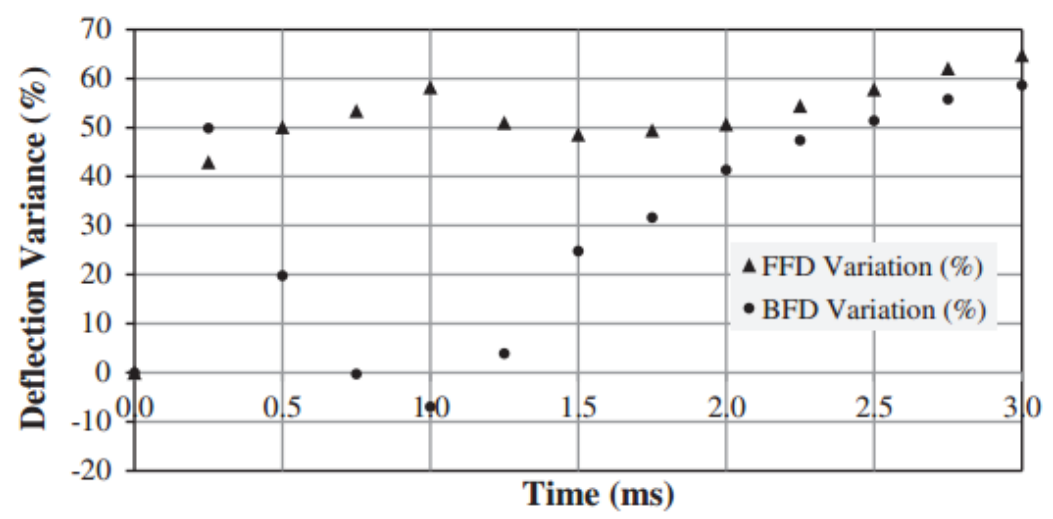

Fig. 15 Corrugated steel core sandwich panel FFD and BFD variation by foam filling.

\section{Numerical results and discussions}

\subsection{Validation of numerical solutions}

To verify the material properties, boundary and contact conditions in the FEM, numerical results were compared to the shock tube experimental results for the face sheet, foam core sandwich panel, empty corrugated steel core sandwich panel, and foam filled corrugated steel core sandwich panels. These comparisons are shown in Fig. 16. 
The Pearson's correlation coefficient $\mathrm{R}^{2}$ was calculated using equations given in [44] as a means to evaluate the model's accuracy. The correlation coefficient is a measure of accuracy of the linear relationship between the experimental and predicted data. The predictability of the finite element model over both the front and back-faces of the four different experimental designs is shown in Table 2.

Table 2 Predictability of the model for the deflection of the panel configurations.

\begin{tabular}{|c|c|c|c|c|c|c|c|}
\hline & \multirow[t]{2}{*}{$\begin{array}{l}\text { Face sheet } \\
\text { only }\end{array}$} & \multicolumn{2}{|c|}{$\begin{array}{l}\text { Foam \& corrugated core } \\
\text { sandwich panels }\end{array}$} & \multicolumn{2}{|c|}{$\begin{array}{l}\text { Foam core } \\
\text { sandwich panels }\end{array}$} & \multicolumn{2}{|c|}{$\begin{array}{l}\text { Corrugated core } \\
\text { sandwich panels }\end{array}$} \\
\hline & & FFD & BFD & FFD & BFD & FFD & BFD \\
\hline $\mathrm{R}^{2}$ & 0.977 & 0.955 & 0.980 & 0.980 & 0.984 & 0.992 & 0.999 \\
\hline
\end{tabular}

The correlation coefficient $\mathrm{R}^{2}$ under all cases is 0.95 or higher, indicating that the trends of both the experimental results and the finite element model are in excellent agreement. Thus, the FEM was next used to further investigate the influences of the foam and thicknesses of the face sheets and core sheets on blast performance. 

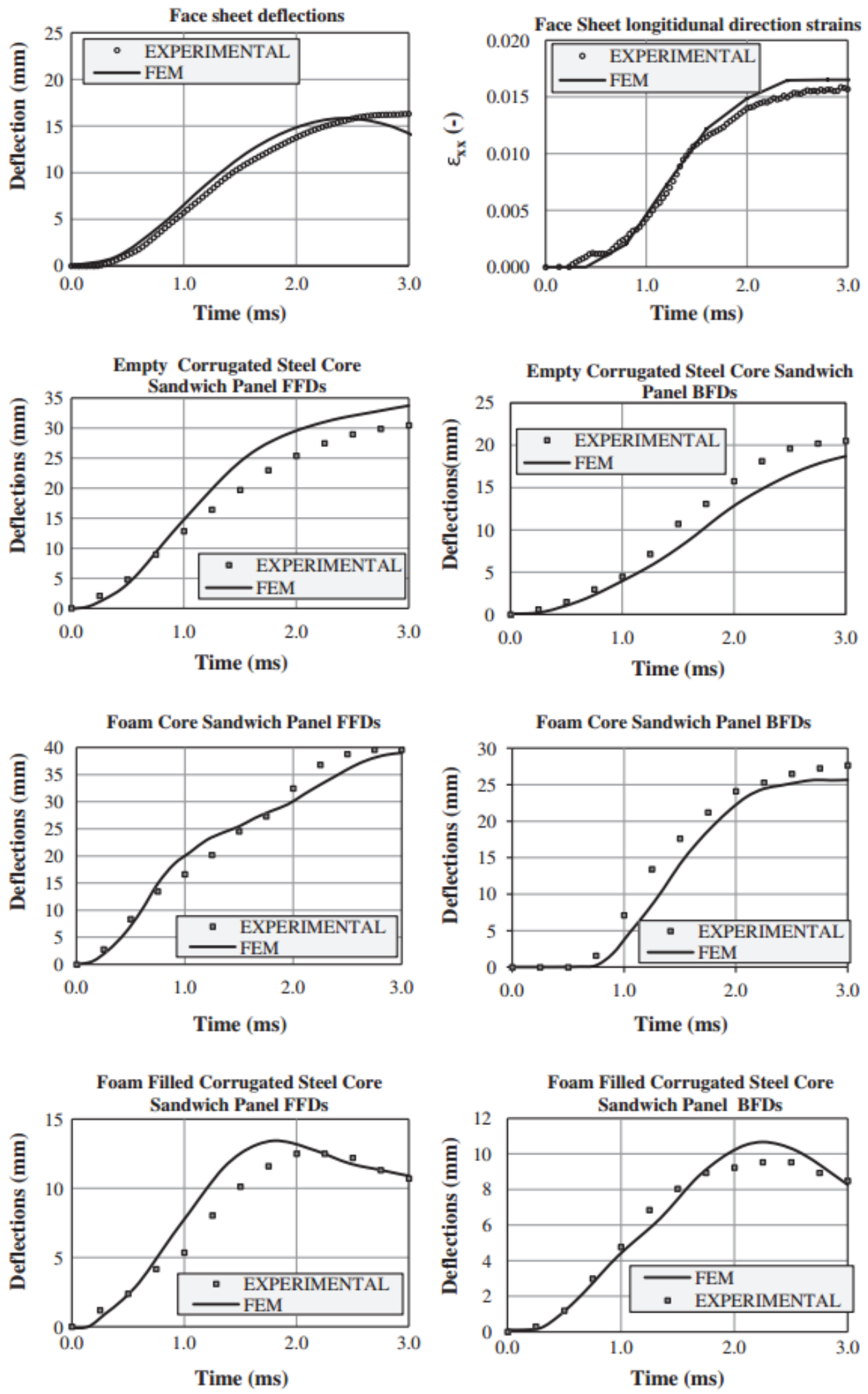

Fig. 16 Validation of FEM simulations with the experimental results for single face sheet, empty corrugated core sandwich panels, foam core sandwich panels and foam filled sandwich panels. 
5.2 Investigation of face sheet thickness, corrugated core sheet thickness, and boundary conditions on blast performance

The effect of face sheet thickness, corrugated steel sheet thickness, and boundary condition (see Fig. 17) were investigated using FEM simulations. The values of all the variables are given in Table 3. Sandwich panel length, width, and core thickness $(184.24 \times 50.8 \times 20.6 \mathrm{~mm})$ were constant in FEM simulations. The applied shock pressure shown in Fig. 4 was also constant in all simulations. The addition of foam filling had little effect on the overall mass of the sample. For example, the maximum variation of mass was $3.8 \%$ in the $0.2 \mathrm{~mm}$ Core Sheet Thickness (CST) and $1 \mathrm{~mm}$ Face Sheet Thickness (FST) case. However, FST had a significant effect on overall mass. The mass was 5 times greater in the $5 \mathrm{~mm}$ FST $-1 \mathrm{~mm}$ CST case as compared to the $1 \mathrm{~mm}$ FST $-0.2 \mathrm{~mm}$ CST case (see Table 4). Thus, unit mass deflections were calculated for comparison to one another. In total, 36 simulations were performed to understand each of the parameter's influences on the behavior of the sandwich panel.

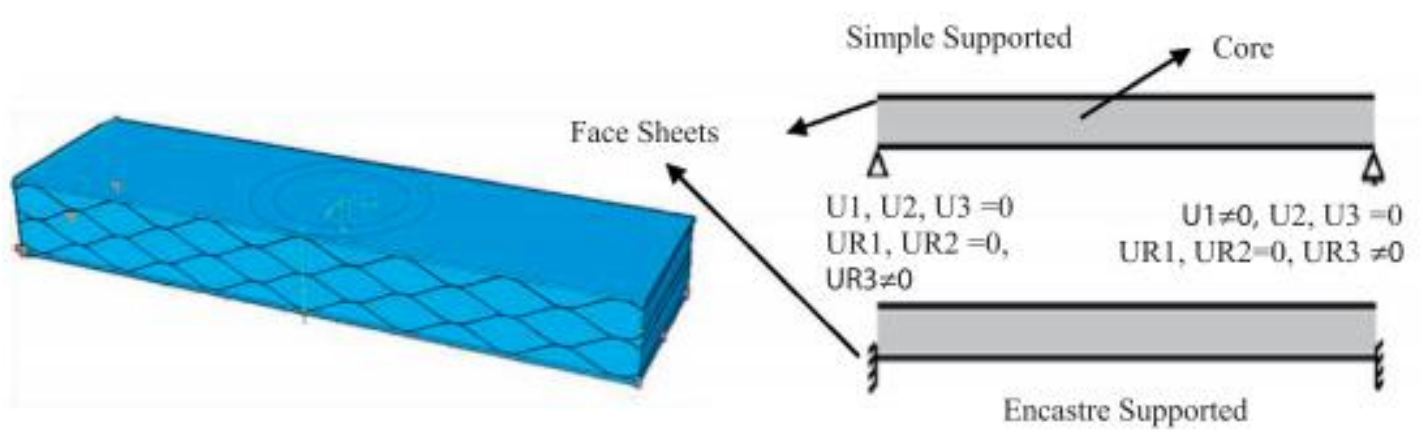

U1, U2, U3, UR1, UR2, UR3 $=0$ at both back face ends

Fig. 17 Boundary conditions used in FEM simulations. 
Table 3 Investigated parameters in FEM simulations of empty and foam filled corrugated steel core sandwich panels.

\begin{tabular}{lll}
\hline Boundary condition & $\begin{array}{l}\text { Face sheet thickness } \\
(\mathrm{mm})\end{array}$ & $\begin{array}{l}\text { Corrugated sheet } \\
\text { thickness }(\mathrm{mm})\end{array}$ \\
\hline Simple supported & $1,3,5$ & $0.2,0.6,1$ \\
Encastre supported & $1,3,5$ & $0.2,0.6,1$ \\
\hline
\end{tabular}

Table 4 Calculated masses of FEM models for the empty corrugated steel core sandwich panels.

\begin{tabular}{llllllllll} 
& \multicolumn{1}{c}{ Face thickness $(\mathrm{mm})$} \\
\cline { 2 - 11 } & 1 & & & 3 & & & & \\
\hline Corrugation thickness (mm) & 0.2 & 0.6 & 1.0 & 0.2 & 0.6 & 1.0 & 0.2 & 0.6 & 1.0 \\
Empty panel mass (g) & 209 & 332 & 462 & 502 & 628 & 754 & 794 & 920 & 1050 \\
\hline
\end{tabular}

\subsection{Front-face deflections (FFDs)}

Fig. 18 shows the behavior of the 1, 3 and $5 \mathrm{~mm}$ FST sandwich panels under different CST and boundary conditions for the empty corrugated steel core and foam filled corrugated steel core cases. All FFDs were obtained from the FEM simulations at the front face center point of the specimens and provided as specific deflection (deflection divided by total mass). In almost all of these cases, the FFD of the specimens decreased with the incorporation of foam filling. It can be seen from Fig. 18, that the foam filling's contribution to mitigating FFD and BFD is lessened with the increase of the CST. From these figures, it can be observed that the Simple Supported (SS) sandwich panels show more deflection then Encastre Supported (ES) sandwich panels in all cases.

The foam filling decreased all FFDs, except in the case of the $1 \mathrm{~mm}$ CST and 5 mm FST, in which cases it became the predominant influence on the core through increased bending resistivity. In the $1 \mathrm{~mm}$ CST cases the filled and empty specimens' FFDs are close in both Simple and Encastre Supported boundary conditions. 


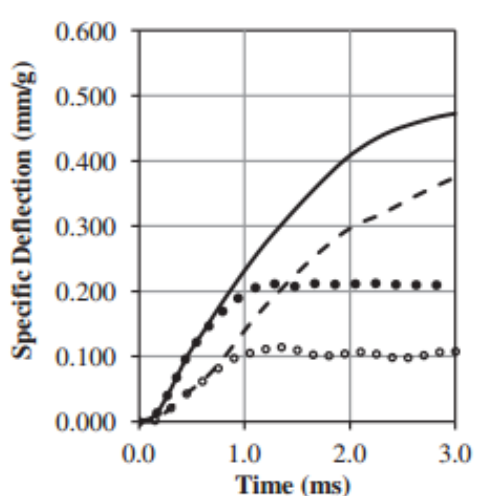

E, SS, FST $1 \mathrm{~mm}, \mathrm{CST} 0.2 \mathrm{~mm}$

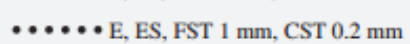

- - FF, SS, FST $1 \mathrm{~mm}, \mathrm{CST} 0.2 \mathrm{~mm}$

- FF, ES, FST $1 \mathrm{~mm}$, CST $0.2 \mathrm{~mm}$

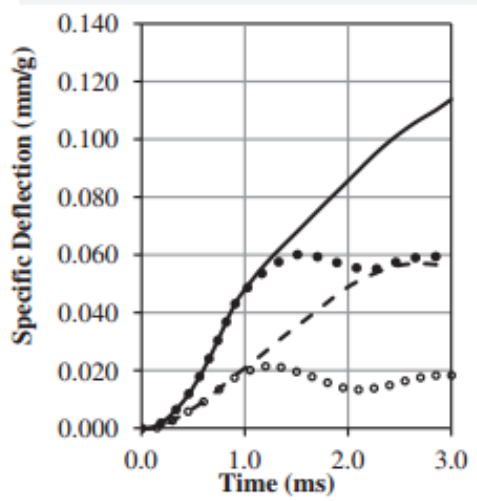

E, SS, FST $3 \mathrm{~mm}$, CST $0.2 \mathrm{~mm}$ $\cdots \cdots$ E, ES, FST $3 \mathrm{~mm}$, CST $0.2 \mathrm{~mm}$

- - - FF, SS, FST $3 \mathrm{~mm}$, CST $0.2 \mathrm{~mm}$

- FF, ES, FST $3 \mathrm{~mm}$, CST $0.2 \mathrm{~mm}$

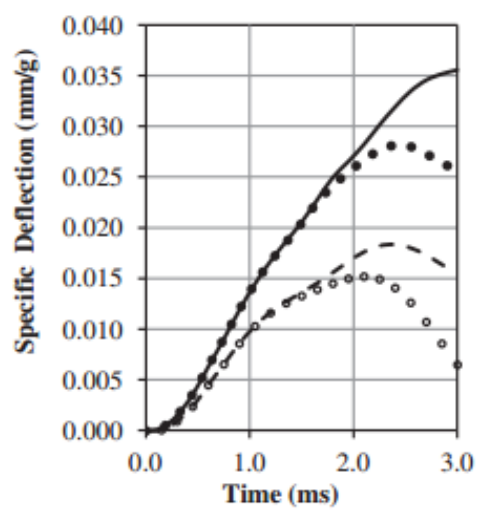

E, SS, FST $5 \mathrm{~mm}$, CST $0.2 \mathrm{~mm}$

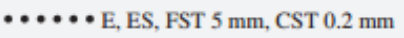

- - - FF, SS, FST $5 \mathrm{~mm}$, CST $0.2 \mathrm{~mm}$

- FF, ES, FST $5 \mathrm{~mm}, \mathrm{CST} 0.2 \mathrm{~mm}$

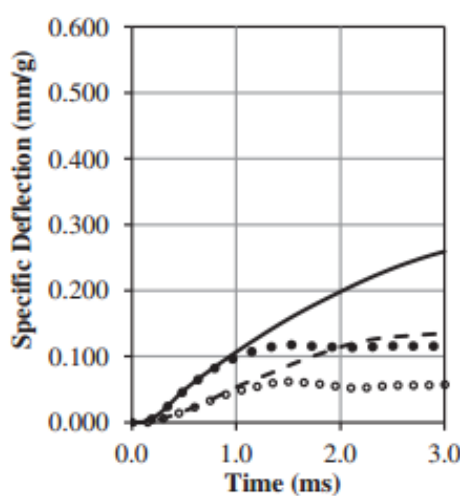

E, SS, FST $1 \mathrm{~mm}$, CST $0.6 \mathrm{~mm}$

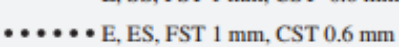

- - - FF, SS, FST $1 \mathrm{~mm}, \mathrm{CST} 0.6 \mathrm{~mm}$

- $\quad$ FF, ES, FST $1 \mathrm{~mm}$, CST $0.6 \mathrm{~mm}$

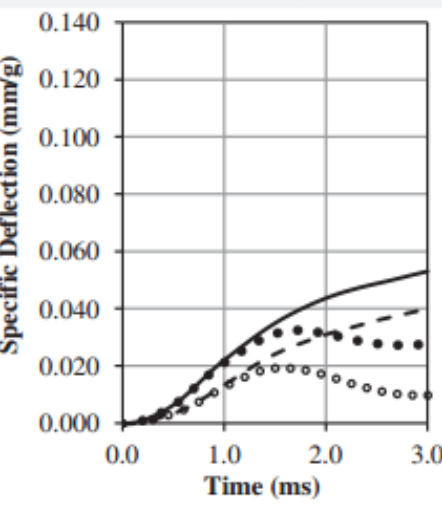

E, SS, FST $3 \mathrm{~mm}$, CST $0.6 \mathrm{~mm}$ •.. E, ES, FST $3 \mathrm{~mm}$, CST $0.6 \mathrm{~mm}$

- - - FF, SS, FST $3 \mathrm{~mm}$, CST $0.6 \mathrm{~mm}$

- FF, ES, FST $3 \mathrm{~mm}$, CST $0.6 \mathrm{~mm}$

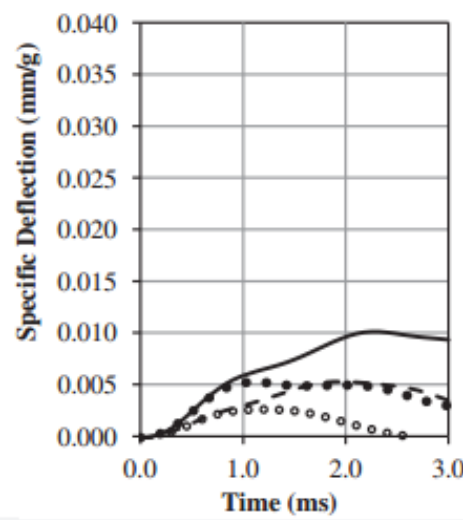

$\longrightarrow$ E, SS, FST $5 \mathrm{~mm}$, CST $0.6 \mathrm{~mm}$ •.. E, ES, FST $5 \mathrm{~mm}$, CST $0.6 \mathrm{~mm}$ - - - FF, SS, FST $5 \mathrm{~mm}$, CST $0.6 \mathrm{~mm}$

- FF, ES, FST $5 \mathrm{~mm}$, CST $0.6 \mathrm{~mm}$

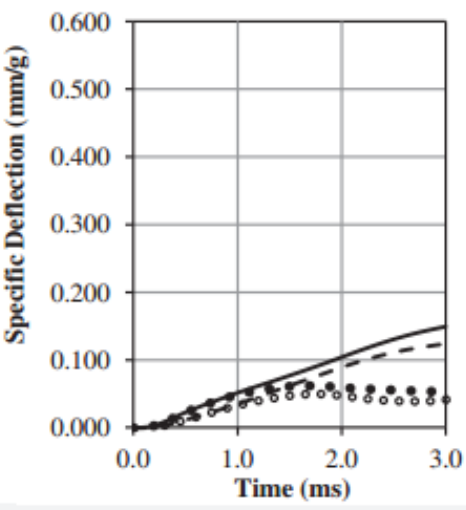

E, SS, FST $1 \mathrm{~mm}$, CST $1 \mathrm{~mm}$ •...E, ES, FST $1 \mathrm{~mm}, \mathrm{CST} 1 \mathrm{~mm}$ - - - FF, SS, FST $1 \mathrm{~mm}$, CST $1 \mathrm{~mm}$

- FF, ES, FST $1 \mathrm{~mm}, \mathrm{CST} 1 \mathrm{~mm}$

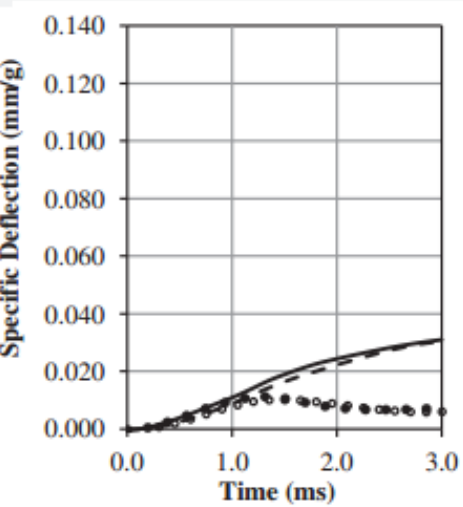

$\longrightarrow$ E, SS, FST $3 \mathrm{~mm}$, CST $1 \mathrm{~mm}$ •.. E, ES, FST $3 \mathrm{~mm}$, CST $1 \mathrm{~mm}$ - - - FF, SS, FST $3 \mathrm{~mm}, \mathrm{CST} 1 \mathrm{~mm}$
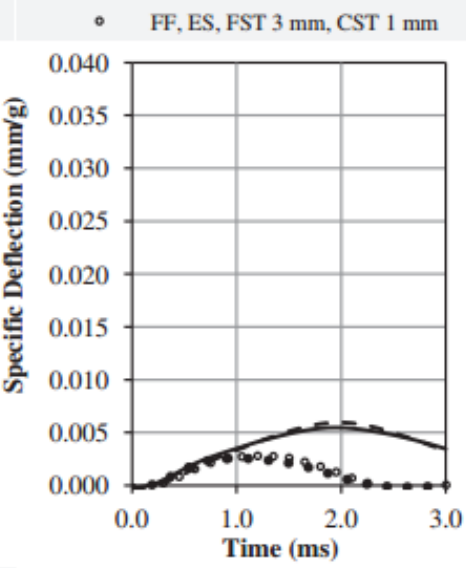

$\longrightarrow$ E, SS, FST $5 \mathrm{~mm}$, CST $1 \mathrm{~mm}$ -...E, ES, FST $5 \mathrm{~mm}$, CST $1 \mathrm{~mm}$ - - - FF, SS, FST $5 \mathrm{~mm}$, CST $1 \mathrm{~mm}$ - FF, ES, FST $5 \mathrm{~mm}$, CST $1 \mathrm{~mm}$

Fig. 18 Specific front-face deflections of empty corrugated steel core (E) and foam filled corrugated steel core (FF) sandwich panels depend on Face Sheet Thickness (FST), Corrugated Sheet Thickness (CST), Boundary Conditions (BC) which are Simple Supported (SS) and Encastre Supported (ES). 


\subsection{Back-face Deflections (BFDs)}

All of the obtained BFDs from FEM simulations can be seen in Fig. 19. The figure shows BFD differences between empty corrugated steel core sandwich panels and foam filled corrugated steel core sandwich panels under shock loading. In sandwich panels, and armor in general, small BFDs are the most desirable characteristic. In most of the investigated sandwich panel cases, BFDs were reduced by foam filling. However, FST and CST increase reduced the influence of the foam infill on mitigating deflection and in the stiffest condition (FST $5 \mathrm{~mm}$-CST $0.6 \mathrm{~mm}$ ), foam filling exacerbated the BFDs. The FST and CST increase reduced the influence of the foam infill on mitigating deflection. Encastre boundary conditions produced less BFDs than Simple Supported in all cases and the change in boundary condition produces greater reductions in deflections than foam filling. It can be observed from Fig. 19 that foam filling is more effective in thinner FST core sandwich panels. The lowest BFDs were observed in the $5 \mathrm{~mm}$ FST $-0.6 \mathrm{~mm}$ CST foam filled sandwich panels. It is interesting to note that in the FST $5 \mathrm{~mm}$-CST $0.2 \mathrm{~mm}$ no foam fill encastre $\mathrm{BC}$ case the core becomes so relatively weak that a sever slapping collapse case is observed. 


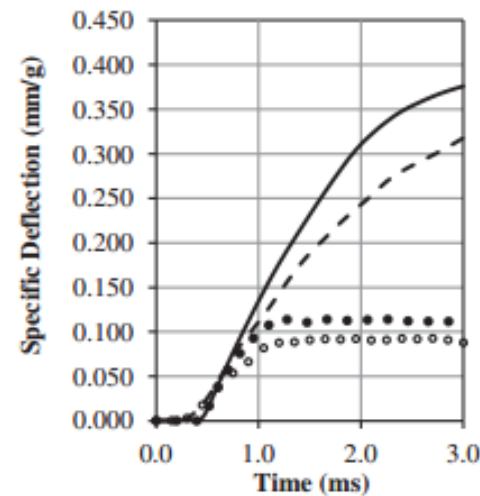

E, SS, FST $1 \mathrm{~mm}$, CST $0.2 \mathrm{~mm}$ .... E, ES, FST $1 \mathrm{~mm}$, CST $0.2 \mathrm{~mm}$

- - FF, SS, FST $1 \mathrm{~mm}$, CST $0.2 \mathrm{~mm}$

- FF, ES, FST $1 \mathrm{~mm}$, CST $0.2 \mathrm{~mm}$

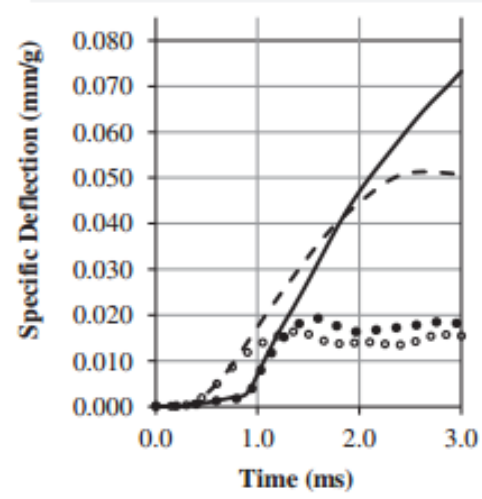

E, SS, FST $3 \mathrm{~mm}$, CST $0.2 \mathrm{~mm}$ .... E, ES, FST $3 \mathrm{~mm}$, CST $0.2 \mathrm{~mm}$

- - - FF, SS, FST $3 \mathrm{~mm}$, CST $0.2 \mathrm{~mm}$

- $\quad$ FF, ES, FST 3 mm, CST 0.2 mm

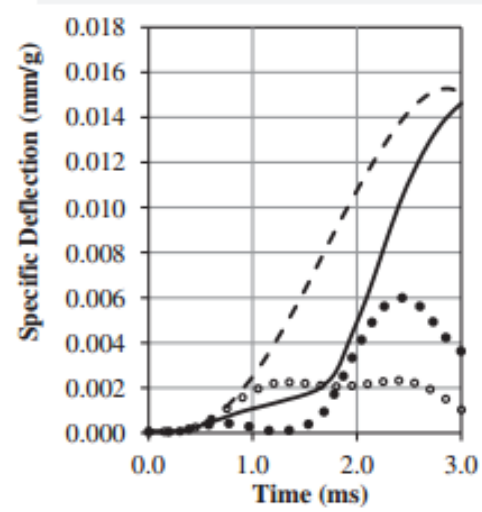

— E, SS, FST $5 \mathrm{~mm}$, CST $0.2 \mathrm{~mm}$ •... E, ES, FST $5 \mathrm{~mm}$, CST $0.2 \mathrm{~mm}$

- - - FF, SS, FST $5 \mathrm{~mm}$, CST $0.2 \mathrm{~mm}$

- FF, ES, FST 5 mm, CST $0.2 \mathrm{~mm}$

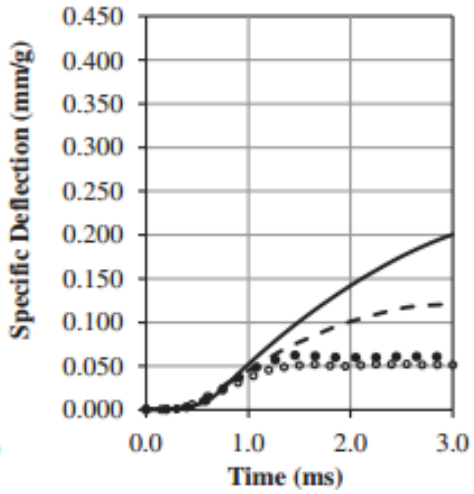

E, SS, FST $1 \mathrm{~mm}$, CST $0.6 \mathrm{~mm}$ .... E, ES, FST $1 \mathrm{~mm}$, CST $0.6 \mathrm{~mm}$

- - - FF, SS, FST $1 \mathrm{~mm}$, CST $0.6 \mathrm{~mm}$ - FF, ES, FST $1 \mathrm{~mm}$, CST $0.6 \mathrm{~mm}$

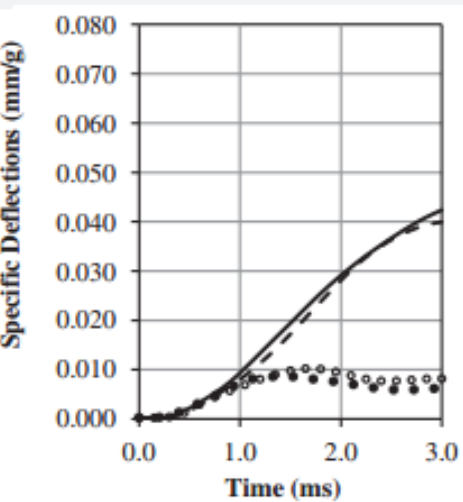

E, SS, FST $3 \mathrm{~mm}$, CST $0.6 \mathrm{~mm}$

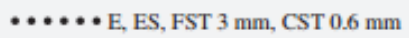

- - - FF, SS, FST $3 \mathrm{~mm}$, CST $0.6 \mathrm{~mm}$

- FF, ES, FST 3 mm, CST $0.6 \mathrm{~mm}$

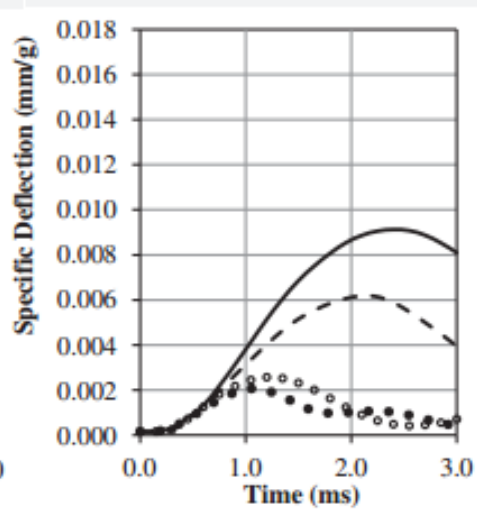

E, SS, FST $5 \mathrm{~mm}$, CST $0.6 \mathrm{~mm}$

... E, ES, FST $5 \mathrm{~mm}$, CST $0.6 \mathrm{~mm}$

- - - FF, SS, FST $5 \mathrm{~mm}$, CST $0.6 \mathrm{~mm}$

- FF, ES, FST 5 mm, CST $0.6 \mathrm{~mm}$

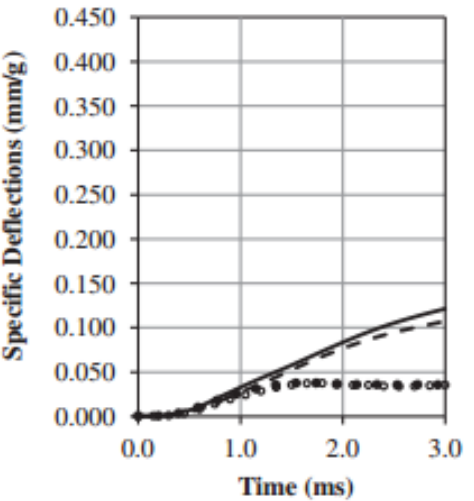

- E, SS, FST $1 \mathrm{~mm}, \mathrm{CST} 1 \mathrm{~mm}$

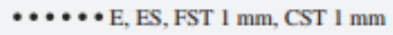

- - - FF, SS, FST $1 \mathrm{~mm}$, CST $1 \mathrm{~mm}$

- FF, ES, FST $1 \mathrm{~mm}, \mathrm{CST} 1 \mathrm{~mm}$

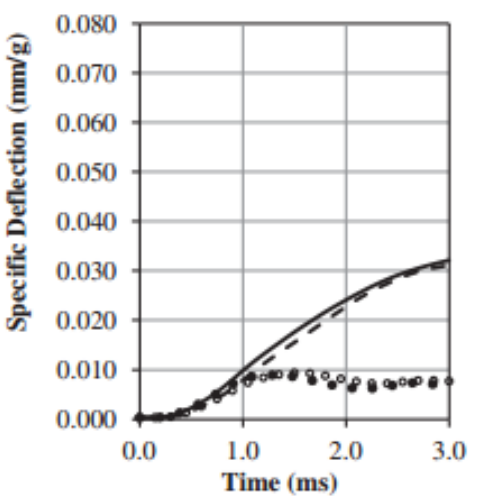

- Empty, SS, FST $3 \mathrm{~mm}$, CST $1 \mathrm{~mm}$ ....E, ES, FST $3 \mathrm{~mm}$, CST $1 \mathrm{~mm}$

- - FF, SS, FST $3 \mathrm{~mm}, \mathrm{CST} 1 \mathrm{~mm}$

- FF, ES, FST $3 \mathrm{~mm}$, CST $1 \mathrm{~mm}$

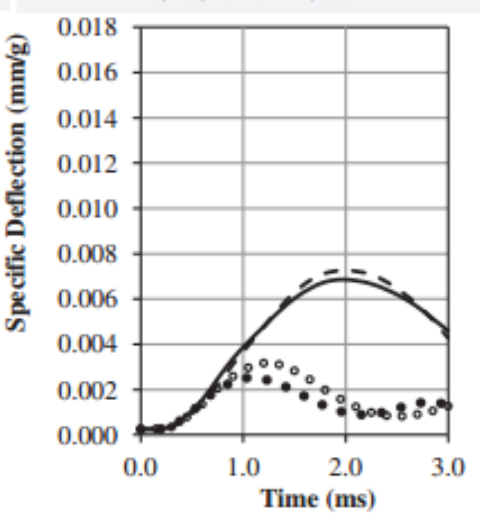

- E, SS, FST $5 \mathrm{~mm}$, CST $1 \mathrm{~mm}$ •.. E, ES, FST $5 \mathrm{~mm}$, CST $1 \mathrm{~mm}$ - - - FF, SS, FST $5 \mathrm{~mm}$, CST $1 \mathrm{~mm}$ - FF, ES, FST $5 \mathrm{~mm}, \mathrm{CST} 1 \mathrm{~mm}$

Fig. 19 Specific back-face deflections of empty corrugated steel core (E) and foam filled corrugated steel core (FF) sandwich panels depend on Face Sheet Thickness (FST), Corrugated Sheet Thickness (CST), Boundary Conditions (BC) which are Simple Supported (SS) and Encastre Supported (ES). 


\section{Conclusions}

The main objective of this study was to develop a sandwich structure with improved performance under shock loading at room temperatures. To achieve this purpose, metallic corrugated core sandwich panels with polymeric foam filling were developed.

The results obtained from this study are summarized as follows:

(1) The corrugations prior to plastic deformation showed elastic buckling and bending. To increase the buckling resistivity and bending rigidity of the corrugations, foam fillings are applied between cells. The foams increased the buckling and bending rigidity of the core, and both experimental and FEM results show that the foam filling generally increased the blast resistivity of the sandwich panels unless the combined factors caused the panels to become too stiff.

(2) For the experimental results front face and back-face deflections were reduced by foam filling by more than $50 \%$ around maximum deflection time, while increasing the mass of the panel by only $2.30 \%$.

(3) The experiments showed hard, soft, and slapping core collapses, and of these three the hard core unexpectedly had the least back-face deflection.

(4) Numerically, the most rigid core, i.e., the fully filled foam core with the thinnest face sheets and maximum corrugation thickness, showed the least back-face deformation. Foam infill also raised the load carrying capacity of the metallic cellular core and the bending rigidity of the sandwich panel 
by improving core cell wall buckling resistivity and bending rigidity. This improvement increased the core compression strength and thus should improve repeated load survivability.

(5) FEM simulations matched very well with the experimental results. The use of Johnson Cook material model for steels and the Ogden material model for low density closed-cell PU foams showed good results in FEM solutions.

(6) FEM simulations showed that foam filling effects changed with face sheet thickness, corrugated sheet thickness, and boundary conditions. In almost all cases, foam filling reduced the front face deflections.

(7) Increasing face sheet thickness and corrugated sheet thickness reduced the benefits of using foam filling in the sandwich structure by $\%$ reduced deflection.

(8) The encastre boundary conditions show lower front face and back face deflections than the simply supported cases.

(9) In the encastre boundary conditions, the face sheet thickness is more effective than the corrugated sheet thickness. This means that the face sheet properties are more dominant than the core properties in fully clamped edge conditions in the metallic core sandwich panels under shock loading. 


\section{Acknowledgments}

This work was supported by the US Department of Homeland Security under Award Number: 2009-ST-061-TS0011. The views and conclusions contained in this document are those of the authors and should not be interpreted as necessarily representing the official policies, either expressed or implied, of the US Department of Homeland Security. Murat Yazici acknowledges the financial support of The Scientific and Technological Research Council of Turkey (TUBITAK), and 2219 International Post Doctoral Research Fellowship Programme. 


\section{References}

[1] Zhu F, Lu GA. Review of blast and impact of metallic and sandwich structures.

Electron J Struct Eng 2007:92-101. Loading on structures:.

[2] Gibson LJ, Ashby MF. Cellular solids: structure and properties. 2nd

ed. Cambridge: Cambridge University Press; 1997.

[3] Hanssen AG, Enstock L, Langseth M. Close-range blast loading of aluminum foam panels. Int J Impact Eng 2002;27:593-618.

[4] Dharmasena KP, Wadley HNG, Williams K, Xue Z, Hutchinson JW. Response of metallic pyramidal lattice core sandwich panels to high intensity impulsive loading in air. Int J Impact Eng 2011;38:275-89.

[5] Dharmasena KP, Queheillalt DT, Wadley HNG, Dudt P, Chen Y, Knight D, et al. Dynamic compression of metallic sandwich structures during planar impulsive loading in water. Eur J Mech A-Solid 2010;29(1):56-67.

[6] Wadleya H, Dharmasena K, Chen Y, Dudt P, Knight D, Charette R, et al. Compressive response of multilayered pyramidal lattices during underwater shock loading. Int J Impact Eng 2008;35(9):1102-14.

[7] Fleck NA, Deshpande VS. The resistance of clamped sandwich beams to shock loading. J Appl Mech-T ASME 2004;71:386-401.

[8] Xue ZY, Hutchinson JW. A comparative study of impulse-resistant metal sandwich plates. Int J Impact Eng 2004;30(10):1283-305.

[9] Theobald MD, Langdon GS, Nurick GN, Pillay S, Heyns A, Merrett RP. Large inelastic response of unbonded metallic foam and honeycomb core sandwich panels to blast loading. Compos Struct 2010;92(10):2465-75. 
[10] Langdon GS, von Klemperer CJ, Rowland BK, Nurick GN. The response of sandwich structures with composite face sheets and polymer foam cores to air-blast loading: preliminary experiments. Eng Struct 2012;36:104-12.

[11] Rathbun HJ, Radford DD, Xue Z, He MY, Yang J, Deshpande V, et al. Performance

of metallic honeycomb-core sandwich beams under shock loading. Int J Solids Struct 2006;43:1746-63.

[12] Valdevit L, Wei Z, Mercer C, Zok FW, Evans AG. Structural performance of near optimal sandwich panels with corrugated cores. Int J Solids Struct 2006;43(16):4888-905.

[13] Qiu X, Deshpande VS, Fleck NA. Finite element analysis of the dynamic response of clamped sandwich beams subject to shock loading. Eur J Mech A Solid 2003;22:801-14.

[14] Cui X, Zhao L, Wang Z, Zhao H, Fang D. Dynamic response of metallic lattice sandwich structures to impulsive loading. Int J Impact Eng 2012;43:1-5.

[15] Evans AG, Hutchinson JW, Ashby MF. Multifunctionality of cellular metal systems. Prog Mater Sci 1998;43(3):171-221.

[16] Nurick GN, Langdon GS, Chi Y, Jacob N. Behaviour of sandwich panels subjected to intense air blast - Part 1: experiments. Compos Struct 2009;91:433-41.

[17] Xue ZY, Hutchinson JW. Preliminary assessment of sandwich plates subject to blast loads. Int J Mech Sci 2003;45(4):687-705.

[18] Tilbrook MT, Deshpande VS, Fleck NA. Underwater blast loading of sandwich 
beams: regimes of behaviour. Int J Solids Struct 2009;46:3209-21.

[19] Tilbrook MT, Deshpande VS, Fleck NA. The impulsive response of sandwich beams: analytical and numerical investigation of regimes of behaviour. J Mech Phys Solids 2006;54:2242-80.

[20] Karagiozova D, Nurick GN, Langdon GS. Behaviour of sandwich panels subject to intense air blasts - Part 2: numerical simulation. Compos Struct 2009;91:442-50.

[21] Vaziri A, Xue Z, Hutchinson JW. Metal sandwich plates with polymer foam filled cores. J Mech Mater Struct 2006;1(1):95-125.

[22] Gupta S, Shukla A. Blast performance of marine foam core sandwich composites at extreme temperatures. Exp Mech 2012;52(9):1521-34.

[23] Schimizze B, Son SF, Goel R, Vechart AP, Young L. An experimental and numerical study of blast induced shock wave mitigation in sandwich structures. Appl Acoust 2013;74(1):1-9.

[24] Zhuang S, Ravichandran G, Grady DE. An experimental investigation of shock wave propagation in periodically layered composites. J Mech Phys Solids 2003;51:245-65.

[25] Homae T, Wakabayashi K, Matsumura T, Nakayama Y. Reduction of explosion damage using sand or water layer. In: Proceedings of the conference of the American Physical Society topical group on shock compression of condensed matter (AIP Conf. Proc. 955), 24-29 June, 2007, Waikoloa. p. 1289-92. 108 M. Yazici et al. / Composite Structures 110 (2014) 98-109 [26] Avachat S, Zhou M. Effect of face sheet thickness on dynamic response of 
composite sandwich plates to underwater impulsive loading. Exp Mech 2012;52(1):83-93.

[27] Gardner N, Wang E, Shukla A. Performance of functionally graded sandwich composite beams under shock wave loading. Compos Struct 2012;94:1755-70.

[28] Liu X, Tian X, Lu TJ, Zhou D, Liang B. Blast resistance of sandwich-walled hollow cylinders with graded metallic foam cores. Compos Struct 2012;94:2485-93.

[29] Wang E, Gardner N, Shukla A. The blast resistance of sandwich composites with stepwise graded cores. Int J Solids Struct 2009;46:3492-502.

[30] Liang YM, Spuskanyuk AV, Flores SE, Hayhurst DR, Hutchinson JW, McMeeking

RM, et al. The response of metallic sandwich panels to water blast. J Appl Mech-T ASME 2007;74(1):81-99.

[31] Wei Z, Deshpande VS, Evansa AG, Dharmasena KP, Queheillalt DT, Wadley HNG, et al. The resistance of metallic plates to localized impulse. J Mech Phys Solids 2008;56(5):2074-91.

[32] Jhaver R, Tippur H. Characterization and modeling of compression behavior of syntactic foam-filled honeycombs. J Reinf Plast Compos 2010;29(21): 3185-96.

[33] Murray G, Gandhi F, Hayden E. Polymer-filled honeycombs to achieve a structural material with appreciable damping. J Intell Mater Syst Struct 2012;23(6):703-18. 
[34] Yungwirth CJ, Radford DD, Aronson M, Wadley HNG. Experiment assessment of the ballistic response of composite pyramidal lattice truss structures.

Compos Part B-Eng 2008;39:556-69.

[35] Wu CL, Weeks CA, Sun CT. Improving honeycomb-core sandwich structures for impact resistance. J Adv Mater 1995;26(4):41-7.

[36] Resewski C, Buchgraber W. Properties of new polyimide foams and polyimide foam filled honeycomb composites. Materialwiss Werkst 2003;34(4):365-9.

[37] Vaidya UK, Ulven C, Pillay S, Ricks H. Impact damage of partially foam-filled co-injected honeycomb core sandwich composites. J Compos Mater 2003;37(7):611-26.

[38] Vaidya UK, Kamath MV, Mahfuz H, Jeelani S. Low velocity impact response of resin infusion molded foam filled honeycomb sandwich composites. J Reinf Plast Compos 1998;17(9):819-49.

[39] Abotula S, Heeder N, Chona R, Shukla A. Dynamic thermo-mechanical response of Hastelloy X to shock wave loading. Exp Mech 2013. doi: 10.1007/s11340013-9796-4.

[40] Kumar P, LeBlanc J, Stargel D, Shukla A. Effect of plate curvature on blast response of aluminum panels. Int J Impact Eng 2012;46:74-85.

[41] Abaqus Analysis user manual, vol. III (Materials). Providence, RI: Dassault Systemes Simulia Corp; 2010.

[42] Schever L. Optional strain-rate forms for the Johnson Cook constitutive model and the role of the parameter epsilon 0. In: 6th European LsDyna User' Conference, 1 October, 2007, Frankenthal. p. 1-14. 
[43] Gardner N, Wang E, Kumar P, Shukla A. Blast mitigation in a sandwich composite using graded core and polyurea interlayer. Exp Mech 2012;52:119-33.

[44] Hou QY, Wang JT. A modified Johnson-Cook constitutive model for Mg-Gd-Y alloy extended to a wide range of temperatures. Comput Mater Sci

2010;50:147-52. 


\section{List of Tables}

Table 1. Johnson Cook parameters for low carbon steel used in FEM analysis [42]

Table 2: Predictability of the model for the deflection of the panel configurations

Table 3. Investigated parameters in FEM simulations of empty and foam filled corrugated steel core sandwich panels

Table 4.Calculated masses of FEM models for the empty corrugated steel core sandwich panels

\section{Figure Captions}

Fig. 1. a) Corrugated core sheet dimensions b) Assembly procedure of corrugated steel core sandwich structures c) Final sandwich panel side view

Fig. 2. Schematic of the sandwich panels a) Empty corrugated steel core sandwich panel b) Foam filled corrugated steel core sandwich panel c) Foam core sandwich panel

Fig. 3. Shock tube apparatus

Fig. 4. Typical experimental pressure profile

Fig. 5. Experimental setup for real-time side-view deflection measurements

Fig. 6. a) FEM model b) pressure distribution function over loaded area 
Fig. 7. Quasi static and high-strain rate compression response of Polyurethane foam

Fig. 8. High-speed images of unfilled corrugated steel core sandwich panel during shock loading

Fig. 9. Experimental results for empty corrugated steel core sandwich panels under shock loading a) Front-face and back-face out of plane velocities b) Front-Face Deflection (FFD), Back-Face Deflection (BFD), Core compression, and strain rate of the core.

Fig. 10. High-speed images of foam core sandwich specimen during shock loading

Fig. 11. Experimental results for foam core sandwich panels under shock loading: front face deflection (FFD), back face deflection (BFD), core compression, and strain rate of the core.

Fig. 12. High-speed images of fully foam filled corrugated core sandwich specimen during shock loading

Fig. 13. Experimental results for foam fillet corrugated steel core sandwich panels under shock loading a) Front face and Back face out of plane velocities b) Front Face Deflection (FFD), Back Face Deflection (BFD), Core compression, and Strain rate of the core

Fig. 14. Experiments results of a) Average Back-Face Deflections (BFD) b) Average Front-Face Deflections (FFD) for all the three configurations

Fig. 15. Corrugated steel core sandwich panel FFD and BFD variation by foam filling 
Fig. 16. Validation of FEM simulations with the experimental results for single face sheet, empty corrugated core sandwich panels, foam core sandwich panels and foam filled sandwich panels

Fig. 17. Boundary conditions used in FEM simulations

Fig. 18. Specific front-face deflections of Empty corrugated steel core (E) and Foam Filled corrugated steel core (FF) sandwich panels depend on Face Sheet Thickness (FST), Corrugated Sheet Thickness (CST), Boundary Conditions (BC) which are Simple Supported (SS) and Encastre Supported (ES)

Fig. 19. Specific back-face deflections of Empty corrugated steel core (E) and Foam Filled corrugated steel core (FF) sandwich panels depend on Face Sheet Thickness (FST), Corrugated Sheet Thickness (CST), Boundary Conditions (BC) which are Simple Supported (SS) and Encastre Supported (ES) 


\title{
Chapter 3: Manuscript 2
}

Published in the Journal of Applied Mechanics, June 2015, Vol. 82

Preferentially Filled Foam Core Corrugated Steel Sandwich Structures for

Improved Blast Performance

Murat Yazici, Jefferson Wright, Damien Bertin, *Arun Shukla

\author{
Murat Yazici \\ Uludag University, Engineering Faculty, Automotive Engineering Department, \\ TR16059 Bursa/TURKEY \\ myazici@uludag.edu.tr \\ Jefferson Wright \\ University of Rhode Island, Dynamic Photomechanics Laboratory, Department of \\ Mechanical Industrial and \\ System Engineering, 92 Upper College Road; Kingston, 02881, RI, USA \\ jeffersonwright@gmail.com

\section{Damien Bertin} \\ University of Rhode Island, Dynamic Photomechanics Laboratory, Department of \\ Mechanical Industrial and \\ System Engineering, 92 Upper College Road; Kingston, 02881, RI, USA \\ damien.bertin@gadz.org \\ Arun Shukla* \\ University of Rhode Island, Dynamic Photomechanics Laboratory, Department of \\ Mechanical Industrial and \\ System Engineering, 92 Upper College Road; Kingston, 02881, RI, USA \\ ASME member \\ shuklaa@egr.uri.edu \\ * Corresponding author phone number 1-401-874-2227
}




\begin{abstract}
The mechanisms by which different morphologies of preferentially foam filled corrugated panels deform under planar blast loading, transmit shock, and absorb energy are investigated experimentally and numerically for the purpose of mitigating back face deflection (BFD). Six foam filling configurations were fabricated and subjected to shock wave loading generated by a shock tube. Shock tube experimental results obtained from high-speed photography were used to validate the numerical models. The validated numerical model was further used to analyze 24 different core configurations. The experimental and numerical results show that, soft/hard arrangements (front to back) are the most effective for blast resistivity as determined by the smallest BFDs. The number of foam filled layers in each specimen affected the amount of front-face deflections (FFDs), but did relatively little to alter BFDs, and results do not support alternating foam filling layers as a valid method to attenuate shock impact.
\end{abstract}

\title{
Keywords:
}

Blast loading, Corrugated Steel Core, Sandwich Panel, Filling Hierarchy

\section{INTRODUCTION}

The search for light weight blast mitigative armor to protect structures from highintesity dynamic loads, created by explosions, has stimulated interest in the mechanical response of metallic core sandwich plates. Sandwich structures were recently studied with different face sheets and cores in an attempt to meet this need. 
To date, many metallic core topologies have been developed for use in the sandwich panels [1-5]. One of the most common core topologies in blast resistant sandwich panel construction is the corrugated metallic core which provides manufacturing advantages, and high strength in the normal and longitidinal directions $[2,6,7]$.

Studies on metallic sandwich panels subjected to dynamic air pressure shock (herein refered to as blasts) $[3,8]$, indicate that sandwich plates with high-ductility, and high energy absorption capacity, perform well. Liang et al. [9] and Wei et al. [10] studied the behavior of metallic sandwich cores with varying strengths and found that "soft" cores reduce the momentum transferred, thus providing better mitigation for blast loading. For metallic sandwich structures, energy absorption in metallic lattice cores is through large scale plasticity, shear and compressive buckling, and eventual tearing of core walls and facesheets [11]. In sandwich panels, scattering due to interfaces between dissimilar materials plays an important role in shock wave dissipation, dispersion, and ultimately, mitigation. Depending on the acoustic impedance of the interacting medium, the shock wave will reflect, transmit, and dissipate to different degrees [12]. Zhuang et al. [13] examined the scattering effects of stress waves in layered composite materials. Their experimental results show that the scattering effects dramatically slows shock propagation in the layered composites and can lower the shock speed in composites below that of either of its components.

Wakabayashi et al. [14] experiments' suggest that low-density materials may provide the most effective blast mitigation. In recent years, sandwich structures with strong 
facesheets and lightweight cores have become central structural components for blast mitigation. Polymeric foams offer unique structural, impact, thermal and acoustic properties, which make them an excellent choice as core materials to obtain low density blast resistive sandwich structures $[11,15]$. These polymeric foams can be used as filler material inside the interstices of cellular metallic core sandwich structures. It is possible to obtain a new sandwich structure, combining these two cores' shock absorption advantages and decrease the transmitted shock load by their differing acoustic impedences [16-20]. Moreover, foam filling stabilizes the core cell walls against buckling and increases the strength of the core. Foam filling interstices of the metallic core sandwich structures also ensure some multifunctional advantages such as acoustic and thermal insulation [21].

In recent years, functionally graded foams (where the material properties vary continuously, or stepwise, within the material itself) have gained attention in improving energy absorbing capabilities of sandwich structures. Gardner et al. [22] found that the higher the number of layers of increasing impedance improved performance (up to the maximum studied of four). The increasing material interfaces, allows for blast wave scattering/dispersion of through interface variations and stepwise compression of the core. Wang et al. [23] studied stepwise graded foam core composite sandwich plates. Three layer cores arranged via acoustic impedance were used in two different configurations: low-mid-high and mid-low-high. In the first configuration, the properties of the layers gradually increased and obtained better performance than the second configuration. 
Work has also been done with the stepwise increasing of metalic core corrugation thickness, similar to the foams mentioned above but focusing on increaseing stiffness rather than impedance. The finding shows that a gradual increase in core stiffness from front to back results in the most effective formation for blast mitigation [24, 25].

The study presented focuses on the blast resistance and energy absorption of foam filled corrugated steel core sandwich structures. These structures had various core configurations that were obtained by different filling strategies and then experimentally and numerically subjected to shock wave loading. The experimental and numerical results show that, soft/hard arrangements (front to back) are the most effective structures for blast resistivity.

\section{EXPERIMENTAL PROCEDURE}

\subsection{Specimen Preparation}

Corrugated steel core sandwich structures were produced with different foam filling configurations. Low carbon steel face sheets were used with sinusoidal corrugated steel for the core in a four layer match up. The corrugated sheet was galvanized low carbon steel; a diagram of the sandwich panel without filling can be seen in Fig. 1(a) illustrating the five interstitial layers (when a layer is later discussed in this document it is in reference to these layers).

The face and corrugated sheets' dimensions are $50.8 \times 203.2 \mathrm{~mm}$ with the face sheet being $3.2 \mathrm{~mm}$ thick and the corrugated sheets being $0.44 \mathrm{~mm}$ thick ( 29 gage). The corrugated sheets are $6.35 \mathrm{~mm}$ high and $31.75 \mathrm{~mm}$ peak to peak. 
Each sheet (including face sheets) is bonded by the epoxy adhesive G/Flex (West System Inc., Bristol, RI), which has a tensile adhesion strength of $20 \mathrm{MPa}$. Select interstices layers within the corrugated steel core were filled with low density polyurethane (PU) foam of varied configurations. These layers between steel sheets are coded in order from front-face to back-face one through five. To distinguish between configurations when an empty layer is filled with foam this layer is coded with an F prefix with each layer filled listed in series (example: configuration F1-F5 would be a panel configuration in which the first and last layers are filled as seen by the first configuration in Fig. 1(b)). Fig. 1(b) shows the section of six different experimentally shock loaded sandwich configurations with a diagram of layer labeling. These were tested under blast loading with simply supported boundary conditions. 


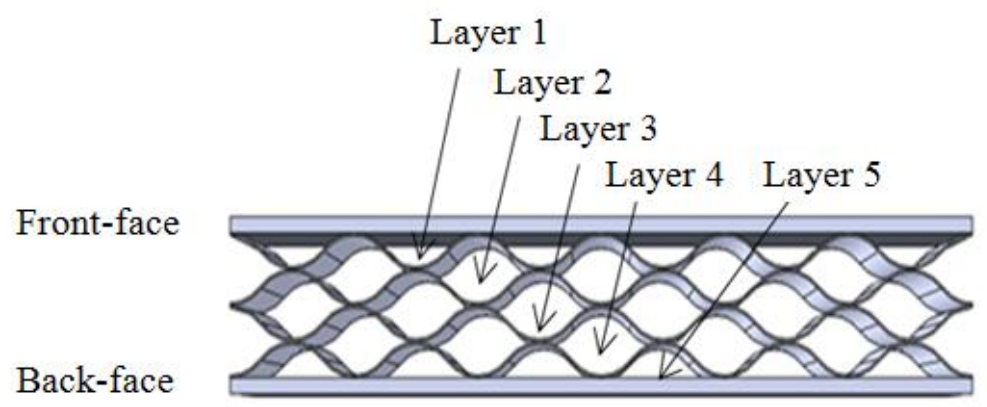

(a)

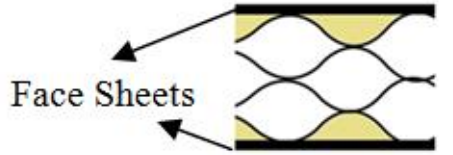

F1-F5

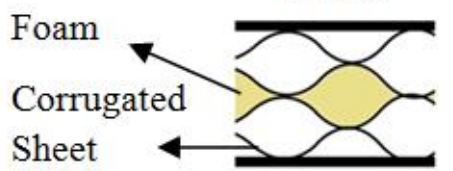

F3

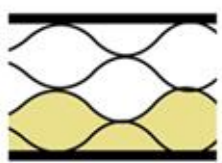

F4-F5

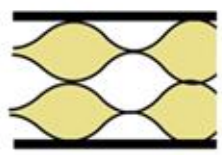

F2-F4

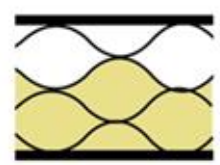

F3-F4-F5

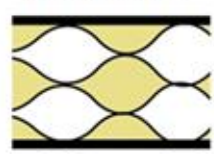

F1-F3-F5

(b)

\section{Fig. 1 Corrugated core with interstitial layering arrangment and $(b)$ Illustration of six core filling configurations}

\subsection{Shock Load Procedure}

A shock tube apparatus was used to load specimens with a planar shock wave. A typical pressure profile generated by the shock tube is shown in Fig. 2. The muzzle inner diameter of the shock tube used was $38.1 \mathrm{~mm}$ (see Fig. 3) [26]. Two pressure transducers (PCB102A) were mounted at the end of the muzzle section to record the incident and reflected pressure profiles. The first pressure sensor was mounted $20 \mathrm{~mm}$ away from the muzzle, and the second was mounted $180 \mathrm{~mm}$ away (160 mm separation from the first pressure sensor). The incident peak pressure of the shock wave was chosen to be $1.1 \mathrm{MPa}$ and a reflected peak pressure of approximately 5.5 MPa was obtained for the panels (Fig. 2). 


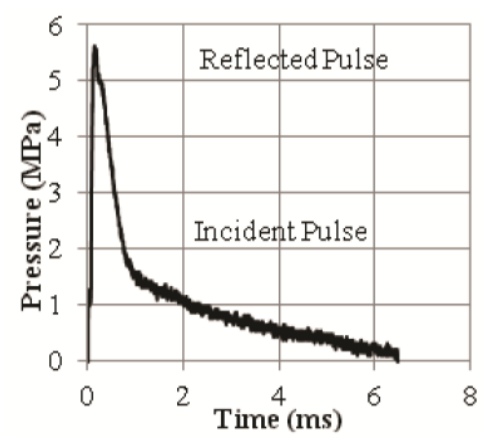

Fig. 2 Typical experimental pressure profile

The specimens were placed onto a simply supported fixture with a $152.4 \mathrm{~mm}$ span. The flat front-face of the specimen was set normal to the axis of the shock tube with the face completely covering the muzzle. A diagram of this set up can be seen in Figure 3. At least three specimens of each type were shock loaded to ensure repeatability.

A high-speed photography system was utilized to determine their deformation and damage propagation by capturing the motion of the specimens. The lens axis of the camera was set perpendicular to the shock tube as shown in Fig. 3. A Photron SA1 high-speed digital camera was used at a frame rate of 20,000 frames per second with an image resolution of $512 \times 512$ pixels over $3 \mathrm{~ms}$ duration. 


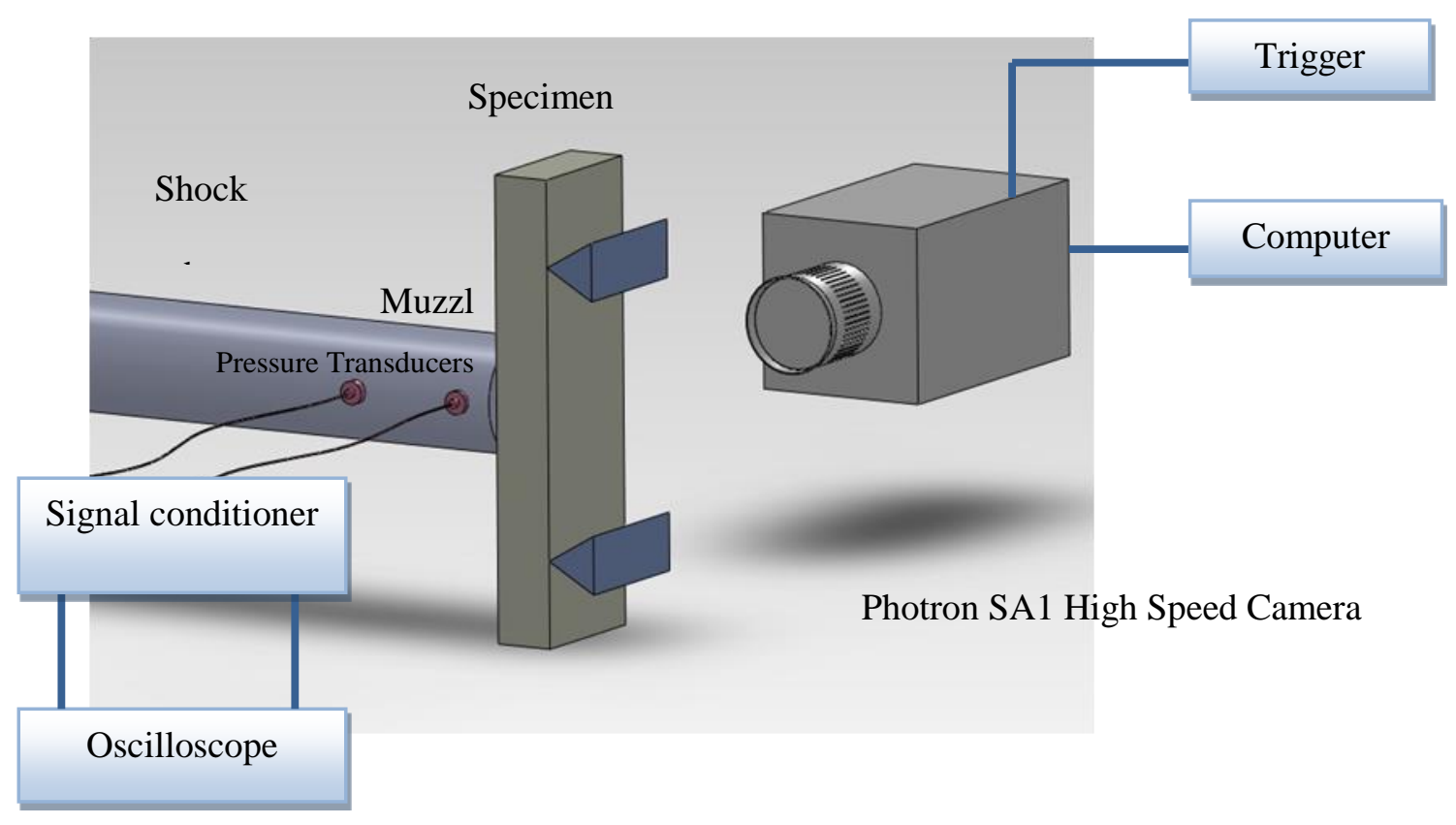

Fig. 3 High-speed camera side-view deflection measurement

\section{NUMERICAL PROCEDURE}

Numerical analyses were obtained by using ABAQUS/EXPLICIT 6.10.1 finite element (FE) software modeling the sandwich panels subjected to blast loading. Dynamic explicit analysis was performed with three-dimensional nonlinear geometry with a 3 ms run time.

\subsection{Finite Element Model}

An explicit finite element model was created to replicate the corrugated steel core sandwich panel's experimental shock loading with identical conditions (geometry, boundary conditions, and loading). The steel plates and corrugated sheets were modeled as homogenous shells with the prescribed thickness. The front and back-face plates were modeled from their back and top faces respectively while the corrugated layers were defined by their mid planes (Fig. 4(a)). Interactions between 
the corrugated core and the face plates were designated as surface-to-surface contacts under the penalty contact method with finite tangential sliding. The shear stress limit to failure was set to the adhesive limit of $20 \mathrm{MPa}$. The foam filling is modeled as 3D brick elements rigidly tied to the surrounding shells using the tie constraint, surface to surface discretization method. All elements utilize reduced integration and hourglass control.

An experimentally obtained shock pressure profile of average impulse, discussed below, (Fig. 5(a)) was imported into Abaqus as tabular pressure data. The shock pressure history imparted onto the FE model is a nonlinear function of the pressure profile and area to be loaded to mimic experimental conditions. This shock pressure distribution is described in literature to be a combination of uniform and nonuniform parts $[27,28]$. A uniform pressure profile is imparted upon the specimen directly in front of the muzzle's inner diameter while the non-uniform shock pressure profile tappers linearly to zero from the edge of the muzzle inner diameter to a range of an additional one-third of the diameter outwards, as shown in Fig. 4(b). Karagiozova et al [27] suggested the non-uniform distributed shock pressure profile had an exponential decay function, however, this study's variation is assumed to be a linear decay function for simplification.

As the experimental specimens were held by simply supported knife edges, to decrease the degrees of freedom of the model these knife edges are not explicitly modeled. The knife edge boundary conditions are modeled by a combination of one simply supported boundary condition and a roller boundary condition to allow the specimen to flex and draw in. After validating the finite element models (FEMs) to the 
experimental data with the $152.4 \mathrm{~mm}$ span FEM, shown below, the boundary conditions are moved to the end of the plates: a $203.2 \mathrm{~mm}$ span for the preferentially filled numerical study resulting in larger deflections and bending than observed in the experiments.

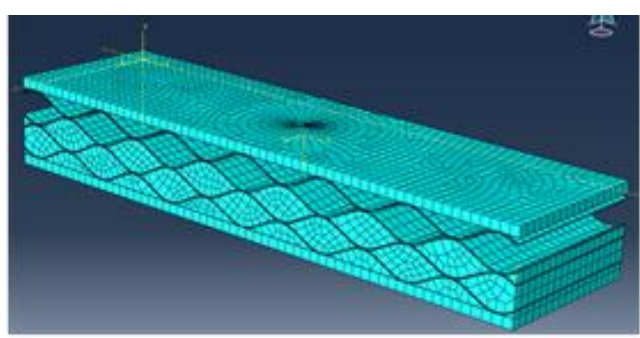

(a)

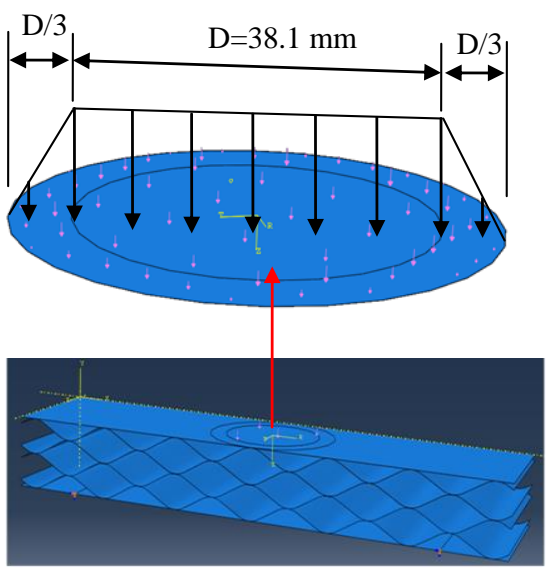

(b)

Fig. 4 (a) Assembly of Sandwich Structure as a Finite Element Model for F3F4F5 filled corrugated steel core sandwich panel. (b) Pressure distribution on applied surface
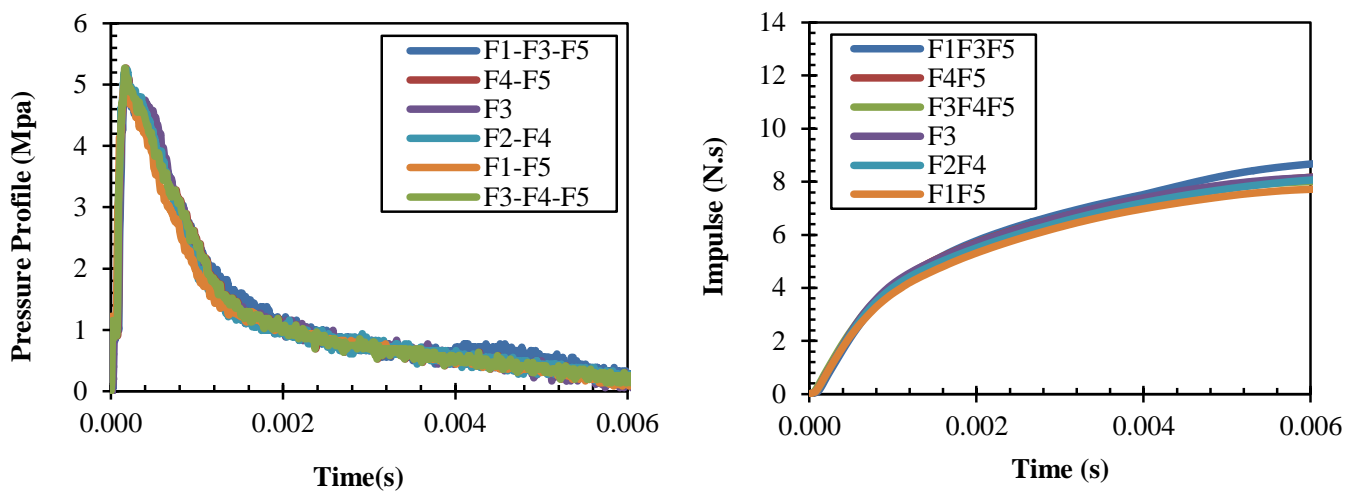

Fig. 5 (a) Blast pressures subjected to specimen in shock tube experiments and (b) Specific Impulses subjected to shock tube experiments 


\subsection{Material Properties}

The material properties of the corrugated steel sheets and face sheets were taken from literature to be: modulus of elasticity $(E) 205 \mathrm{GPa}$, Poisson's ratio (v) 0.29, density ( $\rho) \rho) 7.85 \mathrm{~g} / \mathrm{cm}^{3}$, and one-dimensional acoustic wave impedance $3,962 \times 10^{4}$ $\mathrm{kg} / \mathrm{m}^{2} \mathrm{~s}$ (Table 1). A Johnson-Cook material model with strain hardening was also used in this FEM for steel to capture strain rate effects (Table 2). The yield stress is for a Johnson-Cook material model is expressed as [29, 30]:

$$
\bar{\sigma}=\left[A+B\left(\bar{\varepsilon}^{p l}\right)^{n}\right]\left[1+C \ln \left(\frac{\dot{\bar{\varepsilon}}^{p l}}{\dot{\varepsilon}_{0}}\right)\right]\left(1-\hat{\theta}^{m}\right)
$$

where $\bar{\sigma}$ is the yield stress at nonzero strain rate, $\bar{\varepsilon}^{p l}$ is the equivalent plastic strain, $\dot{\varepsilon}_{0}$ is the quasi static strain rate, $\dot{\bar{\varepsilon}}^{p l}$ is the equivalent plastic strain rate, $A, B, C, n$ and $m$ are material constants. $\hat{\theta}$ is the non dimensional temperature ratio and set to zero in this paper.

Table 1 Low carbon steel Johnson Cook Parameters in FEM analysis [31]

\begin{tabular}{cccccc}
\hline $\mathbf{A}(\mathbf{M P a})$ & $\mathbf{B}$ (MPa) & $\mathbf{n}$ & $\mathbf{C}$ & $\mathbf{m}$ & $\dot{\boldsymbol{\varepsilon}}_{\mathbf{0}}\left(\mathbf{s}^{-\mathbf{1}}\right)$ \\
220 & 499.87 & 0.228 & 0.017 & 0.917 & 1 \\
\hline
\end{tabular}

Table 2 Predictability of the Model for the Deflection of the Panel Configurations

\begin{tabular}{lccccc}
\hline \hline & \multicolumn{2}{c}{$\begin{array}{c}\text { Foam Filled Corrugated } \\
\text { Steel Core Sandwich Panels }\end{array}$} & & \multicolumn{2}{c}{$\begin{array}{c}\text { Empty Corrugated Steel } \\
\text { Core Sandwich Panels }\end{array}$} \\
\cline { 2 - 3 } Error Analysis Type & FFD & BFD & & FFD & BFD \\
\hline $\mathrm{R}^{2}$ & 0.96 & 0.98 & & 0.99 & 1.00 \\
Russell Error & & & & & \\
Phase & 0.0358 & 0.0250 & & 0.0146 & 0.0171 \\
Magnitude & 0.0667 & 0.0242 & & 0.1002 & 0.1256 \\
Comprehensive & 0.0671 & 0.0897 & & 0.0897 & 0.1124 \\
\hline \hline
\end{tabular}


The foam filled sandwich structures used general purpose humidity cured PU, of density $0.0446 \mathrm{~g} / \mathrm{cm}^{3}$ and elastic modulus $0.24 \mathrm{MPa}$ as infill. PU can deform elastically to large strains, up to $90 \%$ in compression and are intended for finite strain applications. The mechanical properties of the PU foam were obtained using quasistatic compression tests, and the high strain rate $(3000 / \mathrm{s})$ properties were found via Split Hopkinson Pressure Bar experiments [31] as shown in Fig. 6.

PU foam material shows non-linear, hyperelastic behavior and is extremely compressible as its porosity permits very large volumetric changes. PU foams under large strains as observed in the experiments can be modeled as compressible hyperelastic solids, if their time dependent mechanical properties and hysteresis are ignored. In the FEM, Ogden strain energy potential was applied using tabular data from the Split Hopkinson Pressure Bar experimentation. In all FE analysis, a Poisson's ratio, $v=0$ was used for the PU foam.

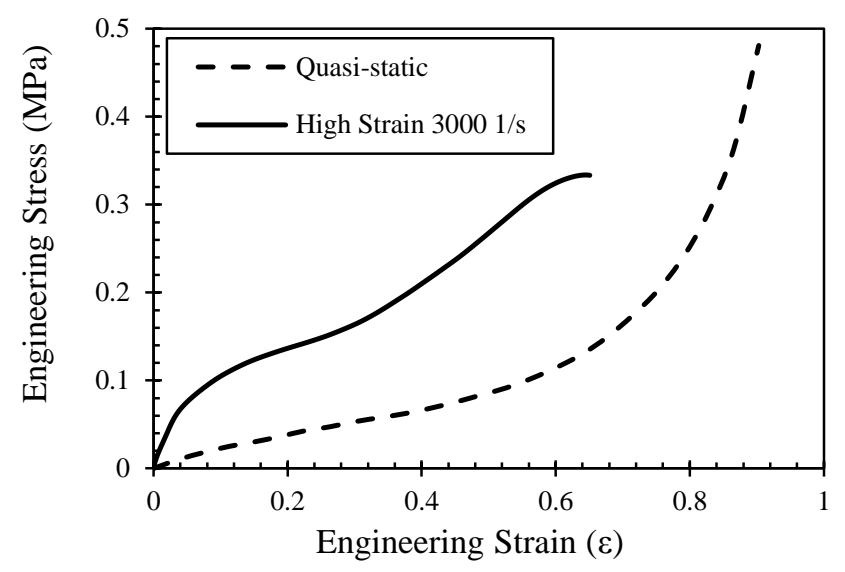

Fig. 6 Quasi static and high-strain rate compression properties of the PU foam 


\section{EXPERIMENTAL RESULTS AND DISCUSSION}

\subsection{Applied Pressure and impulses}

Three, $10 \mathrm{mil}(0.254 \mathrm{~mm})$ Mylar sheets were used as a rupturing diaphragm to create shock waves. Subramaniam et al. [32] showed that the pressure subjected to a movable surface, like the front-face sheet of the sandwich structure, can be accepted as the same as that applied to a fixed rigid wall found by using measured reflected pressure profiles. Real-time measured pressure profiles from the closest pressure sensor (reflected) can be seen in Fig. 5(a). The average peak value of the reflected shock pressure was $5.18 \pm 0.10 \mathrm{MPa}$. The specimens' masses were measured to be $600.2 \pm 2.35 \mathrm{~g}$ and their thicknesses to be $28.85 \pm 1.13 \mathrm{~mm}$.

From the reflected pressure profile captured by the transducer closest to the specimen the impulse imparted onto that specimen can be calculated (see Fig. 5(b)). These pressure profiles can be considered to be the same as the pressure applied to the specimens. Since the cross-sectional area of the muzzle is known the pressure impulse applied on the specimens can be calculated as:

$$
\mathrm{I}_{\text {pressure }}=\int_{0}^{\mathrm{t}_{1}}\left(\mathrm{p}_{\text {reflected }}-\mathrm{p}_{0}\right) S d \mathrm{t}
$$

where $I$ is the impulse, $p_{\text {reflected }}$ is the reflected pressure and $p_{0} p_{0}$ is the atmospheric

pressure. Specific Impulses were calculated for comparison with each other by dividing specimen masses. The impulses were obtained up to $3 \mathrm{~ms}$, with a $2.46 \%$ maximum standard variation. Since the difference in total impulse imparted upon each specimen (regardless of thickness, weight, or filling) was so small, face deflections are considered without normalizations and all numerical simulations were loaded assuming the same average reflected pressure profile. 


\subsection{High Speed Photography and Experimental Results}

The real-time observations of the deformation of each type of specimen are shown in Fig. 7. On the right side of each image is the shock tube: the shock wave impinges upon the front-face of the panels from this side.

In all cases, local collapse of the front-face around the center axes occurs from the elastic deflection of the corrugated core soon after the shock wave impinges upon the specimen. As the specimens are loaded over the $3 \mathrm{~ms}$, the shock load is transferred from front to back-face via the corrugated sheet layers. In each layer, the shock load is divided into horizontal and vertical components in the joints. The corrugated cell walls begin to collapse in on each other by decreasing the corrugation angle (bending around joints). The shear load was transferred from one layer to the other through each cell wall as longitudinal pressure waves. These waves initiated local bending (due to the eccentricity of the shear load according to longitudinal axes and eccentric form of the corrugation). Buckling of these cell walls was observed as this occurred. However, when those cells are foam filled this bending is resisted by the foam infill and the horizontal load component causes foam compression. Energy absorption continues as front plate bending, foam compression, and empty cell collapse. As the core reaches its point of maximum compression (exact timing both relative and exact is core morphology dependent) the back-face begins to bend and the panel goes into a state of global bending. As this deformation progresses to incorporate back-face bending the difference in face plate deformation can lead to the corrugation angle increasing and the opening of some cells. During global bending typically some additional core 
collapse can be observed. The front-face acceleration causes the lateral core compression during this period while front and back-face velocity equalizes.

The sequential images in Fig. 7 show the response of each specimen to blast loading. It was observed that the filling configurations changes the deformation behavior and deforming layer sequence. In all cases, foam filled layers had delayed compression relative to empty layers. Most deformation of the core layers started with bending or buckling of empty layer cells' walls followed by plastic deformation of the cells as the cells collapse.

Shear force components cause the most deformation in the empty cells, particularly when surrounded by stiffer foam filled layers (F3, F2F4, F1F3F5), where more complete empty cell collapse is observed. Under these circumstances, filled cell walls experienced limited buckling or bending; deformation of filled cells was observed as compression of foam and flattening of the corrugation.

Figures $8(a)$ and $8(b)$ show BFDs and FFDs with respect to time for each foam filling configuration of the metallic sandwich panels. The data in these figures were obtained from midpoint deflections of the face sheets using pictures from high-speed photography, shown in Fig. 7. It was observed from these results that, increasing with the amount of foam filling FFDs of the panel were reduced. The mid foam filling case (F3) is the least effective configuration with respect to FFD and BFD of the sandwich panels and exhibits substantially more deflection than the empty panels. However, the F1F3F5 (alternate filling) case showed almost the same performance both in FFD and BFD as with back-face filled F3F4F5. This means, shock pressure wave dissipation and dispersions between filled-empty layers are not the root cause of shock load 
resistivity of the panel. This can also be seen in that the F2F4 alternately filled configuration had the second largest BFD of the experimental runs. From this observation the F1F3F5 case seems to have a relatively decreased BFD through the strengthening of the face plates (through filling F1 and F5). Figure 8 also shows that up to about $1 \mathrm{~ms}$, the panels have little deviation from their deflection histories, which indicates that the metallic structure is the primary component during early shock onset. 


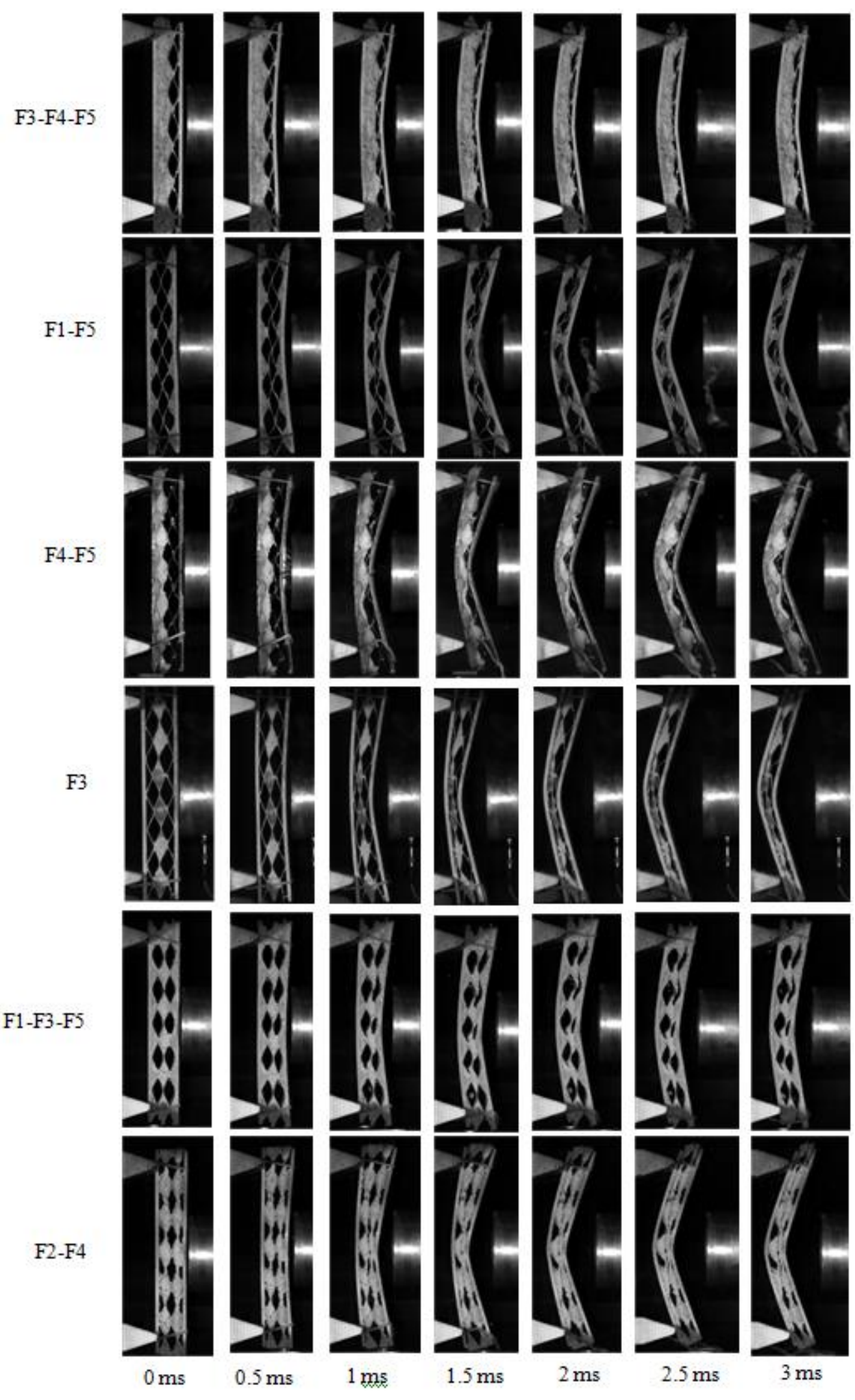

Fig. 7 High-speed images of the foam filled corrugated core sandwich specimens 

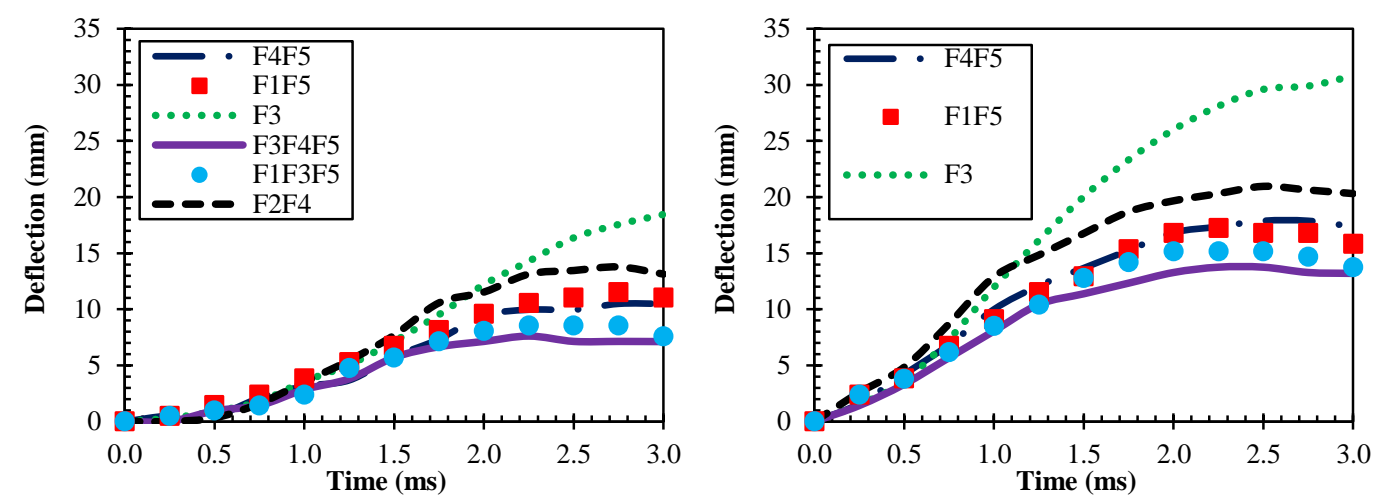

Fig. 8 Shock tube experimental results depend on filling hierarchy of the sandwich panels: (a) BFD and $(b)$ FFD

\section{NUMERICAL RESULTS AND DISCUSSIONS}

\subsection{Validation of Numerical Solutions}

To validate FEM results, FFD and BFD experimental data from high-speed photography for the two extreme panel conditions (the empty corrugated steel core sandwich panel and completely foam filled corrugated steel core sandwich panel) were correlated using Pearson coefficient and Russell error. Comparative results can be seen in Fig. 9 and 10.

Coefficient of determination $\left(\mathrm{R}^{2}\right)$ values were calculated using equations which are given in Ref. [33] as a means to evaluate the model's accuracy. The coefficient of determination is a measure of accuracy of the linear relationship between the experimental and predicted data. The predictability of the FE model over both the front and back-faces of the four different experimental designs is shown in Table 2. Pearson's coefficient equation is given below:

$$
R^{2}=\left(\frac{\sum_{i=1}^{n}\left(X_{i}-\bar{X}\right)\left(Y_{i}-\bar{Y}\right)}{\sqrt{\sum_{i=1}^{n}\left(X_{i}-\bar{X}\right)^{2}} \sqrt{\sum_{i=1}^{n}\left(Y_{i}-\bar{Y}\right)^{2}}}\right)^{2}
$$




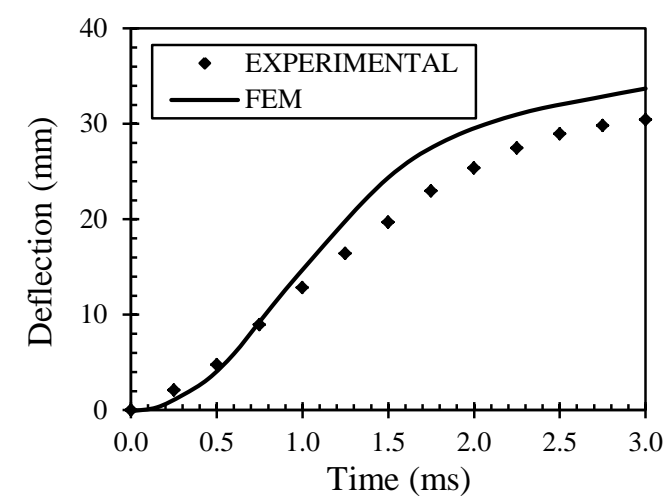

(a)

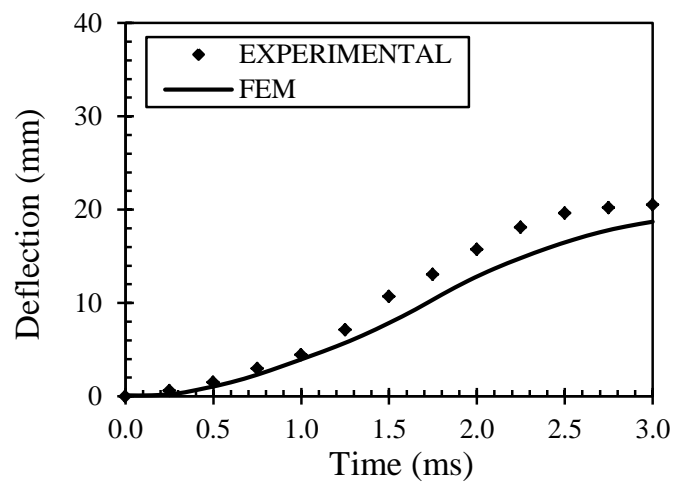

(b)

Fig. 9 FEM and experimental empty corrugated steel core sandwich specimen: (a) FFD and (b) BFD

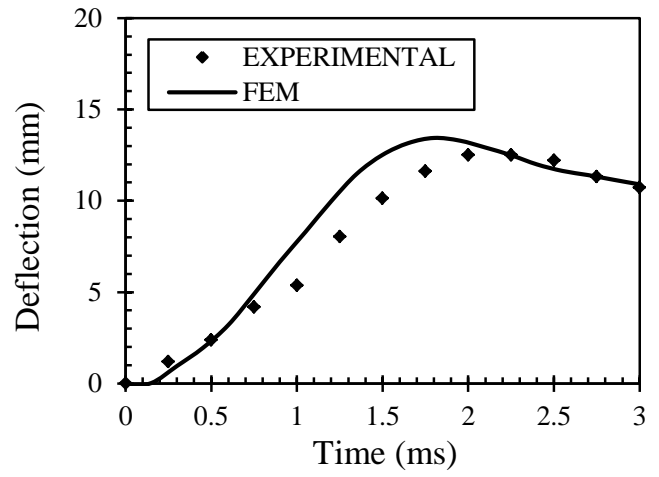

(a)

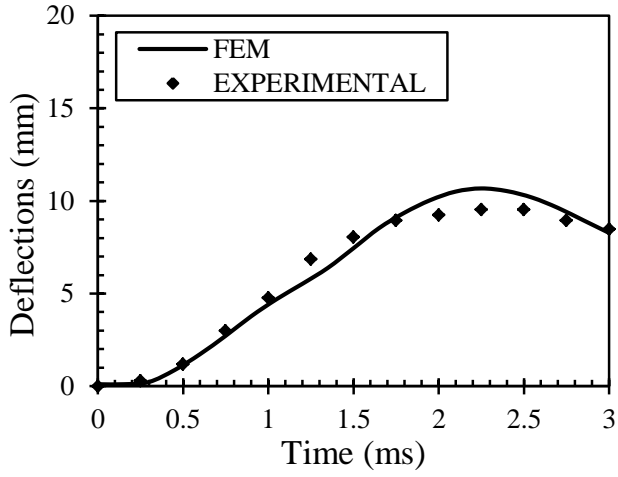

(b)

Fig. 10 FEM and experimental foam filled corrugated steel core sandwich specimen: (a) FFD and (b) BFD

The Russell error method evaluates the difference between two sets of transient phenomena for both magnitude and phase alignment. These two errors are then combined into a single comprehensive error value. The complete derivation and justification of Russell Error can be found in Ref. [34] while the phase $(R P)$, magnitude $(R M)$, and comprehensive error $(R C)$ equations respectively are given below:

$$
R P=\frac{1}{\pi} \cos ^{-1}\left(\frac{\sum c_{i} m_{i}}{\sqrt{\sum c_{i}^{2} \sum m_{i}^{2}}}\right)
$$




$$
\begin{aligned}
& R M=\operatorname{sign}(m) \log _{10}(1+|m|) \\
& m=\left(\sum c_{i}^{2}-\sum m_{i}^{2}\right) / \sqrt{\left(\sum c_{i}^{2} \sum m_{i}^{2}\right)} \\
& R C=\sqrt{\frac{\pi}{4}\left(R M^{2}+R P^{2}\right)}
\end{aligned}
$$

where $c_{i}$ is the simulated transient response and $m_{i}$ is the experimental transient response.

The coefficient of determination in all cases is 0.96 or higher indicating that the trends of the experimental results and the finite element model are well aligned. A Russell error equal to or less than 0.15 is considered excellent while a Russell error between 0.15 and 0.28 is deemed acceptable, and anything greater than 0.28 is poor [35]. All Russell Error measurements are within the excellent range as seen in Table 2 all FE simulations are accepted as having good agreement with experimental results.

\subsection{Investigation of filling hierarchy effect by FEM}

FE analyses were performed using ABAQUS/Explicit 6.10.1 commercial software. Different filling configurations (front-face, back-face, middle, both-face, and alternate layer filled) were analyzed to observe panel responses to blast loading.

Graphical illustrations of these configurations are given in Fig. 11. Figures 12-16 illustrate the BFD and FFD history of the models separated into these five configurations groups. Fully filled and empty cases are shown in all figures for comparison. Figure 17 shows the boundary conditions used in these numerical simulations. A $3 \mathrm{~ms}$ time duration was chosen for finite element analysis (FEA) as all 
experimental configurations had reached their peak BFD by this time with the exception of the extreme F3 case as well as to limit computational costs.

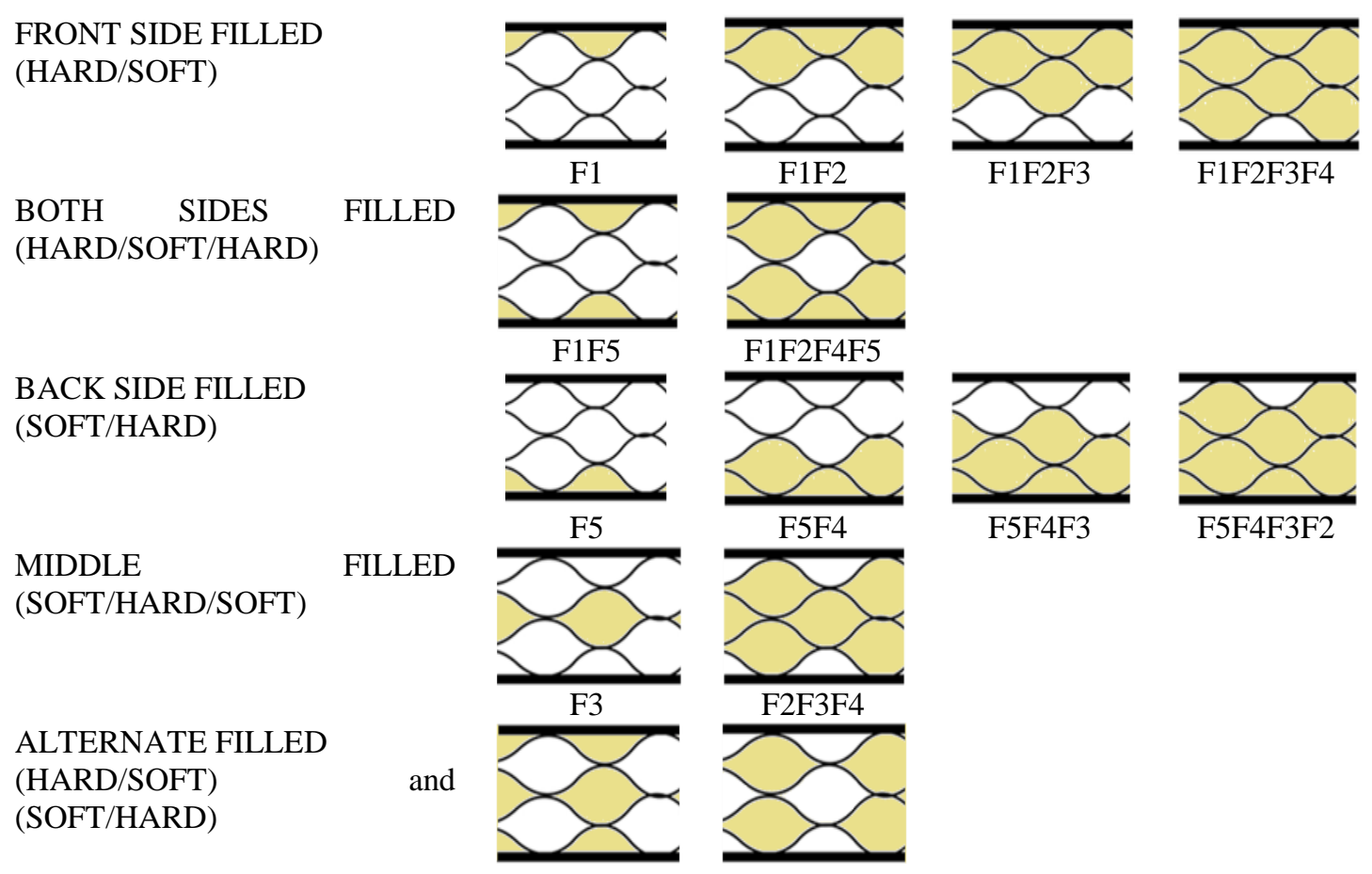

Fig. 11 Categorization of analyzed models by type of configuration 


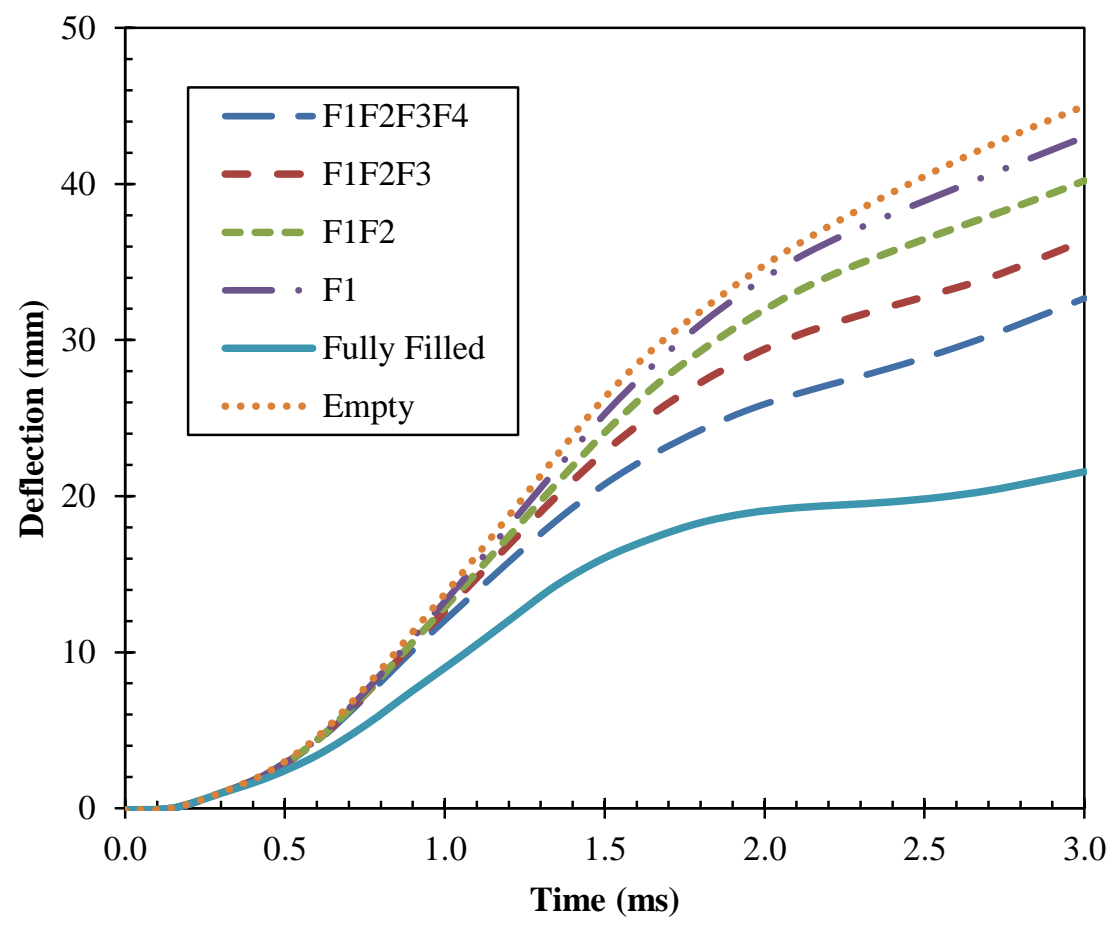

(a)

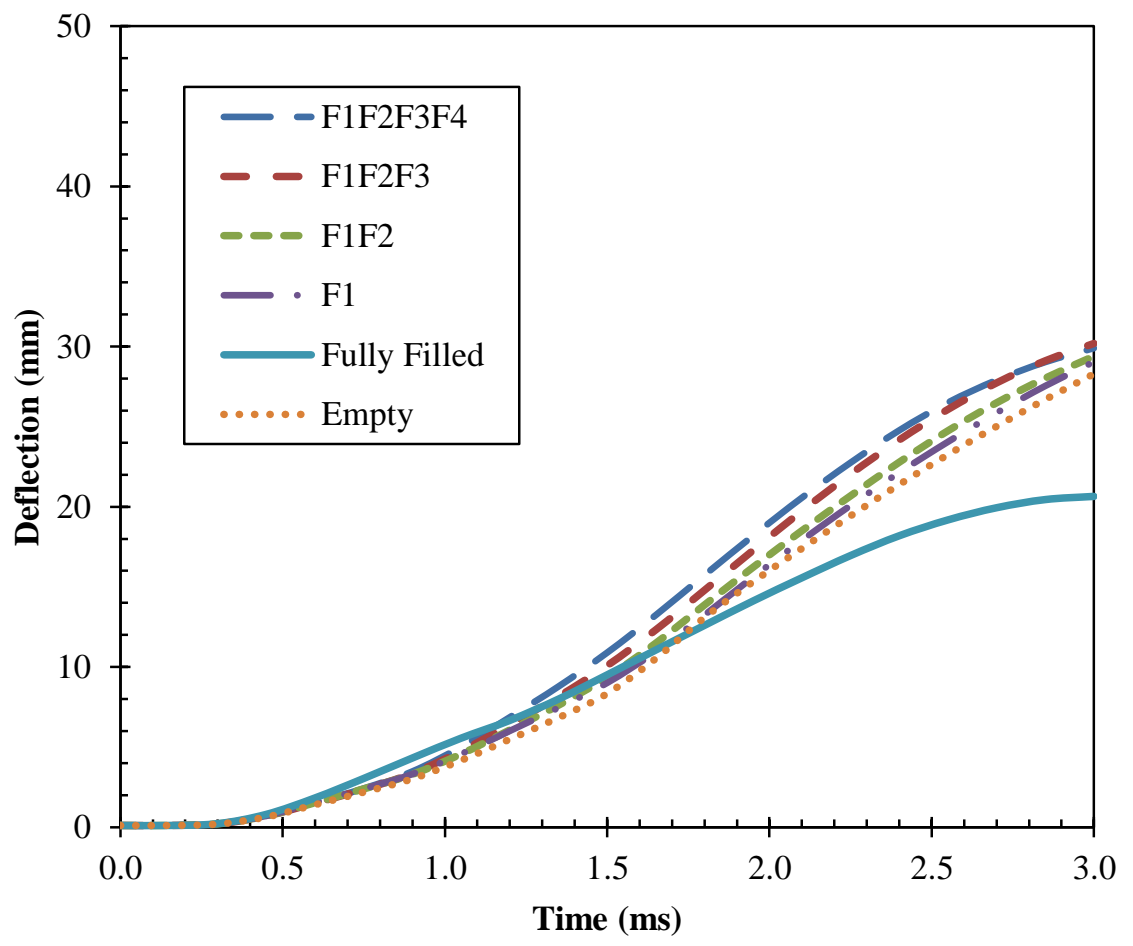

(b)

Fig. 12 Front filled panel configurations' deflection over time: (a) FFD and (b) BFD 


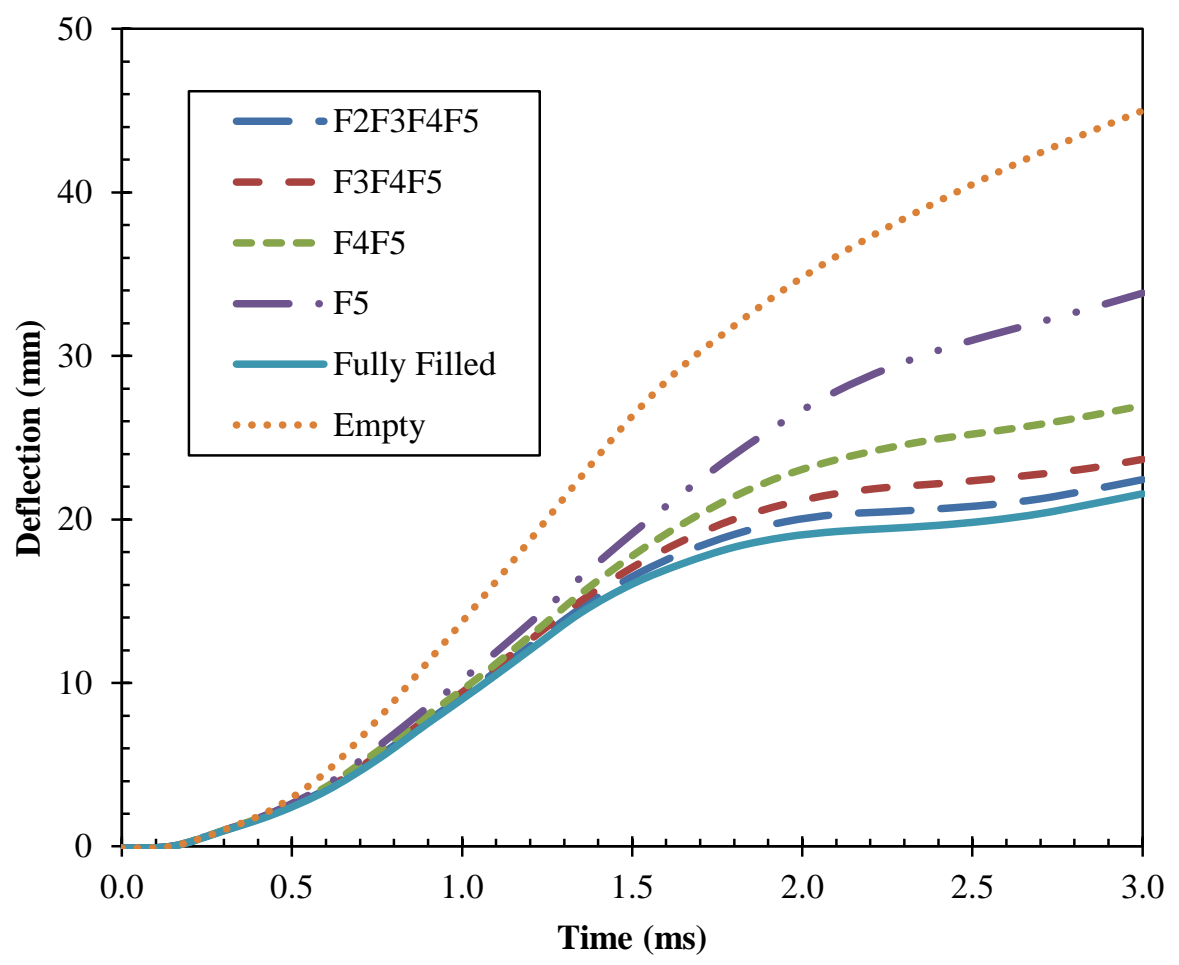

(a)

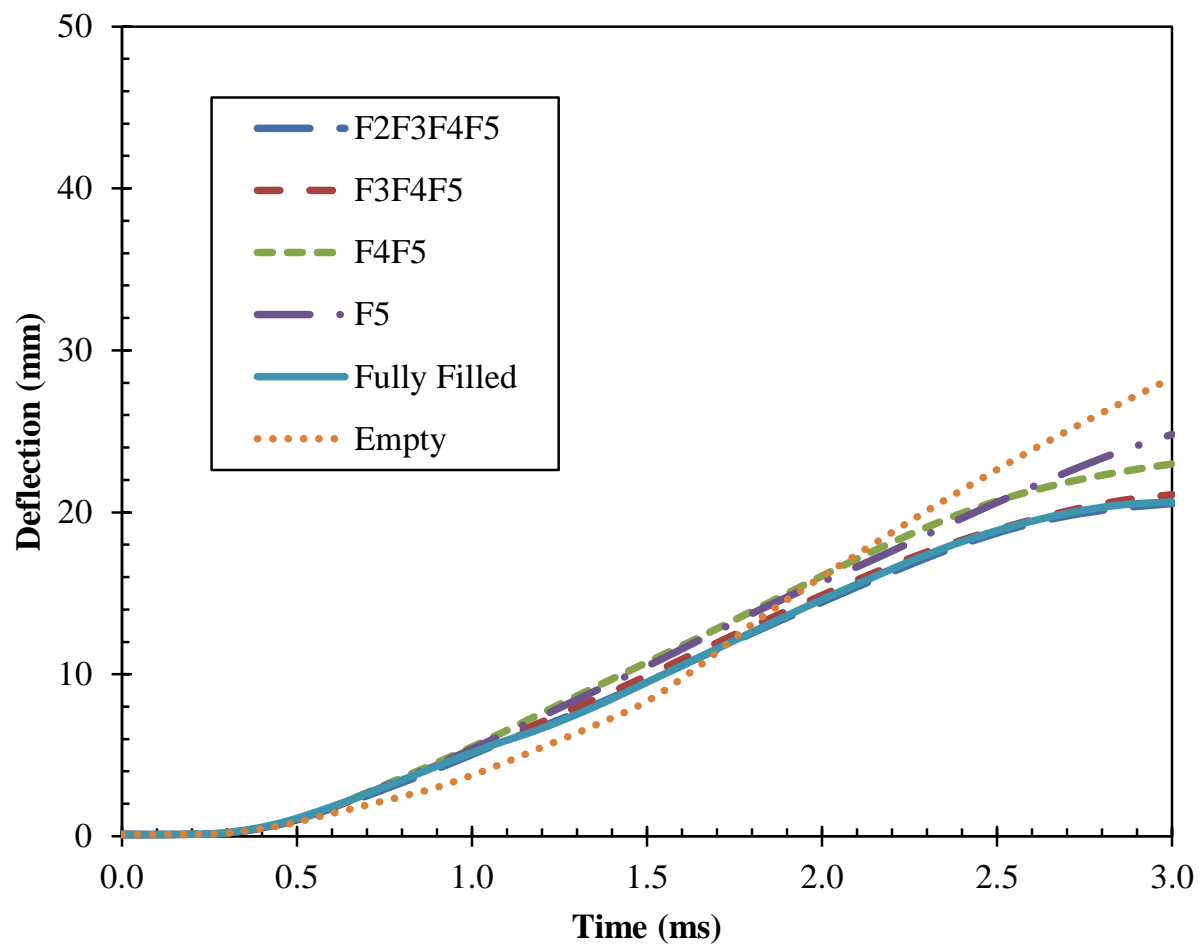

(b)

Fig. 13 Back filled panel configurations' deflection over time: (a) FFD and (b) BFD 


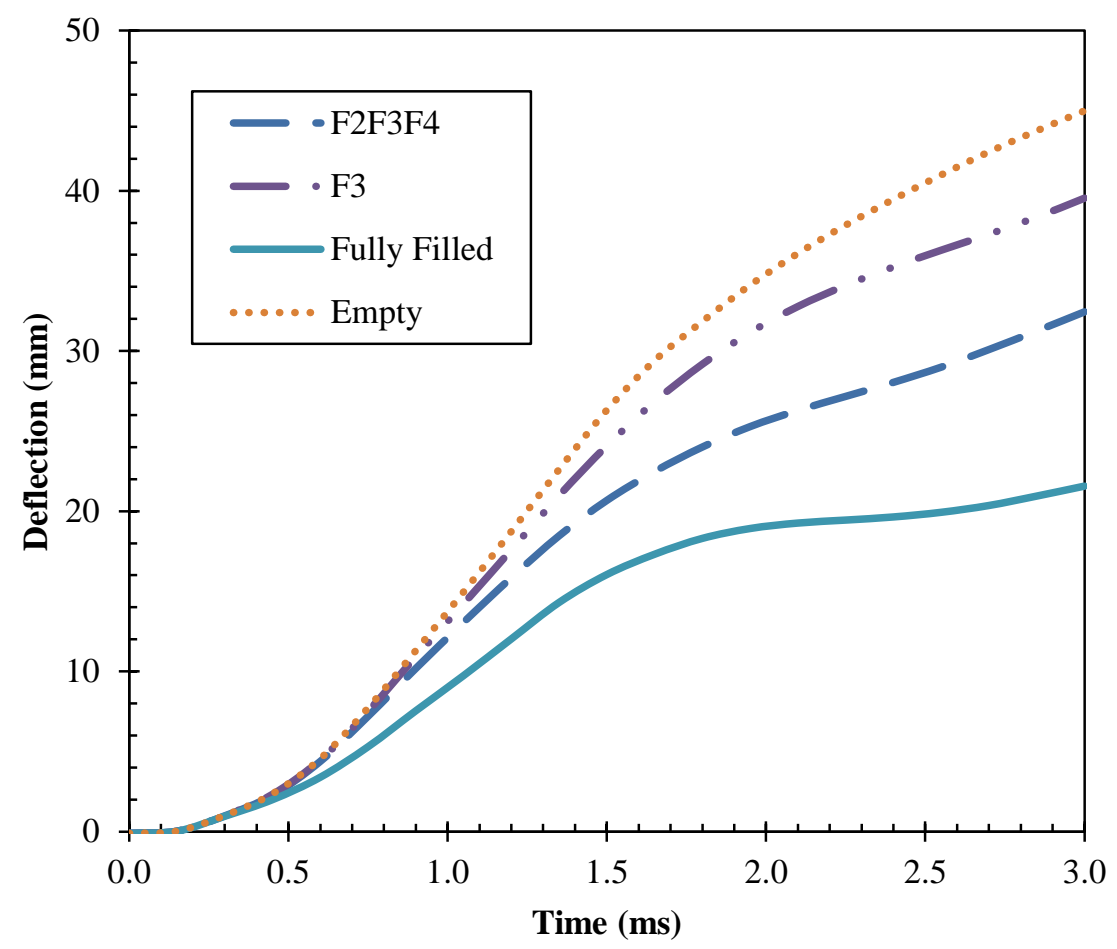

(a)

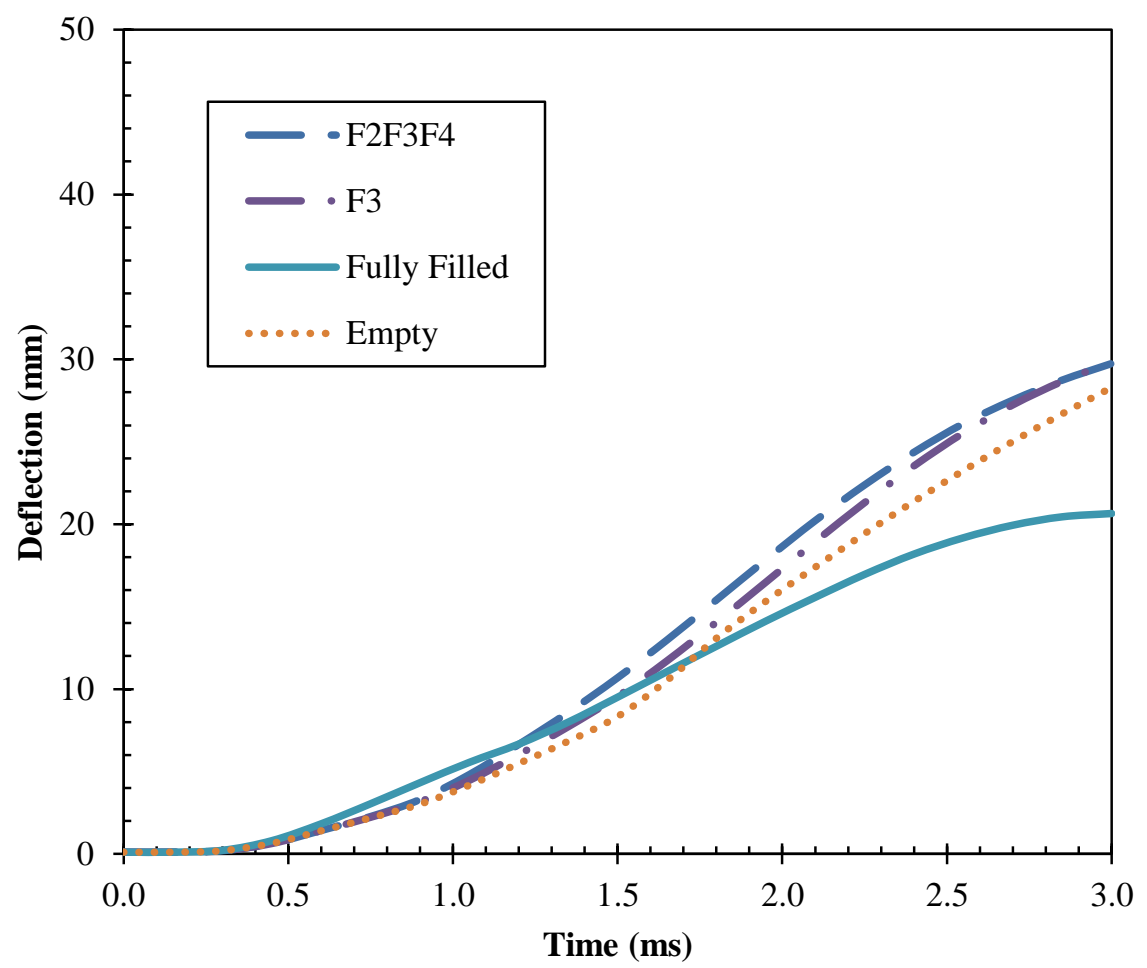

(b)

Fig. 14 Middle filled panel configurations' deflection over time: (a) FFD and (b) BFD 


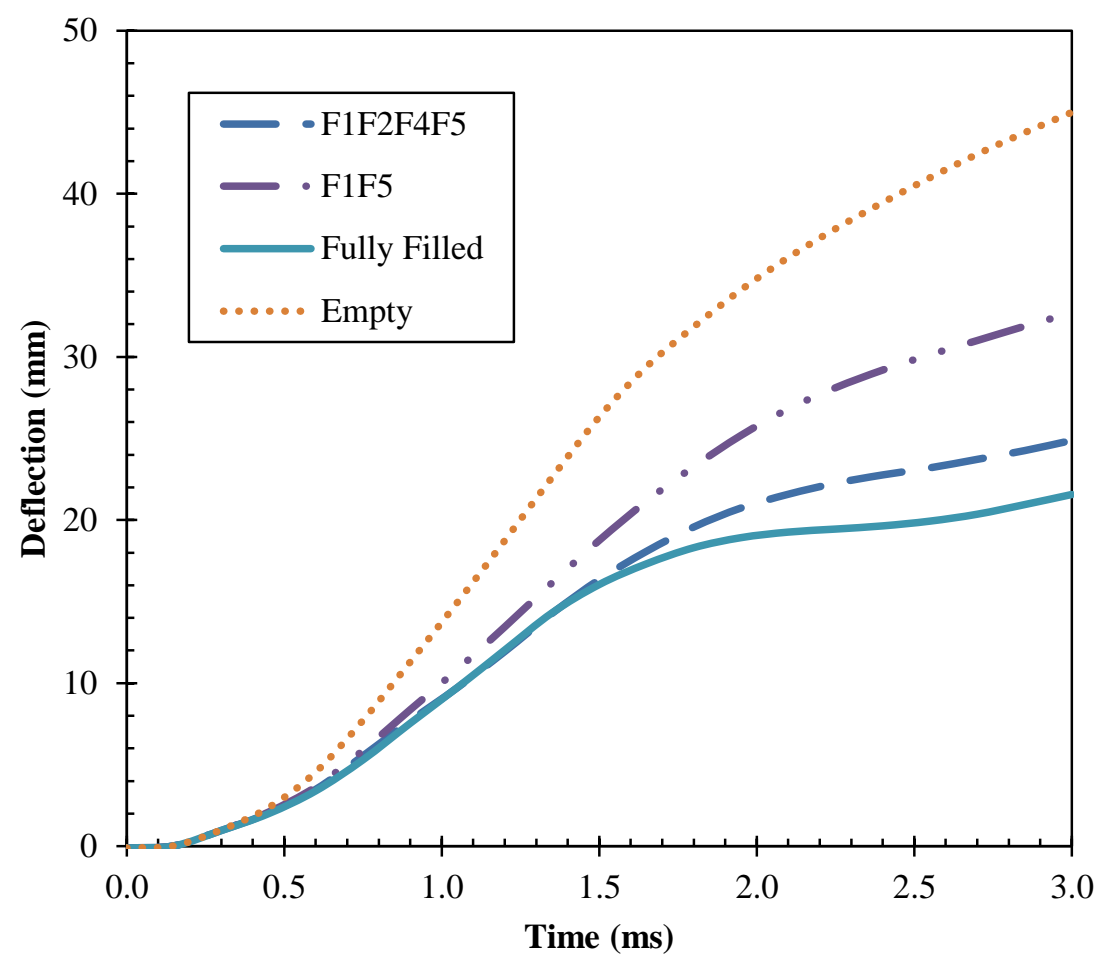

(a)

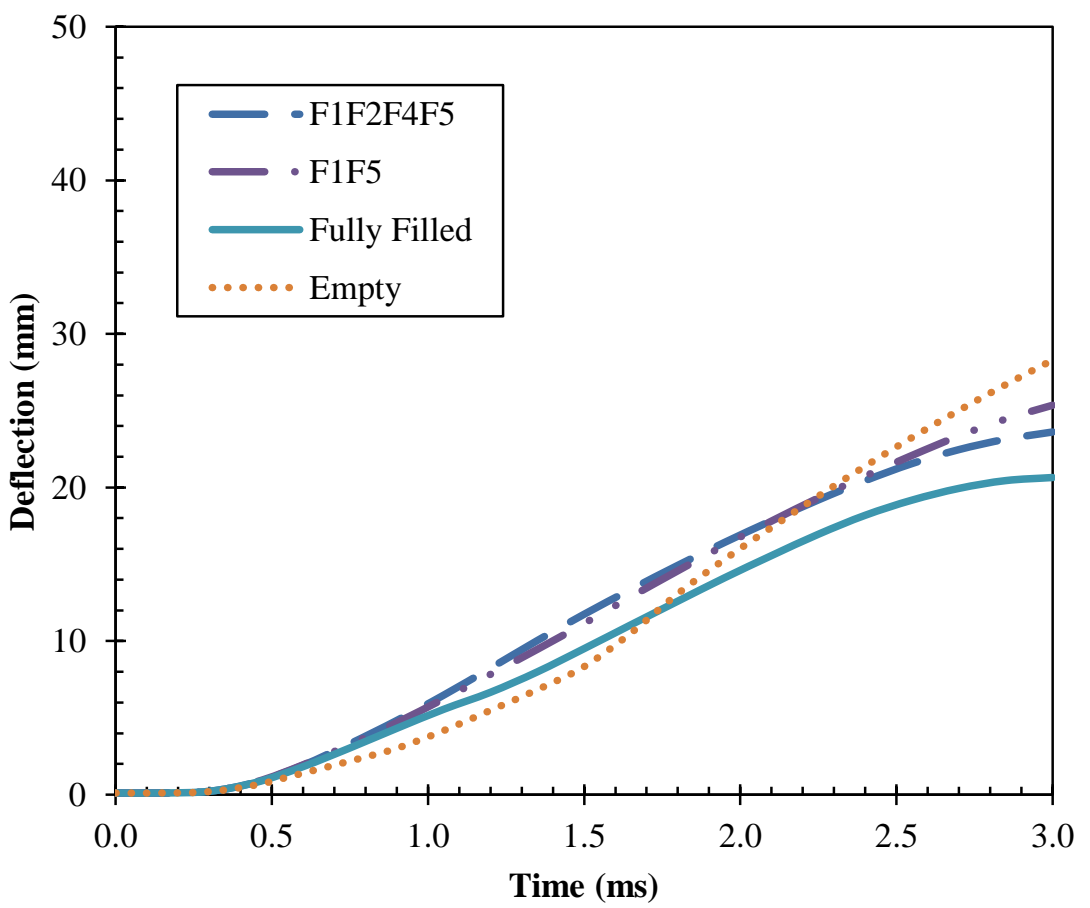

(b)

Fig. 15 Both sides filled panel configurations' deflection over time: (a) FFD and (b) BFD 


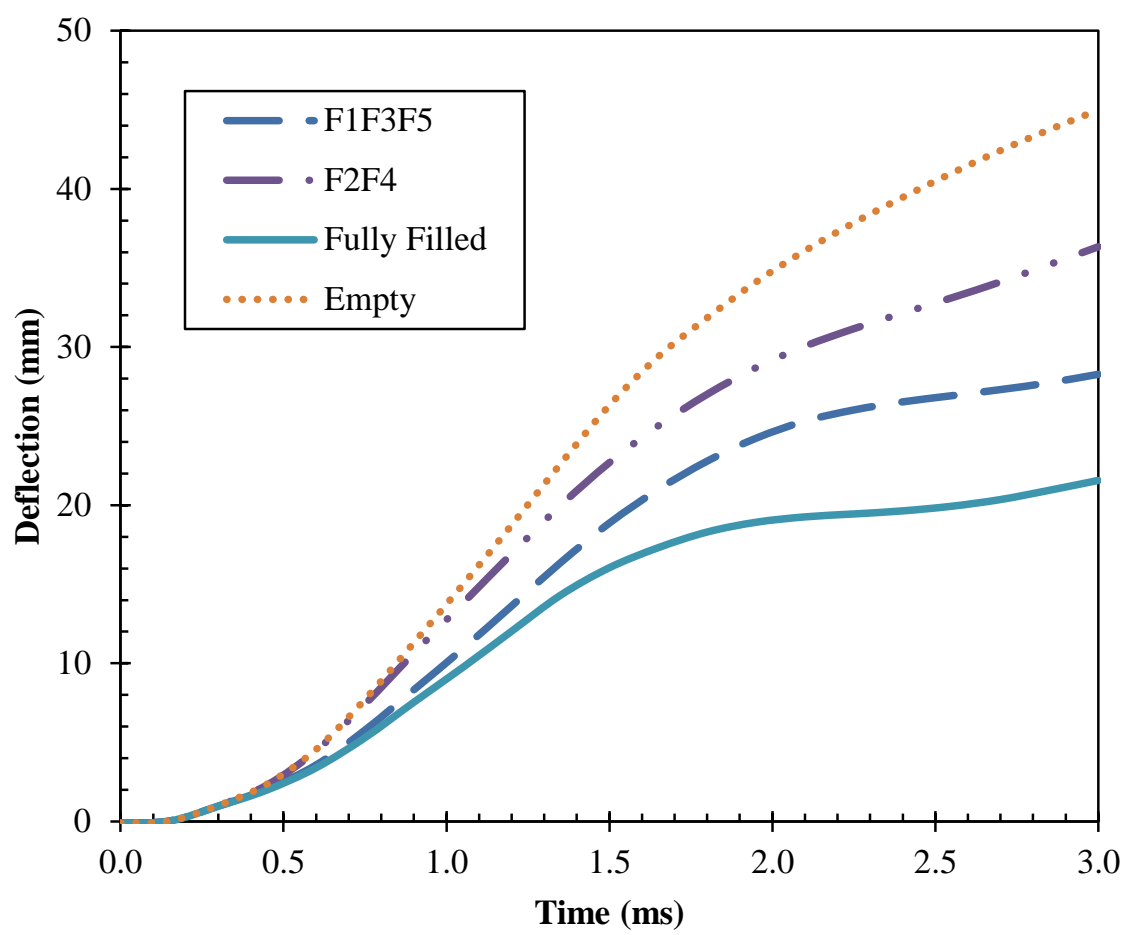

(a)

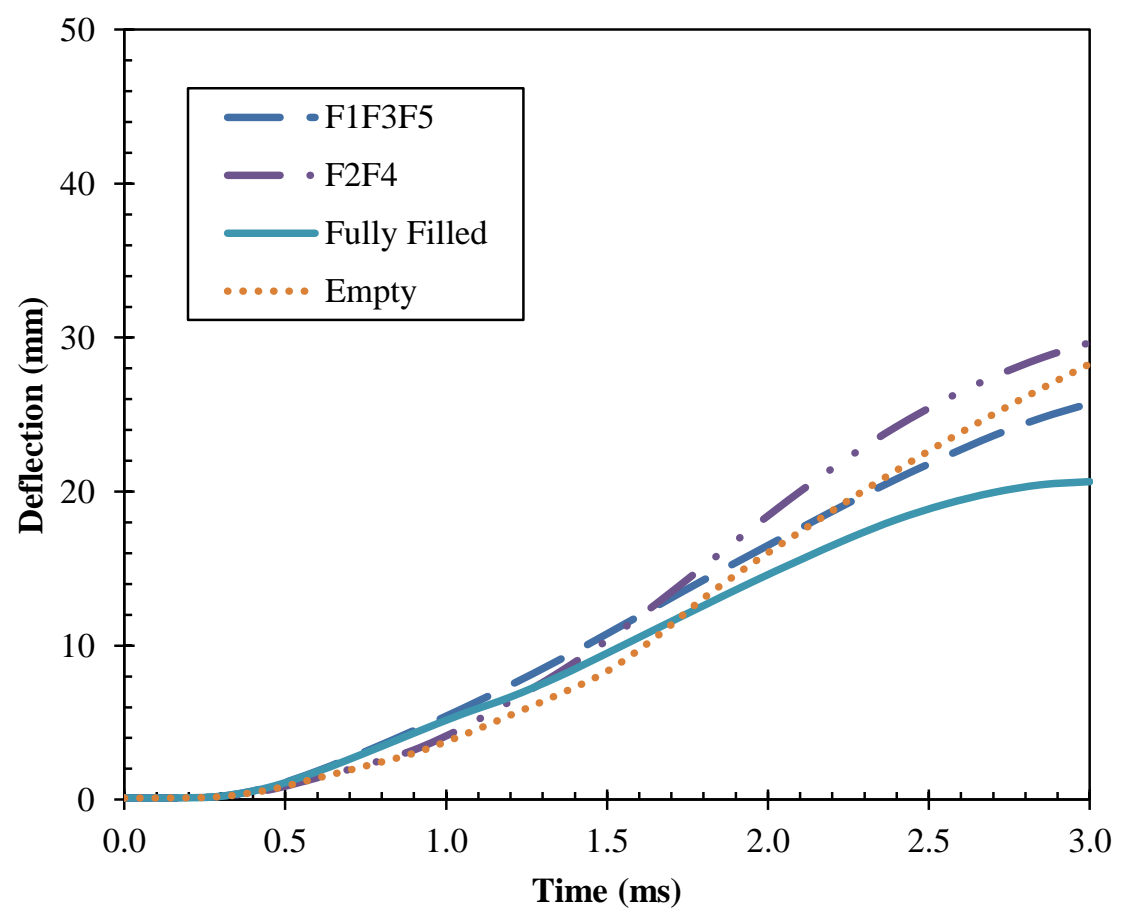

(b)

Fig. 16 Alternately filled panel configurations' deflection over time: (a) FFD and (b) BFD 

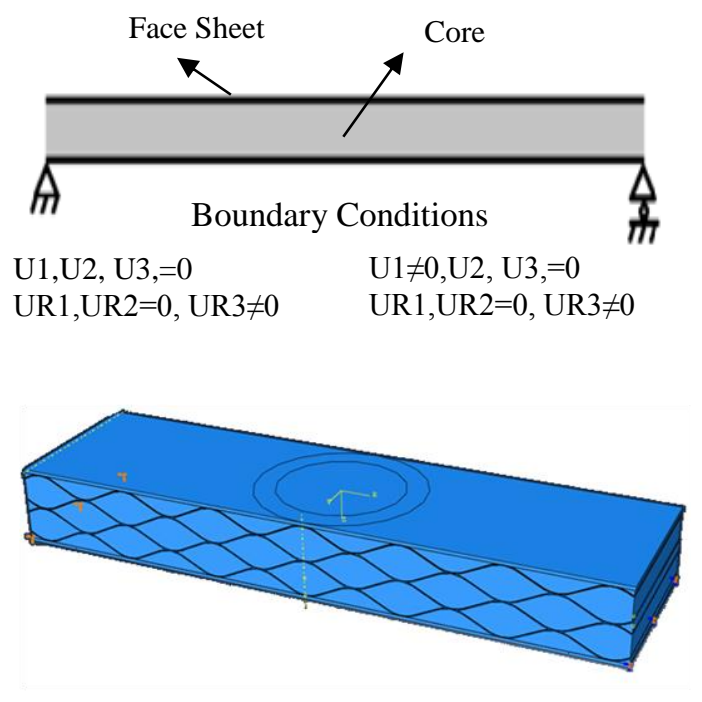

\section{Fig. 17 Boundary conditions used in FEM simulations}

Figure 12 shows the BFD and FFD response of front filled panels by the number of the foam filled layers increasing from front side to back side. By increasing the number of foam filled layers from front to back in the sandwich panels the deflection on the front-face is reduced as the number of layers filled is increased but deflection is increased on the back-face, even more so than the empty case. The increase in BFD is low; the maximum variation in BFD at $3 \mathrm{~ms}$ is $2.95 \%$. However, in FFD, the number of foam filled layers decreased the deflection to a maximum of almost $24 \%$ at $3 \mathrm{~ms}$. The FFD is observed to be more sensitive than BFD to the number of front filled layers.

The back side filling effect on deflections of front and back-face sheets of the sandwich panels is shown in Figure 13. The results show that increasing the number of the foam filled layers from back to front reduced both the FFD and BFD. At $3 \mathrm{~ms}$, this variation was $17.22 \%$ and $33.6 \%$ for FFD and BFD, respectively. Each succesive layer filled decreases deflection on each face by a smaller margine. In addition, the four 
layer filled panel has slightly less BFD than the fully filled panel. Figure 14 shows the deflection history of the center filled panels. Although the number of filled layers increased there is almost no change in BFD (at $3 \mathrm{~ms} 0.31 \%$ ) with respect to one another however, both configurations experienced more BFD than the empty case. A 17.9\% decrease in FFD occurred as the filled middle layers increased from one to three. Figure 15 shows panels filled near both faces. The most interesting result is that there is no difference between the two cases in BFD until $2.4 \mathrm{~ms}$, after which the more filled panel exhibits slightly less deflection. However, in FFD a $23.9 \%$ drop in deflection occurred by the end of $3 \mathrm{~ms}$ as the filling layers increased.

The alternately filled cases were investigated for the effect of Filled (F)/Empty (E) layer alteration. The $\mathrm{F} / \mathrm{E} / \mathrm{F} / \mathrm{E} / \mathrm{F}$ and $\mathrm{E} / \mathrm{F} / \mathrm{E} / \mathrm{F} / \mathrm{E}$ cases were analyzed (Fig. 16) and the results show that beginning and ending with a filled layer is better than the filling scenario where the first and last layer is empty. At $3 \mathrm{~ms}$, BFD deflection of F/E/F/E/F is less than $\mathrm{E} / \mathrm{F} / \mathrm{E} / \mathrm{F} / \mathrm{E}$ by about $13.3 \%$ and FFD deflection is $22.19 \%$ less. With the number of layers studied the influence of filling the layers next to the faces versus the influence of the number of alternate fillings on face deflection cannot be directly separated.

\subsection{Comparisons}

BFD and FFD graphs of the numerical results are rearranged in Fig. 18 based upon the number of foam filled layers rather than their configurations. Three numerical studies of four foam filled layer configurations were performed (front side filled-F1F2F3F4, back side filled-F2F3F4F5, both side filled-F1F2F4F5). All else being equal, this leaves one layer of the five to take the majority of the core collapse. 
The back-face fill experienced the least deformation in both FFD and BFD, both sides filled performed the second best, and front-faced filled had the most deflection. Having the empty layer closest to the shock wave ensures more collapse of that layer, absorbing more energy, and leaving less shock pressure to bend the stiffend back-face causing less plastic strain and collapse overall.

Four three foam filled layer arrangments were investigated: front side filled (F1F2F3), back side filled (F3F4F5), mid filled (F2F3F4), and alternate filled ( F1F3F5). Similarly, the four layer configurations in order of least deflection are back side filled, alternate filled, mid filled, and front-face filled, although for BFD the front and mid filled arrangments are almost identical. In the alternate filling case density change between empty and filling layers $(\mathrm{F} / \mathrm{E} / \mathrm{F} / \mathrm{E} / \mathrm{F})$ was expected to reduce $\mathrm{BFD}$ more than was observed due to impedance mismatch which ablates shock transfer. Its relatively low deflection, however, may be attributed to also having the layers next to both its faces filled, as seen in the four layer arrangments and the poor performance of the two layer alternate filling which does not have filling next to the face plates, instead of impedance mismatch as the foam has a very low density resulting in lower shock dispersion effect (The impedance ratio between foam $\left(3,270\right.$ N.s.m $\left.{ }^{-3}\right)$ and air (413.3 N.s.m $\left.{ }^{-3}\right)$ at room temperature is only 7.91 while steel $\left(3.962 \times 10^{7}\right.$ N.s.m $\left.{ }^{-3}\right)$ to air is 115,093$)$.

In the two layer filling, four-two layer configurations are studied: front side (F1F2) filled, back side filled (F4F5), both sides filled (F1F5), and alternate filled (F2F4). The back side filled case experiences the least deflection again in both faces followed by both sides, alternate fill, and finally front filled for FFD. The same holds 
true for BFD except that the alternate and front filled experience almost the same BFD as in the three layer filled cases. As less filling is applied to the panels it can be noted that the front and alternately filled panels begin their deflection history with less deflection than both the back filled and both face filled cases up to about $1.5 \mathrm{~ms}$.

Three one layer configurations were also investigated: front side filling (F1), mid side filling (F3), and back side filling (F5). The results show that back side filling results in the least deflection for the front face (FF) and back face (BF) under shock loading followed by mid filled and front filled, respectively, for FFD. Interestingly, following the trend seen in more layer filled scenarios these last two perform the best early on and are reversed in BFD performance where the mid layer filled panel now experiences the most deflection. This is due to a more localized collapse seen in the mid filled layer case versus front filled layer case where the core is more evenly compressed over its length incresing the area of deformation while decreasing the maximum deflection. 


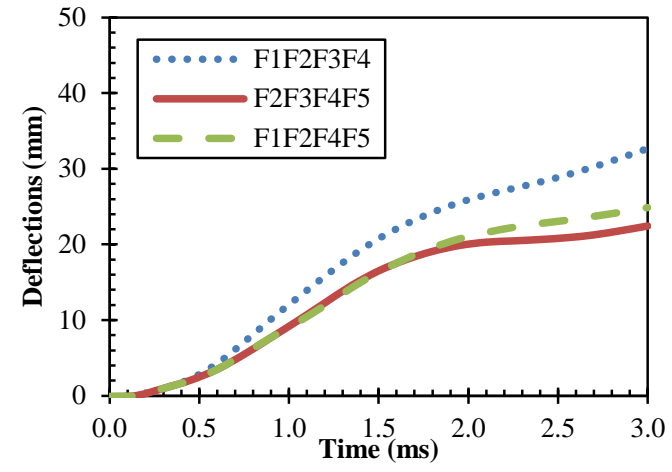

(a)

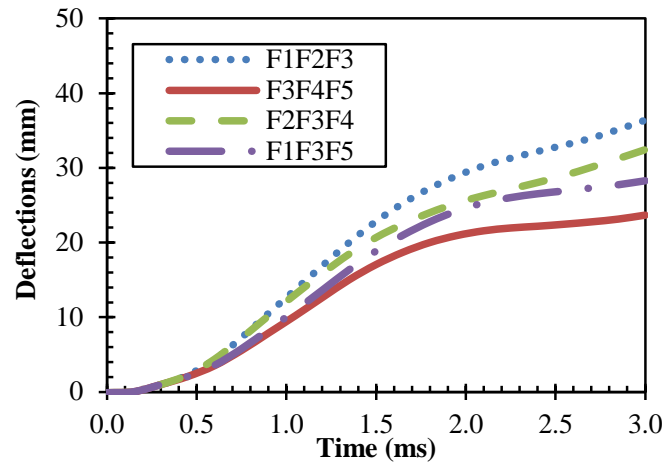

(c)

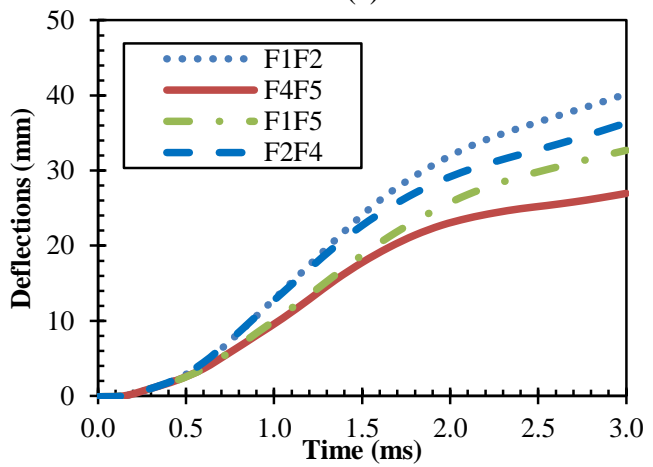

(e)

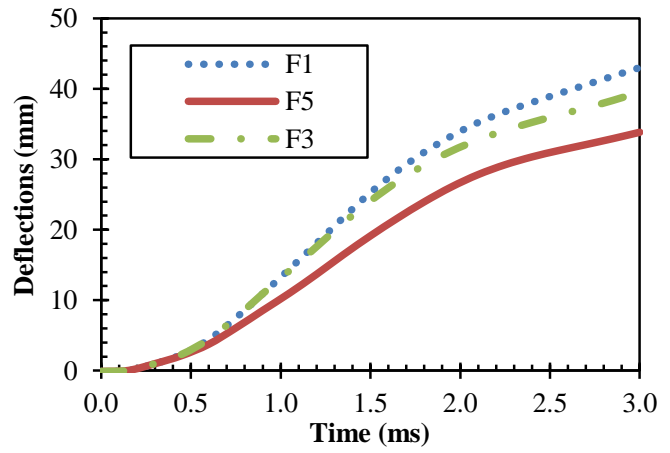

(g)

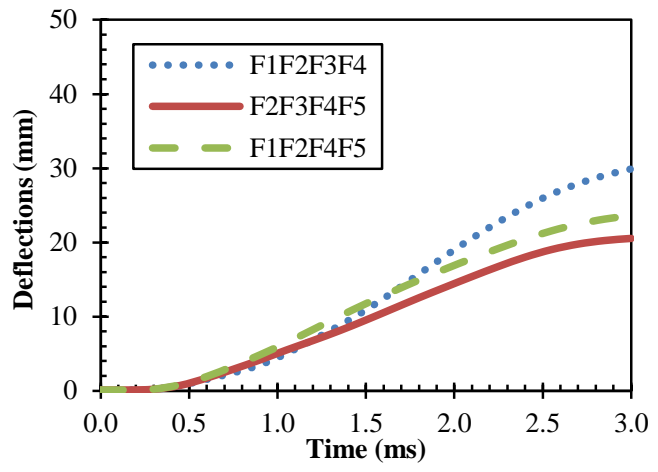

(b)

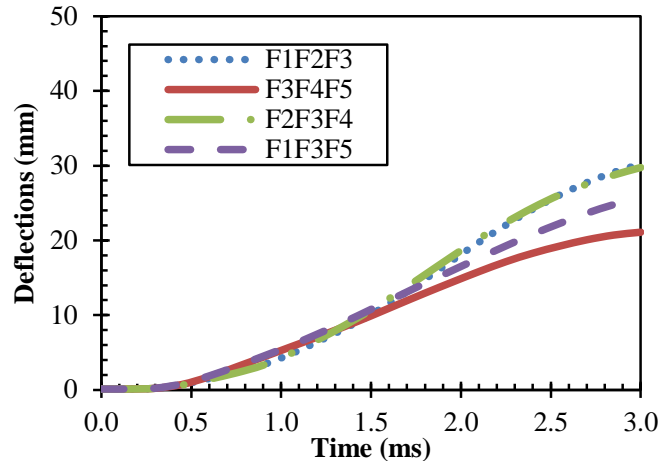

(d)

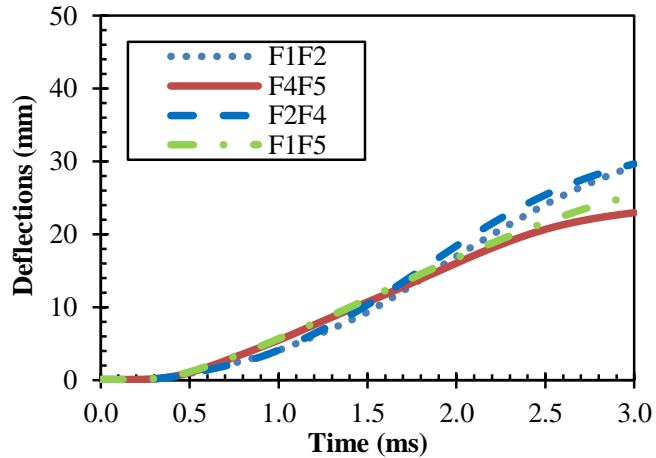

(f)

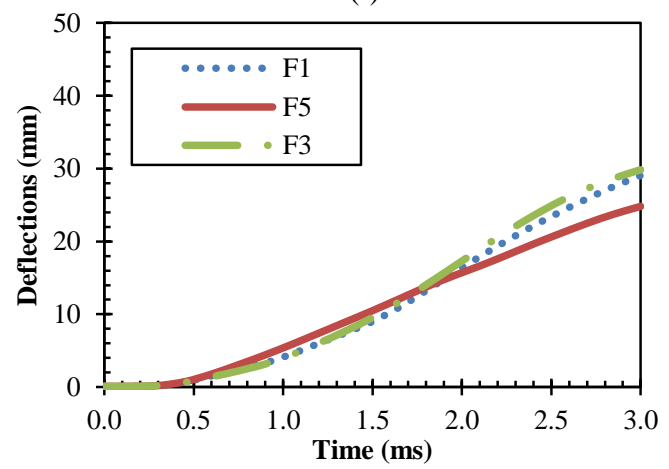

(h)

Fig. 18 Comparison of filling hierarchy with respect equivalent number of filled layers: $(a)$ four filled layers FFD, $(b)$ four filled layers BFD, $(c)$ three filled layers FFD, $(d)$ three filled layers BFD, $(e)$ two filled layers FFD, $(f)$ two filled layers BFD, $(g)$ one filled layer FFD, and $(h)$ one filled layer BFD 


\subsection{Dynamic Collapse Mechanisms}

The core filling hierarchy involves three primary shock wave mitigating mechanisms: (1) The scattering of the stress waves due to different interface impedances, (2) the splitting of stress wave such that it transmits to different parts of the structure at different times due to impedance mismatch (or geometry), and (3) mechanical energy absorptions (i.e., plasticity and hysteresis in the foam). The first two mechanisms are for the most part independent of the filling hierarchy (unless the right delays in the wave front from multiple paths eventually coalesce) instead they are dependant upon the number of filled layers and the impedance mismatch in materials (type of foam and metal). Thus, each hierarchy with the same number of filled layers should experience equal benefits from these two mechanisms so any difference will be due to the third, mechanical energy absorption.

The overall pattern of sandwich panel collapse (mechanical energy absorption) is described by Xue and Hutchinson [36, 37] as comprising of three stages: (1) fluid structure interaction, (2) core compression, and (3) beam bending and stretching.. Here, we see a sepepration of the second stage of compression into two parts: the compression and then buckling of empty cells followed by the compression and then buckling of foam filled cells. Just as stage 2 and 3 (global bending) can often overlap in some cases so can these cell compressions, although the unsupported empty cells always initiate collapse first. The plastic compression of the cells initiated at the nodes of the corrugation where the forces were concentrated caused compression then buckling in the empty cells. The filled cells being reinforced by the foam resisted compression as well as the shear and compressive buckling slowing the deformation 
of the layer that they filled, however, they often exaserbated the deformation of the surrounding empty layers. In the case of the back filled hierarchies this forced compression into the front of the panel which resulted in lower momentum transfer into the back of the reinforced panel. On the other extreme the front filled panels resisted collapse forcing more energy to be transferred to the rear layers and back face panel causing the more undesierable BFD.

\section{Conclusions}

In this study, the effects of preferentially foam filled metallic corrugated core sandwich panels subjected to blast loading were investigated. A series of shock tube experiments and FEM simulations were performed. Front side filling, back side filling, mid filling, alternating filling and both sides filling are compared with one another. Comparing the different filling patterns to the baseline non-filled corrugated panel, the following observations can be made:

1. The both side-filled cases decrease FFD as more layers are filled and also decrease BFD.

2. The front-filled cases decrease FFD as more layers are filled but increase BFD.

3. The back-filled cases decrease FFD as more layers are filled and also decrease BFD.

4. The middle-filled cases decrease FFD as more layers are filled but increase BFD.

5. The alternate-filled cases decrease FFD as more layers are filled but behave differently for BFD. The F2F4 fill behaves like the middle-filled cases and 
increase BFD while the F1F3F5 case behaves like the side-filled cases and decrease BFD.

6. The front-filled, middle-filled, and one alternate-filled (F2F4) cases increases the amount of BFD over the baseline empty case.

7. Comparing the foam cases to one another shows that the back-filled cases are the most effective at decreasing BFD per filled layer.

Additional results obtained in this research can be concluded as follows:

8. Filling hierarchy changes the deformation history and deforming layer sequence. In all cases, empty layers deformed first followed by foam filled layers. Most layer deformation began with bending or buckling of empty layer cell walls followed by plastic deformation of cells and ultimately collapse.

9. Shear force components are more effective in the empty cells.

10. In the foam filled cells, limited compression is observed.

11. The most deformed foam filled cells are observed in the center layers, when both side layers are empty (F3, F2F4, and F1F3F5).

12. Back side filling are universally more effective for reduction of the deformation in the back-face of the panel than the others, even fully filled panels.

13. Both side filled sandwich structures studied behave as thickened face sheeted sandwich panels. So, foam filling can be used as a method to increase face sheet thickness behavior. 
14. Alternate filling did not perform as well as expected showing little dissipation in the transfer of shock pressure. Perhaps due to the low mismatch between air and foam.

15. The number of foam filled layers in all configurations affects the FFD more than the BFD. The number of the foam filled layers and configurations should be optimized according to design requirements such as which side mitigation is important for purposed application. 


\section{ACKNOWLEDGMENT}

This work was supported by the U.S. Department of Homeland Security under Award Number: 2009-ST-061-TS0011. The views and conclusions contained in this document are those of the authors and should not be interpreted as necessarily representing the official policies, either expressed or implied, of the U.S. Department of Homeland Security. Murat YAZICI acknowledges the financial support of The

Scientific and Technological Research Council of Turkey (TUBITAK), 2219 International Post-Doctoral Research Fellowship Programme. 


\section{REFERENCES}

[1] Dharmasena, K. P., Wadley, H.N.G., Williams, K., Xue, Z., and Hutchinson, J. W., 2011, "Response of Metallic Pyramidal Lattice Core Sandwich Panels to High Intensity Impulsive Loading in Air," International Journal of Impact Engineering, 38(5):pp.275-289.

[2] Fleck, N.A., and Deshpande, V.S., 2004, "The Resistance of Clamped Sandwich Beams to Shock Loading," Journal of Applied Mechanics, 71, pp.386-401.

[3] Li, R., Kardomateas, G. A., and Simitses, G. J., 2008, "Nonlinear Response of a Shallow Sandwich Shell With Compressible Core to Blast Loading," Journal of Applied Mechanics, 75, Article Number:061023, pp.1-10. DOI: 10.1115/1.2937154.

[4] Theobald, M.D., Langdon, G.S.; Nurick, G.N., Pillay S., Heyns, A., and Merrett, R.P., 2010, "Large Inelastic Response of Unbonded Metallic Foam and Honeycomb Core Sandwich Panels to Blast Loading," Composite Structures, 92 (10), pp.24652475 .

[5] Langdon, G.S., von Klemperer, C.J., Rowland, B.K., and Nurick G.N., 2012 " The Response of Sandwich Structures with Composite Face Sheets and Polymer Foam Cores to Air-Blast Loading: Preliminary Experiments," Engineering Structures, 36:pp.104-112.

[6] Ferri, E., Deshpande, V.S., and Evans, A.G. , 2010, "The Dynamic Strength of a Representative Double Layer Prismatic Core: A Combined Experimental, Numerical, and Analytical Assessment," Journal of Applied Mechanics, 77(6), Article Number: 061011, pp.1-7

[7] Qiu, X., Deshpande, V.S., and Fleck, N.A., 2004, "Dynamic Response of a Clamped Circular Sandwich Plate Subject to Shock Loading," Journal of Applied Mechanics, 71, pp. 637-645, DOI: 10.1115/1.1778416

[8] Cui, X., Zhao, L., Wang, Z., Zhao, H., and Fang, D., 2012, "Dynamic Response of Metallic Lattice Sandwich Structures to Impulsive Loading," International Journal of Impact Engineering, 43:1-5.

[9] Liang, Y., Spuskanyuk, A. V., Flores, S. E., Hayhurst, D.R., Hutchinson, J. W., McMeeking, R. M. and Evans A. G., 2007, "The Response of Metallic Sandwich Panels to Water Blast," Journal of Applied Mechanics, 74, pp 81-99. DOI: 10.1115/1.2178837.

[10] Wei, Z., Deshpande, V. S., Evans, A. G., Dharmasena, K.P. , Queheillaltc, D.T., Wadleyc, H.N.G., Murtyd, Y.V., Elzeyd, R.K., Dudte, P., Chene, Y., Knighte, D. 
and Kiddyf, K., 2008, "The Resistance of Metallic Plates to Localized Impulse," Journal of Mechanics and Physics of Solid, 56(5), pp. 2074-2091.

[11] Avachat, S. and Zhou, M., 2012, "Effect of Facesheet Thickness on Dynamic Response of Composite Sandwich Plates to Underwater Impulsive Loading," Experimental Mechanics, 52(1), pp. 83-93.

[12] Schimizze, B., Son, S. F., Goel, R., Vechart, A.P., and Young, L., 2013, "An Experimental and Numerical Study of Blast Induced Shock Wave Mitigation in Sandwich Structures," Applied Acoustics, 74(1), pp.741-1749

[13] Zhuang, S., Ravichandran, G., and Grady, D.E., 2003, "An Experimental Investigation of Shock Wave Propagation in Periodically Layered Composites," Journal of the Mechanics and Physics of Solids, 51, pp. 245 - 265.

[14] Wakabayashi, T. H., Matsumura, T., and Nakayama, Y., 2007, "Reduction of Explosion Damage Using Sand or Water Layer," Shock Compression Of Condensed Matter, Proceedings of the Conference of the American Physical Society Topical Group on Shock Compression of Condensed Matter. Location: Waikoloa (Hawaii) AIP Conf. Proc. 955, pp. 1289-1292; DOI: http://dx.doi.org/10.1063/1.2832958

[15] Gibson, L.J., and Ashby, M.F., 1997, "Cellular Solids: Structure and Properties (2’nd edition), " Cambridge University Press, Cambridge.

[16] Wu, C.L., Weeks, C.A. and Sun, C.T., 1995, "Improving Honeycomb-Core Sandwich Structures for Impact Resistance," Journal of Advanced Materials, 26(4), pp. 41-47.

[17] Resewski, C. and Buchgraber, W., 2003, "Properties of New Polyimide Foams and Polyimide Foam Filled Honeycomb Composites," Material Wissenschaft und Werkstofftechnik, 34(4): 365-369.

[18] Vaidya, U.K., Ulven, C., Pillay, S. and Ricks, H., 2003, "Impact Damage of Partially Foam-filled Co-injected Honeycomb Core Sandwich Composites," Journal of Composite Materials, 37(7), pp. 611-626.

[19] Vaidya, U.K., Kamath, M.V., Mahfuz, H. and Jeelani, S., 1998, "Low Velocity Impact Response of Resin Infusion Molded Foam filled Honeycomb Sandwich Composites," Journal of Reinforced Plastics and Composites, 17(9), pp.819-849.

[20] Yazici, M., Wright, J., Bertin, D., Shukla, A., 2013 "Experimental and Numerical Study of Foam filled Corrugated Core Steel Sandwich Structures Subjected to Blast Loading," Composite Structures, 110, pp. 98-109.

[21] Vaziri A. and Xue Z., 2007, "Mechanical Behavior and Constitutive Modeling of Metal Cores" Journal of Mechanics of Materials and Structures. 2(9), pp. 1743-1760. 
[22] Gardner, N., Wang, E. and Shukla, A., 2012, "Performance of Functionally Graded Sandwich Composite Beams under Shock Wave Loading," Composite Structures, 94, pp.1755-1770.

[23] Wang, E., Gardner, N., and Shukla, A., 2009, "Blast Resistance of Sandwich Composites with Stepwise Graded Cores," International Journal of Solids and Structures, 46, pp.3492-502.

[24] Zhang et al., "Dynamic Response of Corrugated Steel Plates with Graded Cores," International Journal of Impact Engineering, 65:185-194, 2014

[25] Wright, J., Hebert, R., Maddala, D., and Shukla, A., 2014 "Experimental study on the loading of graded corrugated steel armor to shock loading," Experimental Solid Mechanics, 50:479-492

[26] Abotula, S., Heeder, N., Chona, R., and Shukla, A., 2013, "Dynamic Thermomechanical Response of Hastelloy $\mathrm{X}$ to Shock Wave Loading," Experimental Mechanics, 54(2), pp. 279-291. (DOI) 10.1007/s11340-013-9796-4.

[27] Karagiozova, D., Nurick, G.N., and Langdon, G.S., 2009, "Behaviour of Sandwich Panels Subject to Intense Air Blasts - Part 2: Numerical Simulation," Composite Structures, 91, pp. 442-450.

[28] Kumar, P., LeBlanc, J., Stargel, D., and Shukla A., 2012, "Effect of Plate Curvature on Blast response of Aluminum Panels," International Journal of Impact Engineering, 46, pp.74-85.

[29] Johnson, G.R.; Cook, W.H., 1983, "A Constitutive Model and Data for Metals Subjected to Large Strains, High Strain Rates and High Temperatures," Proceedings of the $7^{\text {th }}$ International Symposium on Ballistics: 541-547

[30] Schever, L., 2007, "Optional Strain-Rate Forms for the Johnson Cook Constitutive Model and the Role of the Parameter Epsilon 0," 6th European LsDyna User' Conference, Frankenthal, Session Impact, pp. 1-14.

[31] Gardner, N., Wang, E., Kumar, P. and Shukla A., 2012, "Blast Mitigation in a Sandwich Composite Using Graded Core and Polyurea Interlayer," Experimental Mechanics, 52, pp.119-133.

[32] Subramaniam, K.V., Nian, W. and Andreopoulos, Y., 2009, " Blast Response Simulation of an Elastic Structure: Evaluation of the Fluid-structure Interaction Effect," International Journal of Impact Engineering 36, pp.965-974.

[33] Pearson, K., 1895, " Notes on Regression and Inheritance in the Case of Two Parents," Proceedings of the Royal Society of London, 58, pp. 240-242. 
[34] Russell, D.M., 1997, "Error Measure for Comparing Transient Data, Part I: Development of a Comprehensive Error Measure, Part II: Error Measure Case Study," In: Proceedings of the 68th shock \& Vibration symposium, 3-6th November.

[35] Russell, D.M., 1998, "DDG53 Shock Trial Simulation Acceptance Criteria," In 69th Shock and Vibration Symposium, 12-19th October.

[36] Xue ZY, Hutchinson JW., 2004, “A comparative study of impulse-resistant metal sandwich plates," International Journal of Impact Engineering, 30(10):1283-1305

[37] Xue Z, Hutchinson JW., 2003, "Preliminary assessment of sandwich plates subject to blast loads," International Journal of Mechanical Sciences, 45:687-705 


\section{Chapter 4: Manuscript 3}

Prepared for submission to the journal of Composites Science and Technology

Experimental Investigation of Sandwich Panels with non-Newtonian Fluid Cores to Shock

JEFFERSON WRIGHT ${ }^{\text {a }}$, JOSEPH SULLIVAN ${ }^{\mathrm{b}}$, ARIJIT BOSE ${ }^{\mathrm{b}}$, ARUN SHUKLA $\mathrm{a}^{*}$

${ }^{a}$ University of Rhode Island, Dynamic Photomechanics Laboratory, Department of Mechanical Industrial and System Engineering,92 Upper College Road; Kingston, 02881, RI, USA

${ }^{\mathrm{b}}$ University of Rhode Island, Department of Chemical Engineering, 51 Lower College Road; Kingston, 02881, RI, USA 


\begin{abstract}
The influence of Newtonian and non-Newtonian fluid infills of sandwich composite panels is investigated experimentally for the purpose of mitigating back face deflection (BFD). Sandwich panels with five different types of fluids were subjected to shock wave loading generated by a shock tube. The experimental results show that, shear thickening fluids increase the BFD of sandwich panels. Viscoelasticity has minimal impact on shock mitigation and small changes in viscosity of the fluid do not alter the panels' response to shock.
\end{abstract}

\title{
Keywords:
}

non-Newtonian Fluid, Shock, Sandwich Panel, STF, blast, explosive, fluidfilled 


\section{Introduction}

The proliferation of terrorist attacks in the past two decades has caused considerable damage to infrastructure, injuries, and loss of life $[1,2]$. The majority of these attacks is explosive in nature, according to the U.S. Department of State, and demonstrates a need for effective blast mitigation to protect structures that are known to be in harm's way. This need has renewed interest in a type of composite plate: sandwich panels, as a means of protection. Sandwich structures have low areal density and show improved performance against shock over more traditional monolithic plates. This improved protection comes primarily from the behavior of the core as they are optimized to absorb energy and mitigate the transmitted impulse into the infrastructure of concern [3-5]. A great deal of work both experimental and numerical has been conducted into characterizing sandwich panels under shock. As well as further refining their efficacy in mitigating blast using a variety of concepts such as cellular solids (metallic foam or polymeric foams are common) [6-8], impedance mismatching [9-13], architectured structures [14-17], and increasing stiffness designs [18].

In addition, the incorporation of non-Newtonian fluids, specifically shear thickening fluids (STFs), also known as dilatants, into body armor has been an area of increasing research. STFs are characterized by a nonlinear increase in viscosity with at a critical shear rate [19-22]. STF are composed of nano-particles dispersed within a fluid. The behavior of the STF arises from the behavior of the particles in suspension which as shear rate increases often initially causes the fluid to undergo shear thinning as the particles form layers which slip over one another until a critical shear rate value 
at which point the particles will cluster together, inhibiting flow and increasing viscosity. Two theories have been proposed to explain this phenomenon: orderdisorder theory and hydrodynamic clustering theory which are discussed at length in [23-31]. The magnitude of increases in viscosity and critical shear rate when this viscosity jump occurs is determined by a number of factors, primarily by the concentration of the nano-particles within the fluid. Other contributing factors include particle length (anisotropy), particle size, particles stiffness, particle surface energy, and temperature. [32-34]

These fluids have a number of applications but when used as additives to body armor (typically fibrous body armor) they allow for thinner more flexible armor (as the relatively slow shear rate from human activity results in low viscosity) with greater ballistic protection (when the high shear rate ballistic impact results in high viscosity which dissipates the impact). It has been found that incorporating STFs into ballistic fiber armor increases both the ballistic and stab protection offered by the armor; work pioneered by Norman Wagner. Although significant research has been conducted on both STFs and its use in armor [35-41] relatively little research is available on its effect on explosive induced air-blast loading referred to in the rest of this article as shock loading. Tan et al [42] found that STF impregnated fibers reduced peak pressure and rate of pressure rise relative to unimpregnated fibers. M.A. Dawson [43] numerical analyzed fluid filled armor for both Newtonian fluids (with high and low viscosity) and STFs for sandwich panel-like constructs concluding that STFs do not improve shock resistance but highly viscous fluids do. 
In this study, shock tube experiments and rheological tests were used to investigate the influence of Newtonian and non-Newtonian fluids infused in foam sandwich panels loaded via dynamic air pressure shock.

\section{Experimental procedures}

\subsection{STF Synthesis}

Three STFs reported in literature where created for their potential use in a fluid infused sandwich panel: silica with polyethylene glycol (PEG), calcium carbide with PEG, and corn starch with water.

\subsubsection{Silicon and PEG 200}

Fumed silica (12 nm diameter Aerosil RD) was mixed with PEG 200 (200 molecular weight) and ethanol in a mixture ratio of 13:18:193 respectively. The mixture was hand stirred to an even consistency then sonicated using a QSonica sonication machine at $20 \mathrm{KHz}, 125 \mathrm{~W} / \mathrm{cm} 2$ at $50 \%$ amplitude, $30 \mathrm{~s}$ on $10 \mathrm{~s}$ off for 5 hrs. The excess ethanol was then removed by heating the solution to $100 \mathrm{C}$ until the ethanol was completely removed resulting in a $58 \% \mathrm{w} / \mathrm{w}$ mixture.

\subsubsection{Calcium Carbide and PEG 200}

Calcium Carbide was mixed with PEG 200 at a 50\% Volume fraction. The mixture was hand stirred to an even consistency then sonicated using a QSonica sonication machine at $20 \mathrm{KHz}, 125 \mathrm{~W} / \mathrm{cm} 2$ at $50 \%$ amplitude, $30 \mathrm{~s}$ on $10 \mathrm{~s}$ off for 5 hrs.

\subsubsection{Corn Starch and Water}

Corn starch (Argo) and water where hand mixed at a ratio of roughly $53 \% \mathrm{w} / \mathrm{w}$ until even in consistency. 


\subsection{Specimen Preparation}

Fluid filled sandwich panels were produced with different fluid infills. Low carbon steel face sheets were used with open cell low density polyurethane (PU) foam (Aquazone, McMaster Carr) which has approximately $72 \%$ unoccupied volume. A picture of the sandwich panel can be seen in Fig. 1. The face and foam's dimensions are $50.8 \times 203.2 \mathrm{~mm}$ with the face sheet being $3.2 \mathrm{~mm}$ thick and the foam being 25.4 mm thick.

The face sheets are bonded to the foam by an epoxy adhesive, G/Flex (West System Inc., Bristol, RI), which has a tensile adhesion strength of $20 \mathrm{MPa}$. The fluids are then entrained within the sandwich panel foam by submergence within the fluid via vacuum action drawing in the fluid after compression. The fluid is the sealed within the panel and foam using silicon (silicon caulk, Ace brand architectural grade clear silicon). Test pieces of foam were cut open after the infusion process to ensure the methodology allows for the foam to be nearly fully filled without filtering particles. A high contrast speckle is painted on the back face, see Fig. 1, to facilitate measurement via DIC. 

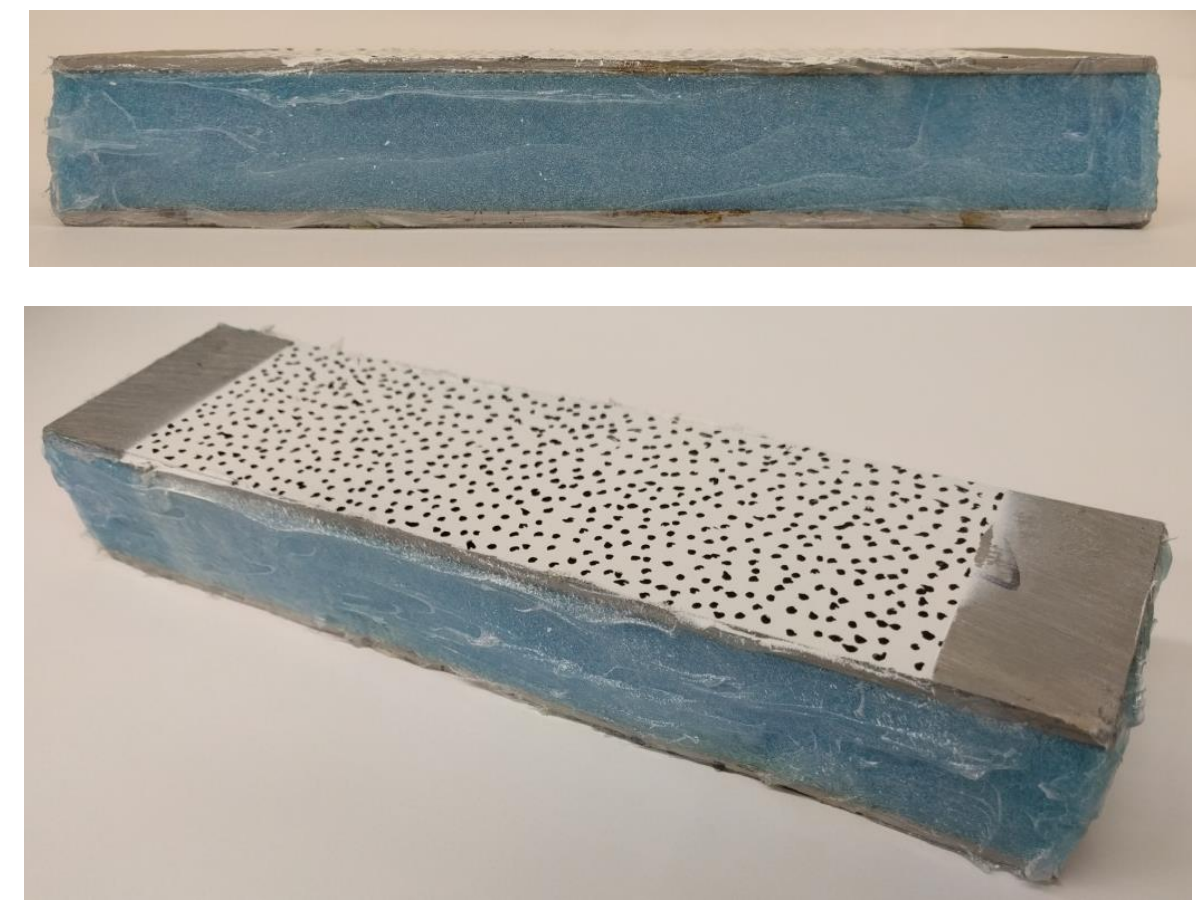

Fig. 1 Sandwich panel with silicone sealing

\subsection{Shock Load Procedure}

A shock tube apparatus was used to load specimens with a planar shock wave. A typical pressure profile generated by the shock tube is shown in Fig. 2. The muzzle inner diameter of the shock tube used was $38.1 \mathrm{~mm}$ (see Fig. 3) [26]. Two pressure transducers (PCB102A) were mounted at the end of the muzzle section to record the incident and reflected pressure profiles. The first pressure sensor was mounted $20 \mathrm{~mm}$ away from the muzzle, and the second was mounted $180 \mathrm{~mm}$ away $(160 \mathrm{~mm}$ separation from the first pressure sensor). The incident peak pressure of the shock wave was chosen to be $1.0 \mathrm{MPa}$ and a reflected peak pressure of approximately 4.4 MPa was obtained for the panels. 


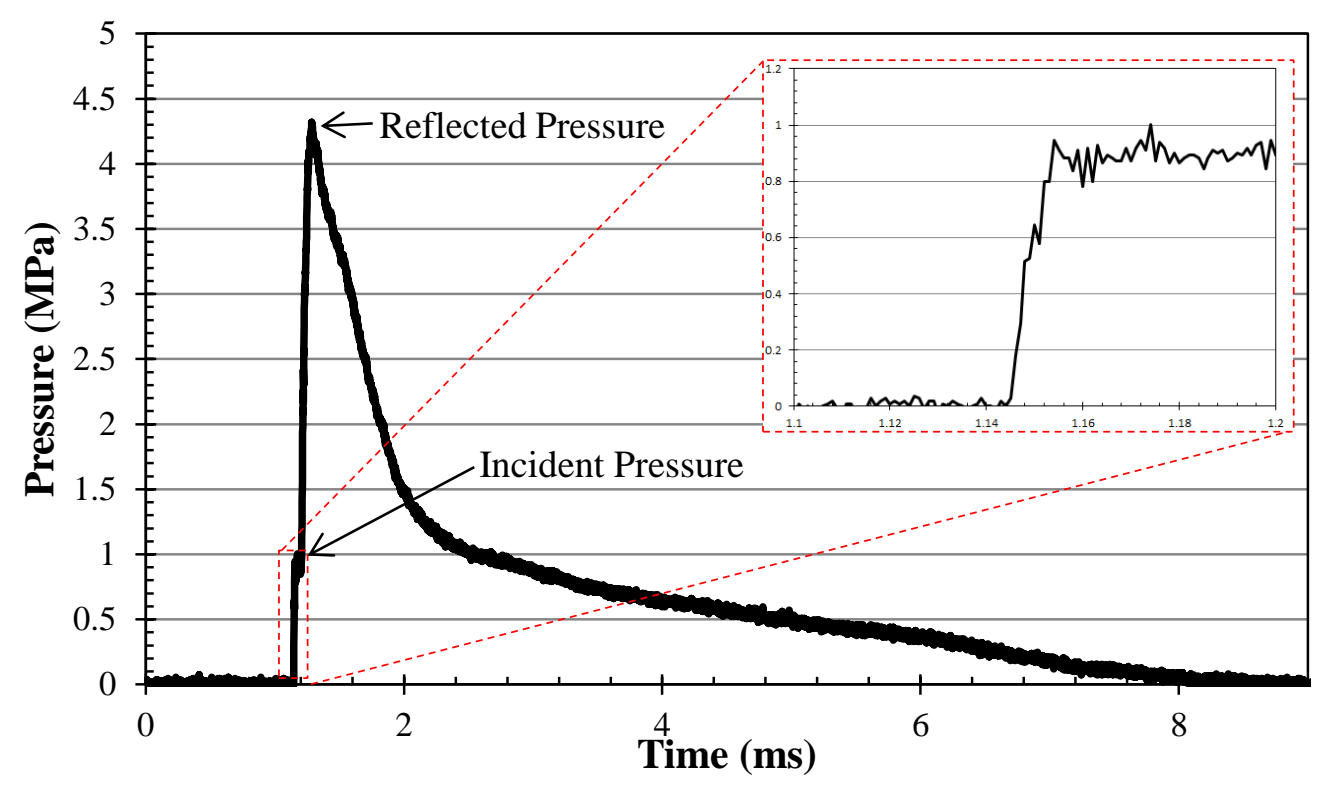

Fig. 2 Typical experimental pressure profile

The specimens were placed onto a simply supported fixture with a $152.4 \mathrm{~mm}$ span. The flat front-face of the specimen was set normal to the axis of the shock tube with the face completely covering the muzzle. A diagram of this set up can be seen in Fig. 3. At least three specimens of each type were shock loaded to ensure repeatability.

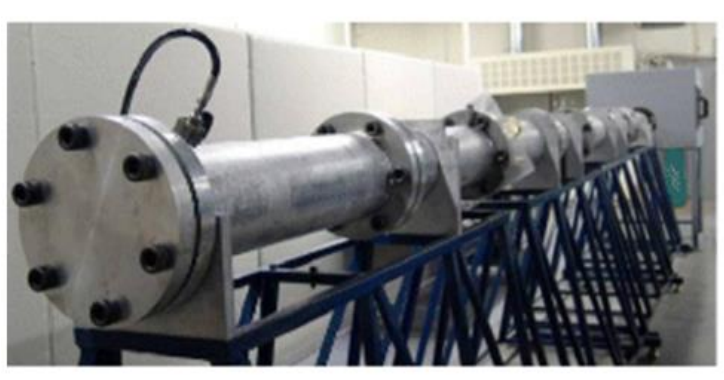

(a) Shock tubc

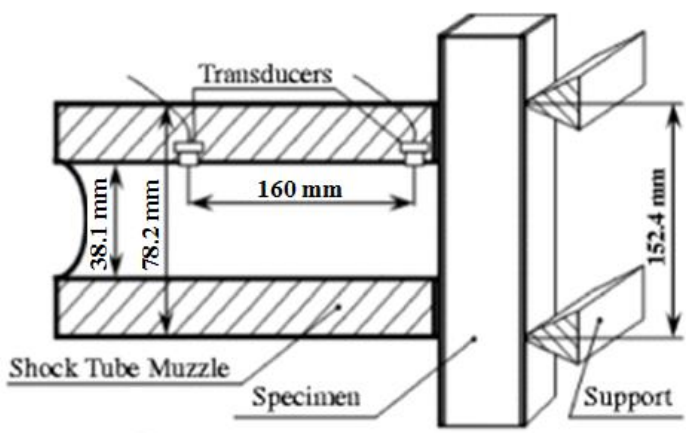

(b) Detailed dimensions of the muzzle

Fig. 3 (a) Shock Tube at the DPML Facility (b) Diagram of the Muzzle of the Shock Tube with Specimen

Three high speed photography systems (Photron SA1s) were used in this study oriented to the specimen as shown in Fig. 4. The side view camera records the front facesheet deflection, deformation shape and core compression while the two facing the 
rear of the specimen are combined for use as a 3-D Digital Image Correlation (DIC) system to obtain the real-time full-field in-plane strain, out-of-plane deflection, and velocity of the back facesheet. The DIC tracking and analysis is facilitated by painting a high contrast speckled pattern on the back face. A framing rate of 20,000 or 50,000 (50 $\mu$ s or $20 \mu$ s interframe time respectively) was chosen depending upon the specimen.

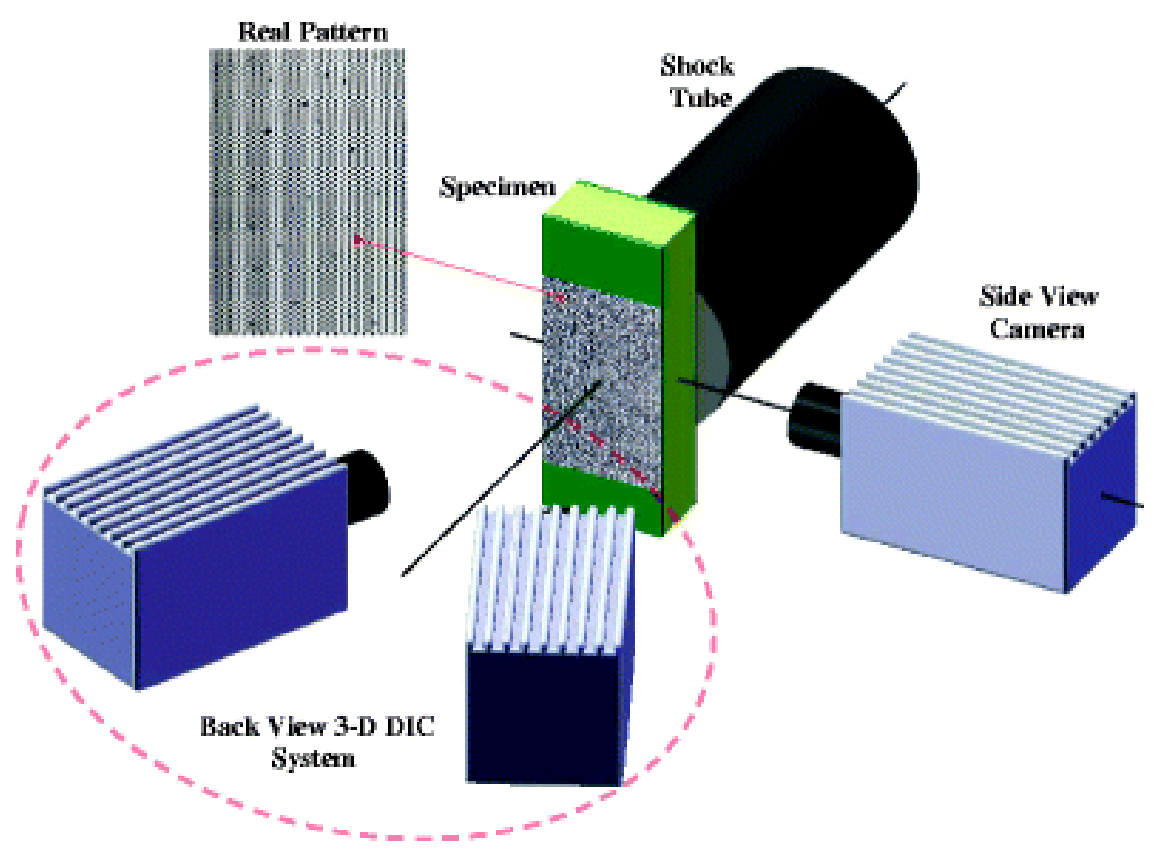

Fig. 4 High-Speed Photography System with Speckle Pattern [11]

\subsection{Rheological Tests}

Rheological tests were conducted on all samples to obtain both their viscosity with increasing shear rate as well as complex modulus. These tests were performed on glycerin (vegetable glycerin, chemworld), polydimethylsiliconase (also known as silicon oil, consolidated chemicals \& solvents), calcium carbonate with polyethylene glycol (PEG) 200 (200 molecular weight, Tex Lab Supply, 50\% w/w), fumed silica 
(Aerosil RD) with PEG 200 (58\% w/w), water, and corn starch (Argo) with water (53\% w/w). A TA Instruments AR2000 ex shear rheometer was used with a $40 \mathrm{~mm} 2$ degree cone at $25 \mathrm{C}$. A gap of $0.051 \mathrm{~mm}$ was used for the tests. An initial shear rate range of 0.001 to $5,000 / \mathrm{s}$ was used (this range could not be completed for all materials). The only exception was corn starch in water that used a $40 \mathrm{~mm}$ flat plate at $25 \mathrm{C}$ due to its high viscosity.

Glycerin, water, and PEG 200 are Newtonian fluids with water and PEG 200 being common liquid components that constitute STFs. Silicon oil is a viscoelastic non-Newtonian fluid. Calcium carbonate with PEG 200, fumed silica with PEG 200, water, and corn starch with water (all in appropriate concentrations) are known STFs and were examined for the effect shear rate has on their viscosity in order to determine an optimal candidate for shock testing.

\section{Experimental Results and Discussion}

\subsection{Applied Pressure and Impulses}

Two, $10 \mathrm{mil}(0.254 \mathrm{~mm})$ Mylar sheets were used as a rupturing diaphragm to create shock waves. Subramaniam et al. [44] showed that the pressure subjected to a movable surface, like the front-face sheet of the sandwich structure, can be accepted as the same as that applied to a fixed rigid wall found by using measured reflected pressure profiles. Real-time measured pressure profiles from the closest pressure sensor (reflected) can be seen in Fig. 5. The average peak value of the reflected shock pressure was $4.42 \pm 0.17 \mathrm{MPa}$.

From the reflected pressure profile captured by the transducer closest to the specimen the impulse imparted onto that specimen can be calculated (Fig. 6). These 
pressure profiles can be considered to be the same as the pressure applied to the specimens. Since the cross-sectional area of the muzzle is known the pressure impulse applied on the specimens can be calculated as:

$$
\mathrm{I}_{\text {pressure }}=\int_{0}^{\mathrm{t}_{1}}\left(\mathrm{p}_{\text {reflected }}-\mathrm{p}_{0}\right) S d t
$$

where $I$ is the impulse, $p_{\text {reflected }}$ is the reflected pressure and $p_{0} p_{0}$ is the atmospheric pressure. The impulses were obtained up to $10 \mathrm{~ms}$ (generally reaching their peak at 8.5 ms).

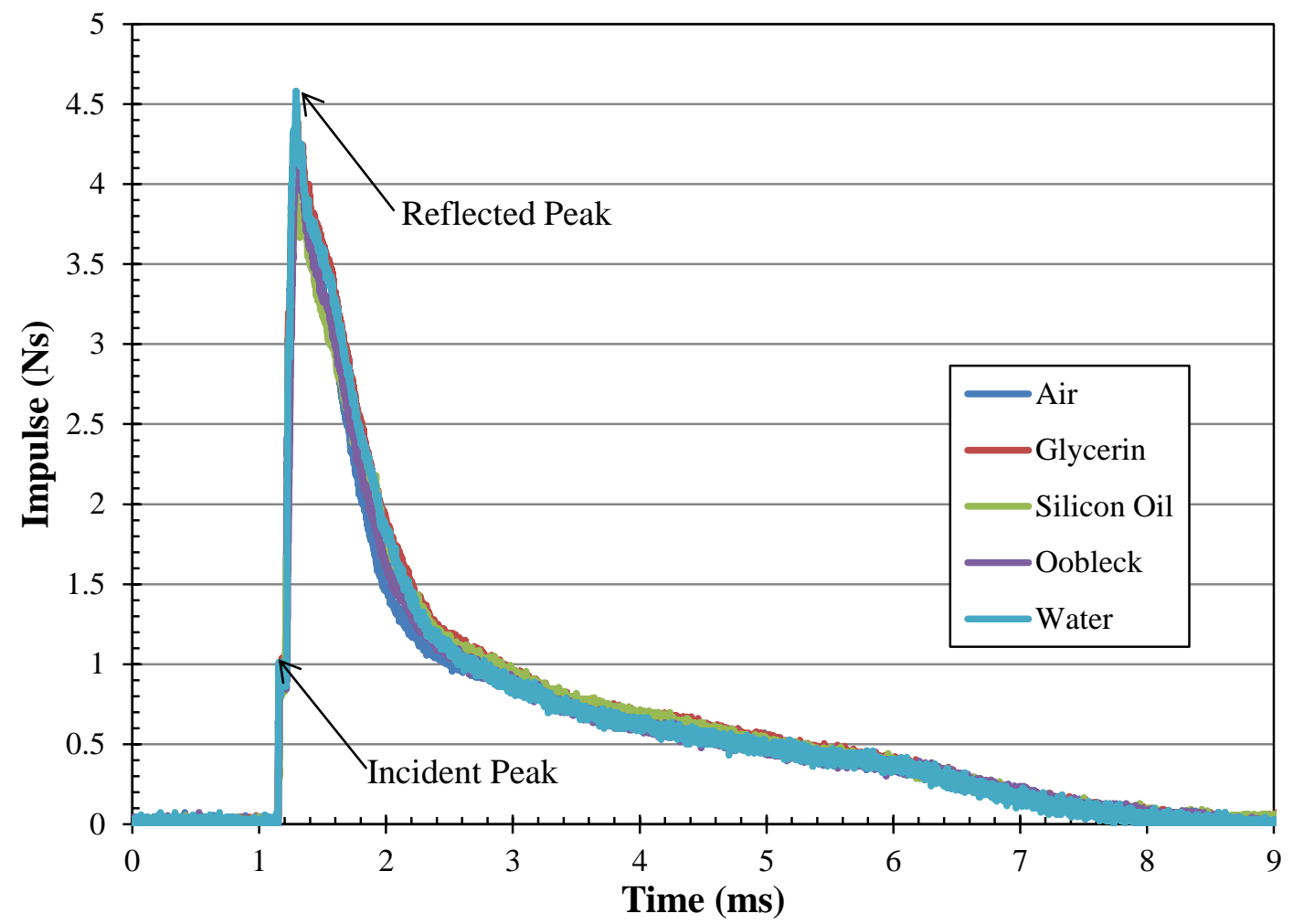

Fig. 5 Blast pressures specimen subjected to in shock tube experiments 


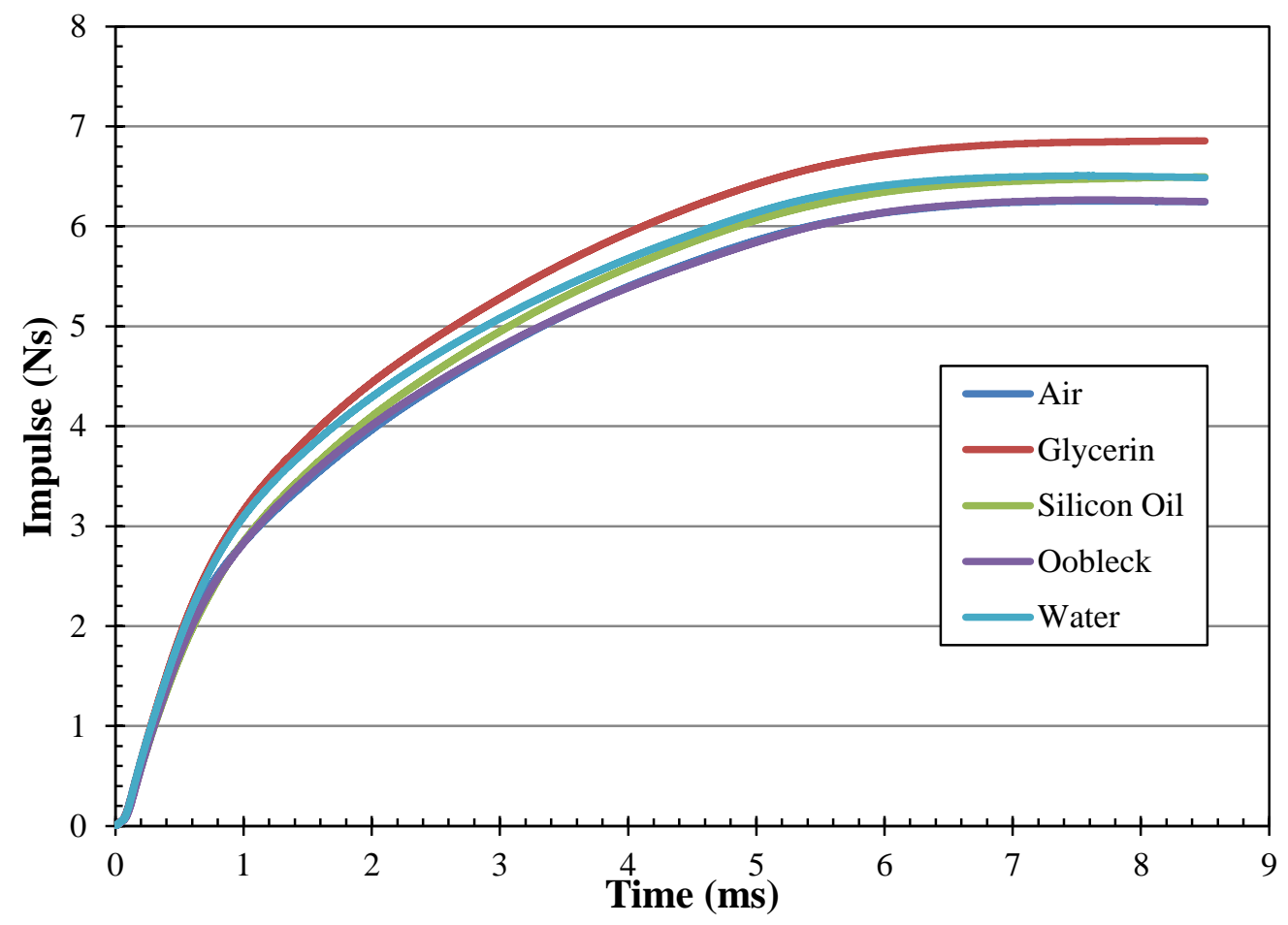

Fig. 6 Average Impulses imparted on the fluid filled panels by infill

Specific impulses were calculated for comparison with each other by dividing specimen average areal density and idealized areal density (neglecting mass from sealing silicon etc.) see Table 1 . The fluids have nearly identical applied impulses once areal density is accounted for with the exception of air in foam which is much higher and the Oobleck which is lower.

Table 1 Density of the Foam Infills with Correlating Average Impulses

\begin{tabular}{|l|c|c|c|c|c|}
\cline { 2 - 6 } \multicolumn{1}{c|}{} & Foam & Silicon Oil & Water & Glycerin & Oobleck \\
\hline Density (g/ml) & 0.03 & 1.00 & 1.00 & 1.26 & 1.31 \\
\hline Impulse (Ns) & 6.25 & 6.50 & 6.51 & 6.86 & 6.51 \\
\hline $\begin{array}{l}\text { Impulse per Average } \\
\text { Areal Density }\end{array}$ & 0.179 & 0.136 & 0.132 & 0.136 & 0.129 \\
\hline $\begin{array}{l}\text { Impulse per Idealized } \\
\text { Areal Density }\end{array}$ & 0.188 & 0.144 & 0.144 & 0.142 & 0.134 \\
\hline
\end{tabular}




\subsection{Rheologic Results}

Rheologic tests were performed on glycerin, silicon oil, PEG 200, water, calcium carbonate with PEG 200 (50\% w/w), fumed silica with PEG 200 (58\% w/w), water, and corn starch with water $(53 \% \mathrm{w} / \mathrm{w})$. Table 2 below is a synopsis of the density and quasi static viscosity of the pertinent liquids.

Table 2 Density and quasi static viscosity of liquids

\begin{tabular}{|l|c|c|c|c|c|}
\hline & Glycerin & Silicon oil & Water & Foam & Oobleck \\
\hline Density g/ml & 1.26 & 1.00 & 1.00 & 0.02883 & 1.3088 \\
\hline Viscosity Pa*s & 0.60 & 1.00 & 0.00089 & - & $7,500,000$ \\
\hline
\end{tabular}

\subsubsection{Viscoelastic Response of Silicone Oil}

The complex moduli (G' and G', storage and loss moduli respectively) over a range of frequencies and the effect of shear rate on viscosity of Glycerin and Silicon Oil is shown by Fig. 7 and Fig. 8 respectively. In Fig. 7 one can see that with nearly identical elastic (storage) moduli between the silicon oil and glycerin the silicon oil has a much larger loss modulus (energy lost to heat) and is thus considered a viscoelastic fluid. In Fig. 8 we see that both fluids have relatively stable viscosities with respect to shear rate unlike the next three fluids (note the other three fluids use log scales for viscosity while Fig. 8 is linear). 


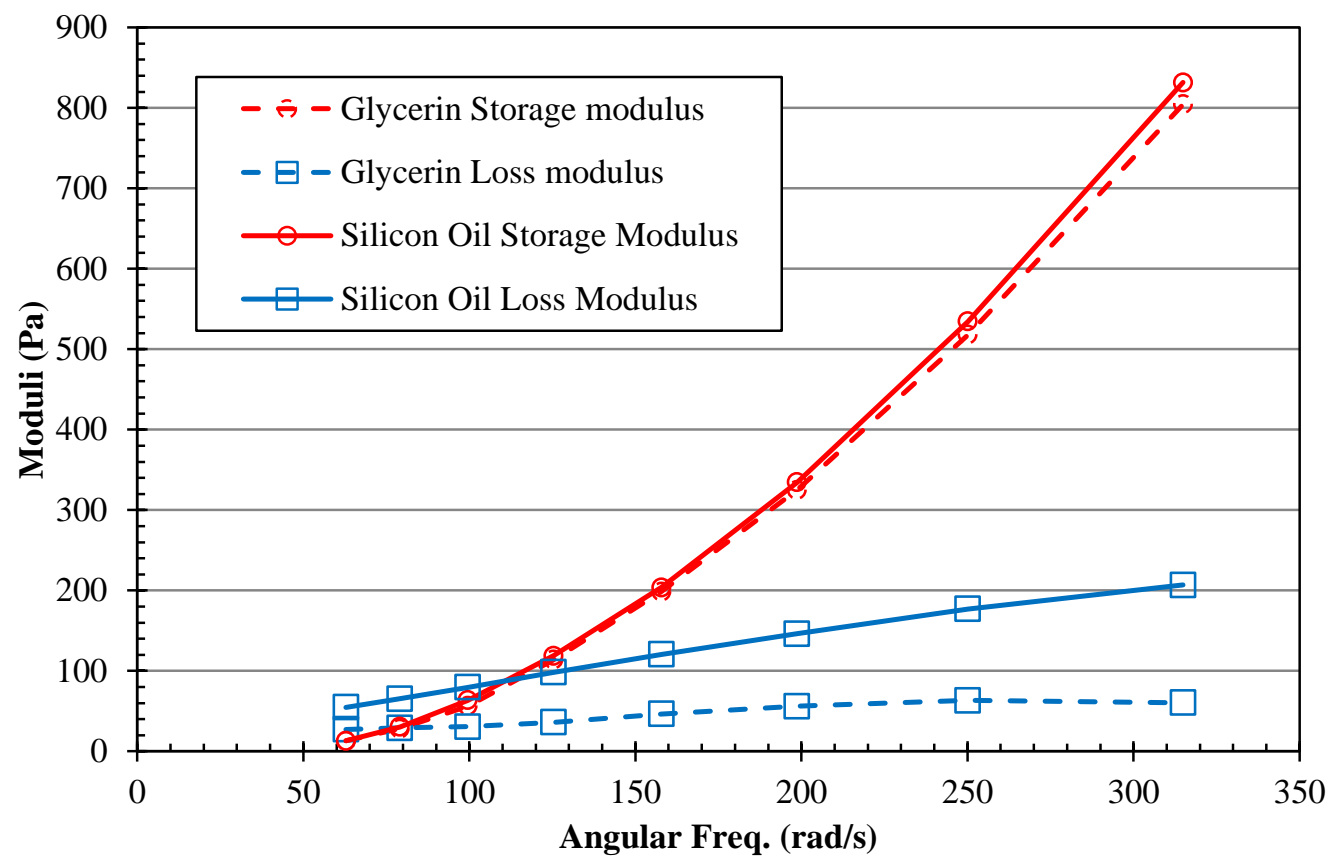

Fig. 7 The complex moduli of glycerin (Newtonian Fluid) and silicone oil (nonNewtonian viscoelastic) over a range of frequencies

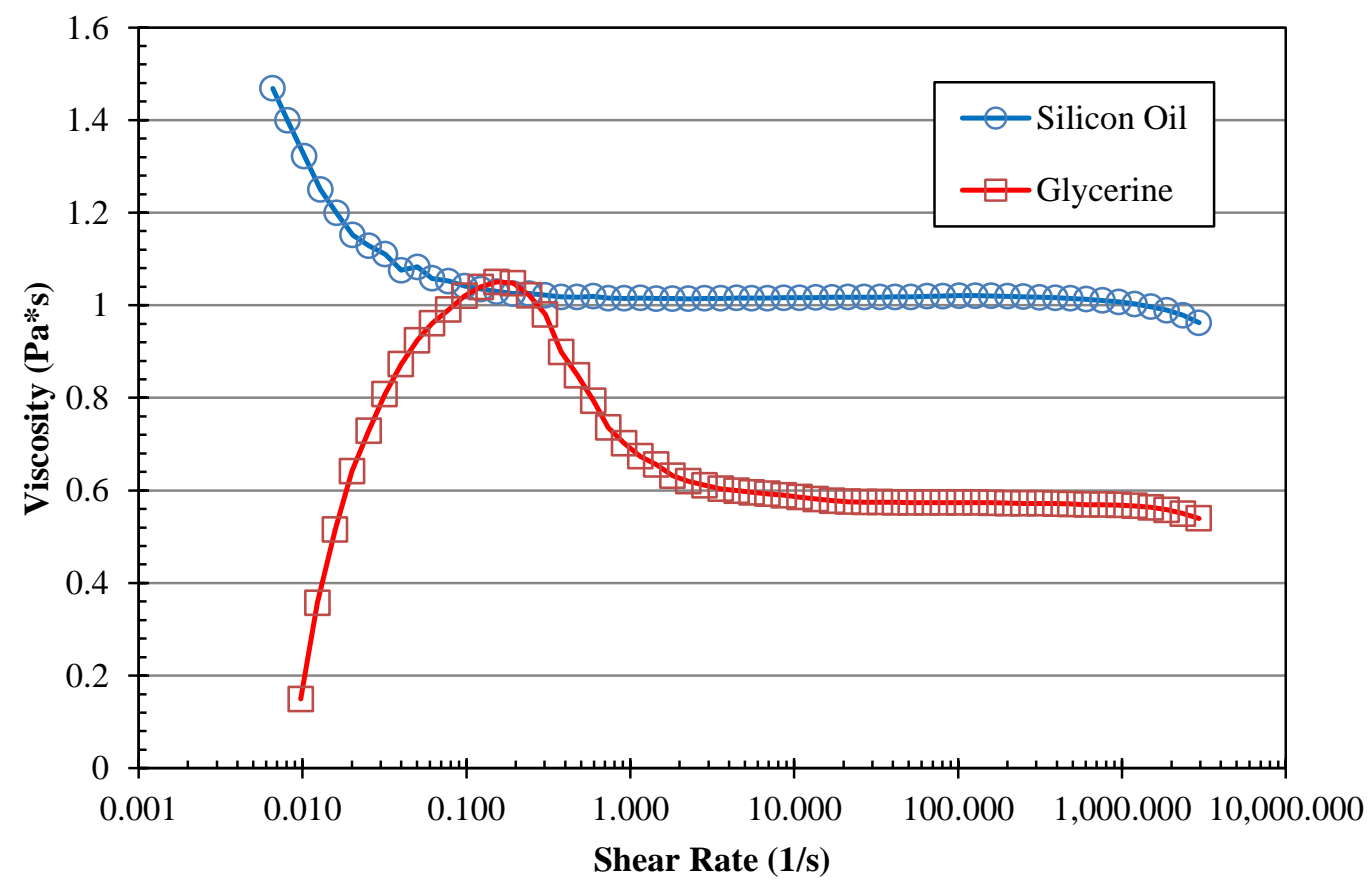

Fig. 8 Effect of shear rate on the viscosity of silicone oil and glycerin 


\subsubsection{Fumed Silica and PEG 200}

Silica in PEG 200 (58\% w/w) did not have observable non-Newtonian (shear thickening) responses during hand mixing, even after excess ethanol had been removed. In addition, no shear thickening behavior was found in rheologic testing over a range of shear rates as seen in Fig. 9. The viscosity of this mixture drops steadily from over $11 \mathrm{~Pa}^{*} \mathrm{~s}$ to less than $0.5 \mathrm{~Pa}^{*} \mathrm{~s}$ from 3 /s to $1150 / \mathrm{s}$ showing shear thinning properties but no shear thickening.

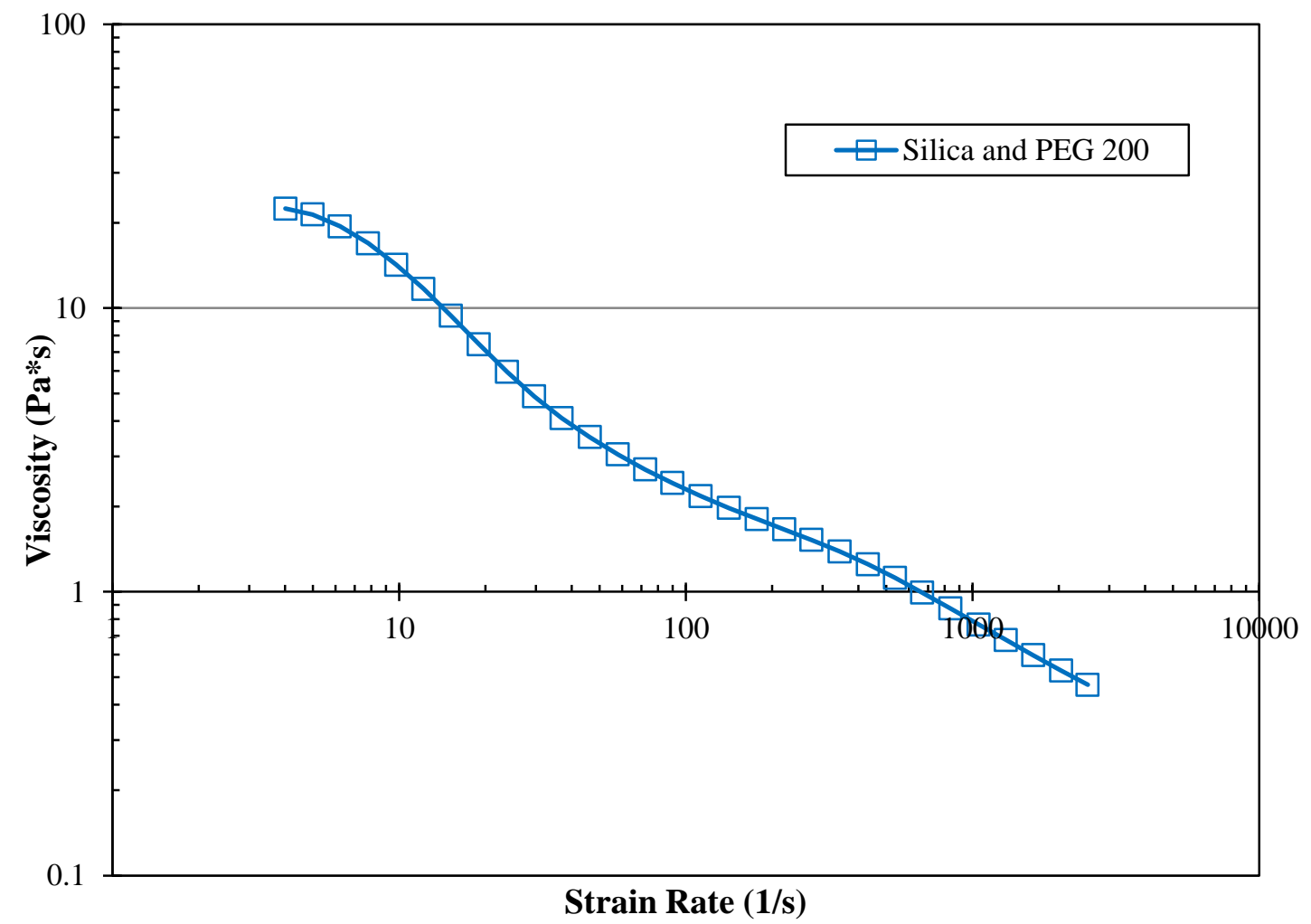

Fig. 9 Effect of shear rate on the viscosity of Fumed Silica and PEG 200

\subsubsection{Calcium Carbide and PEG 200}

Calcium Carbide in PEG 200 (50\% w/w) had observable non-Newtonian responses during hand mixing. However, this observation was not confirmed by 
rheologic testing over a range of shear rates as seen in Fig. 10. The viscosity of this mixture drops steadily from over $400 \mathrm{~Pa}^{*}$ s to less than $1 \mathrm{~Pa}^{*} \mathrm{~s}$ from $0.001 / \mathrm{s}$ to $1000 / \mathrm{s}$ showing shear thinning properties but no shear thickening.

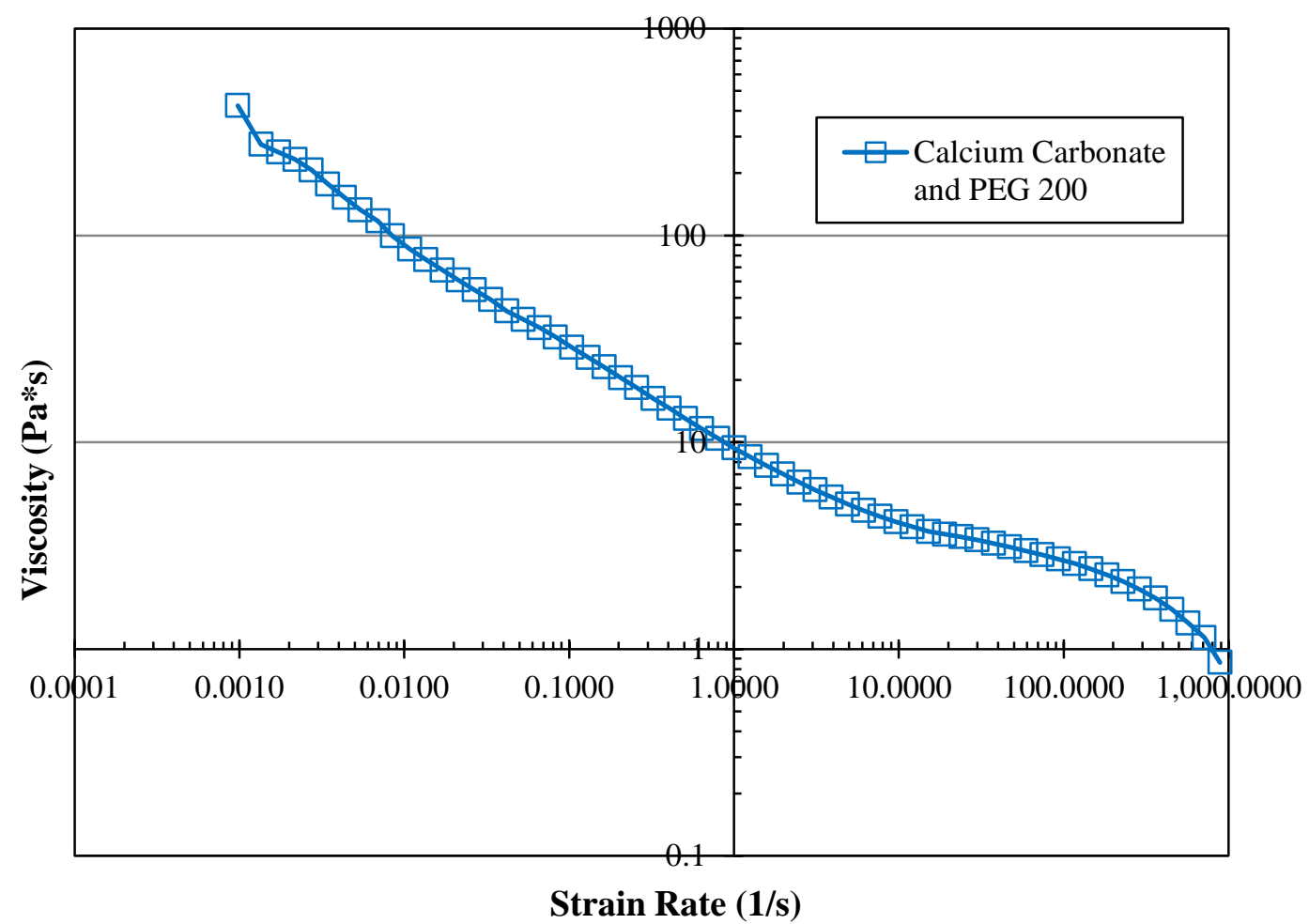

Fig. 10 Effect of shear rate on the viscosity of Calcium Carbonate and PEG 200

\subsubsection{Corn Starch and Water}

Corn starch in water as with Calcium Carbide in PEG 200 had observable nonNewtonian responses during hand mixing. This was in part confirmed by rheologic testing over a range of shear rates as seen in Fig. 11. After a plateau of roughly $7,500,000 \mathrm{~Pa}^{*} \mathrm{~s}$ a typical shear thinning regime is observed between the shear rates of $0.00025 / \mathrm{s}$ and $0.15000 / \mathrm{s}$ down to $80,000 \mathrm{~Pa}^{*} \mathrm{~s}$ (all shown in green in Fig. 11) at which point the testing machine was overwhelmed by the sample's viscous response 
forcing it into a slower shear rate and eventually taking more force to shear than available to the machine.

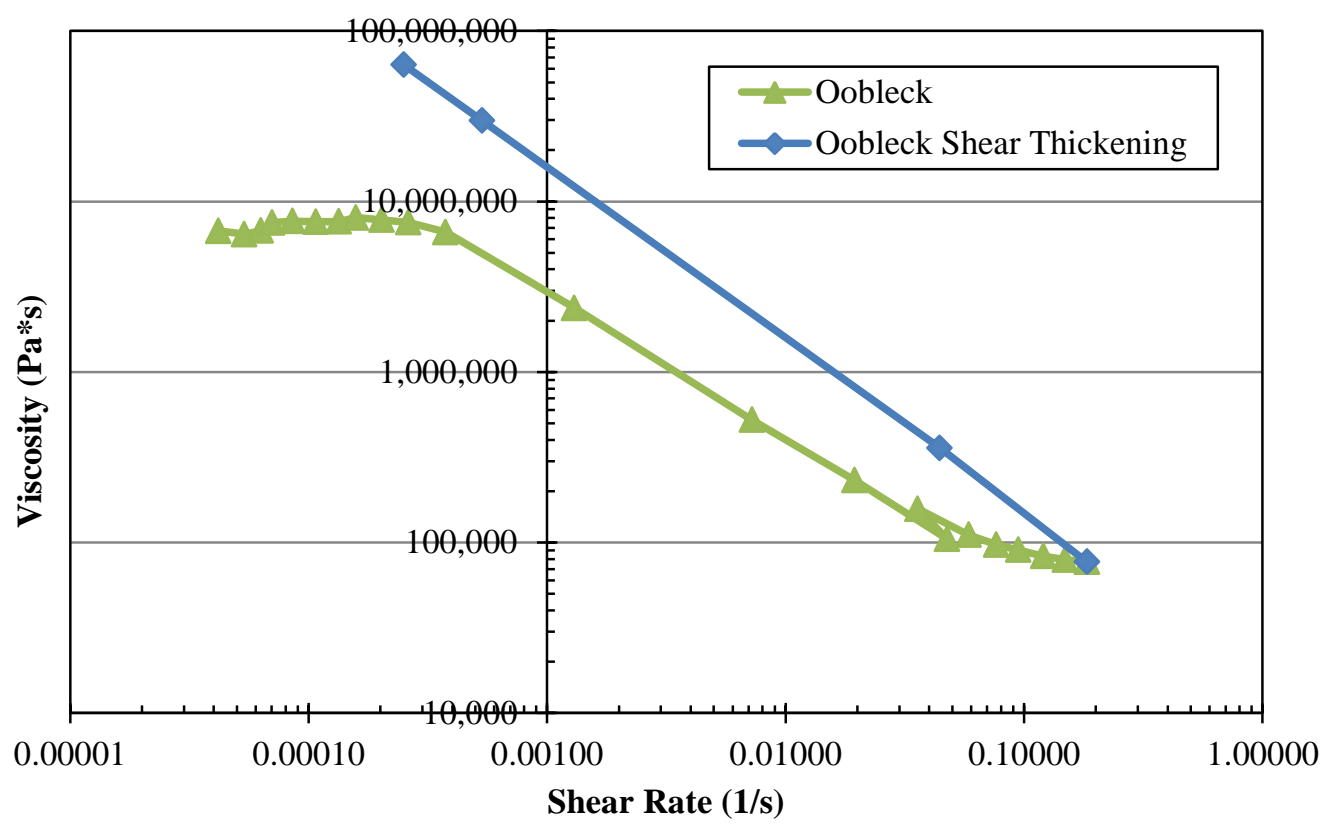

Fig. 11 Effect of shear rate on the viscosity of corn starch and water

Given the lack of a clear shear thickening response both manually and via testing from the other two STF candidates the corn starch in water was chosen as the STF for further shock experimentation.

\subsection{High Speed Photography and Experimental Results.}

The real-time observations of the deformation of each type of specimen are shown in Fig. 12. On the right side of each image is the shock tube: the shock wave impinges upon the front-face of the panels from this side. The side view images of the five types of panels are shown by Fig. 12, in which they are being exposed to a shock event over $2.5 \mathrm{~ms}$. Note that the silicon enclosing the fluids in the water and oobleck panel cases shears away allowing the fluid within to be violently excreted beginning around $1.0 \mathrm{~ms}$. 

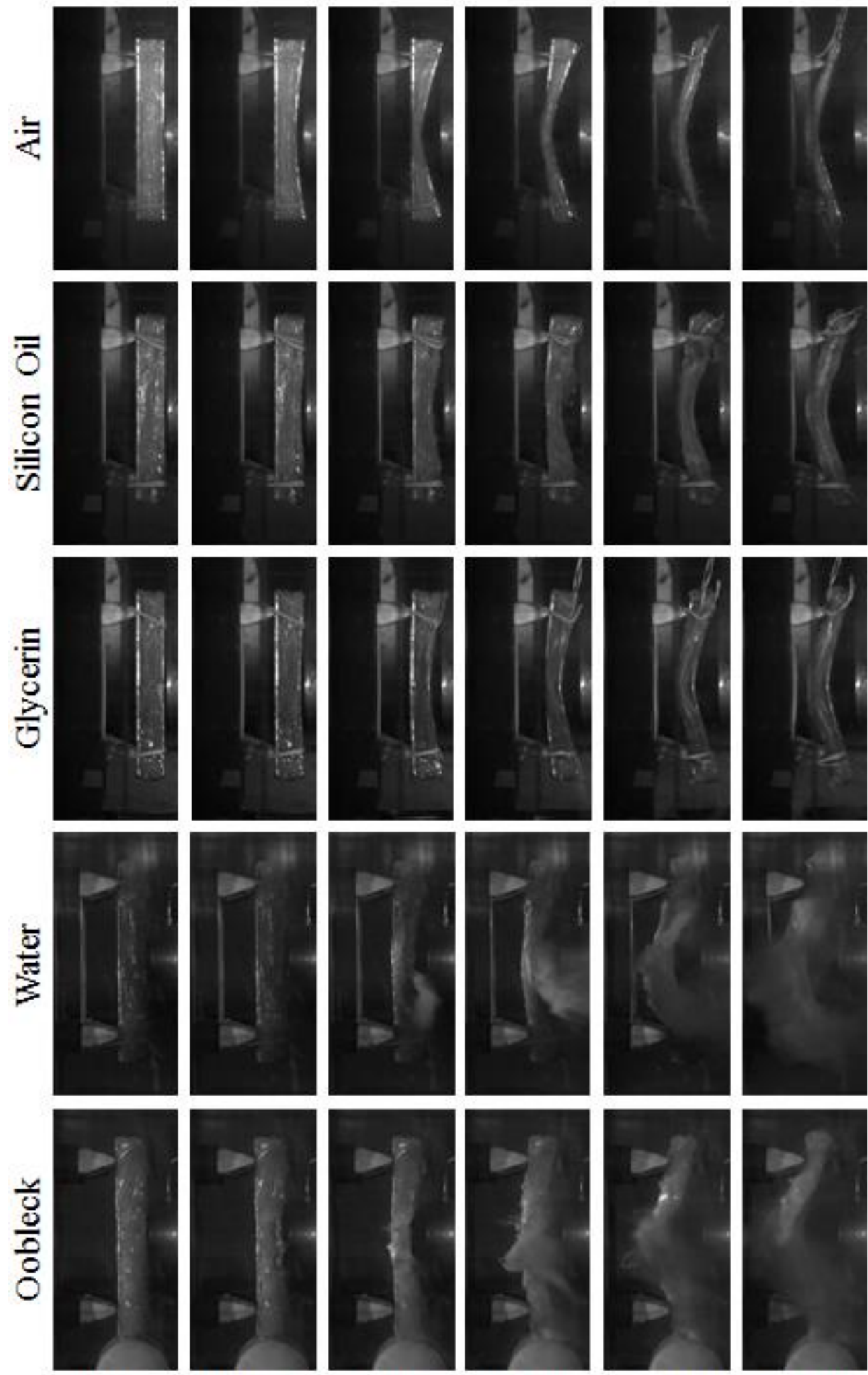

$\mathrm{t}=0.5 \mathrm{~ms}$

$\mathrm{t}=1.0 \mathrm{~ms}$

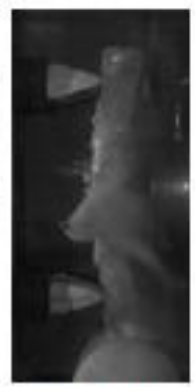

$t=1.5 \mathrm{~ms}$

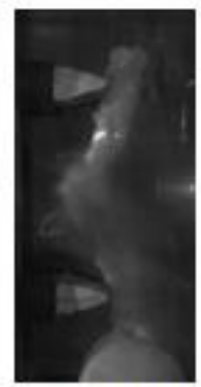

$\mathrm{t}=2.0 \mathrm{~ms}$

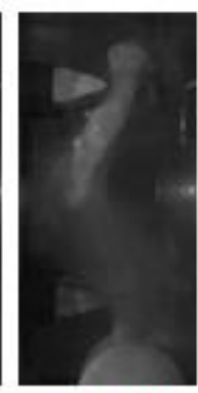

$\mathrm{t}=2.5 \mathrm{~ms}$

Fig. 12 High-speed images of the sandwich specimens 


\subsubsection{Back Face Deflections}

Fig. 13 shows the average back face deflections (BFDs) with respect to time for each fluid filled sandwich panel. These deflections were calculated using the point inspection tool from the Digital Image Correlation (DIC) software. A point in the center of the panel was chosen to extract the BFD. The air filled panel experiences the most deflection over time $(25.2 \mathrm{~mm})$ and is also the most delayed as very little force is transferred to the back face due to the air filled foam minimally resisting being compressed by the blast; this resulted in the panel undergoing a "slapping" style collapse. The silicon oil and the glycerin filled panels are the next two most deflected panels (18.0 $\mathrm{mm}$ and $17.3 \mathrm{~mm}$ maximum average deflection) with the silicon and glycerin having similar deflection curves. The silicon oil undergoes slightly more deflection than the glycerin and has a steeper rise once BFD begins. Lastly, the Oobleck, $15.5 \mathrm{~mm}$, deflects slightly more on average than the water, $14.0 \mathrm{~mm}$, (both of which are less than glycerin and silicon oil) and has a BFD rise similar to that of silicon oil while water with the lowest BFD has the lowest BFD slope. 


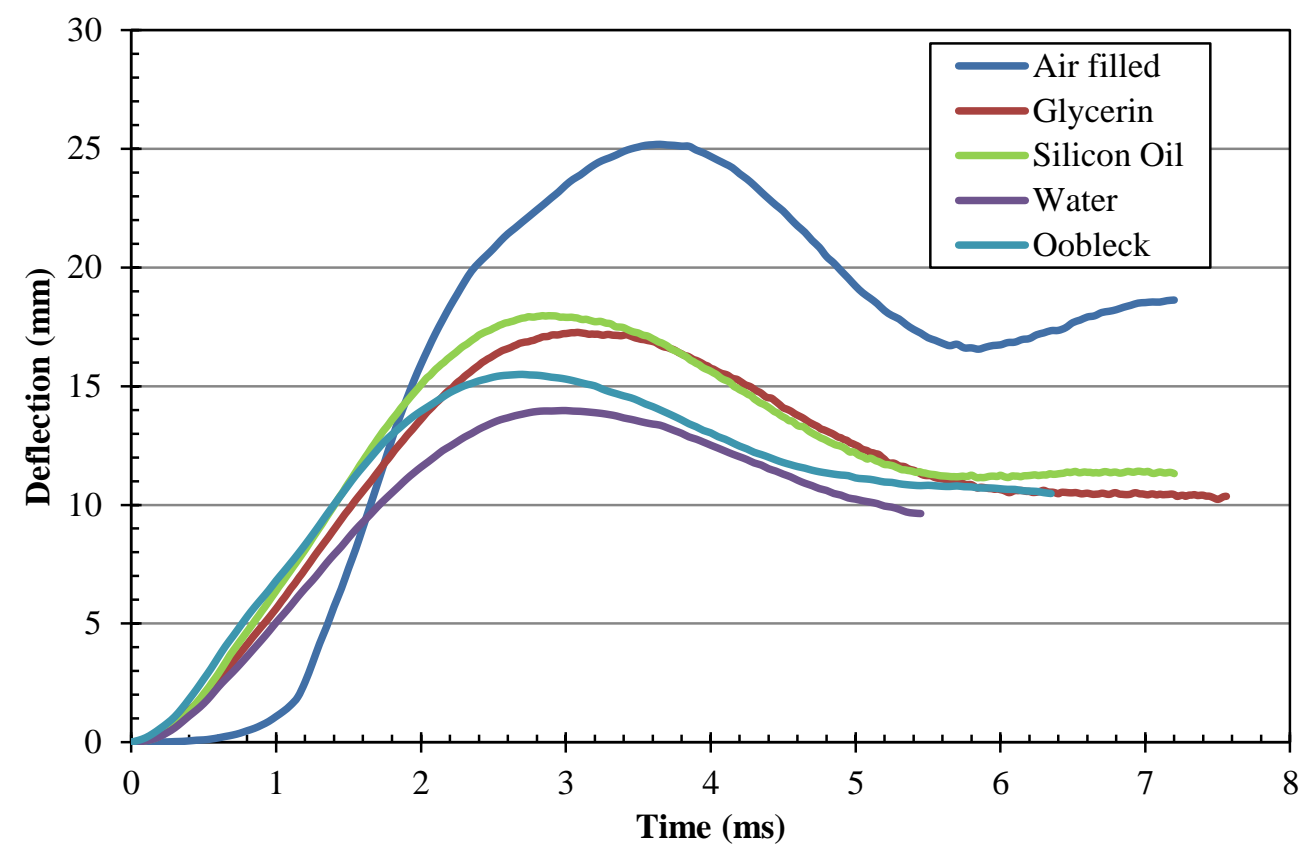

Fig. 13 BFD of sandwich panels exposed to shock wave

\subsubsection{Front Face Deflections}

Fig. 14 shows FFDs with respect to time for each fluid filled sandwich panel. The front face data in these figures were obtained from midpoint deflections of the face sheets using pictures from high-speed photography, shown in Fig. 12. This method gives pixel level fidelity to the deflection of the panels $(0.5$ to $0.7 \mathrm{~mm}$ depending on the rate of capture) whereas the DIC method for the back face provides subpixel definition. In the cases of the water and Oobleck filled sandwich panels the failure of the silicon siding retaining the fluid and subsequent release of fluid obscures the side view images during some portions of the response. In these cases the position of the mid-point FFD is estimated and/or interpolated from the deflection history. 


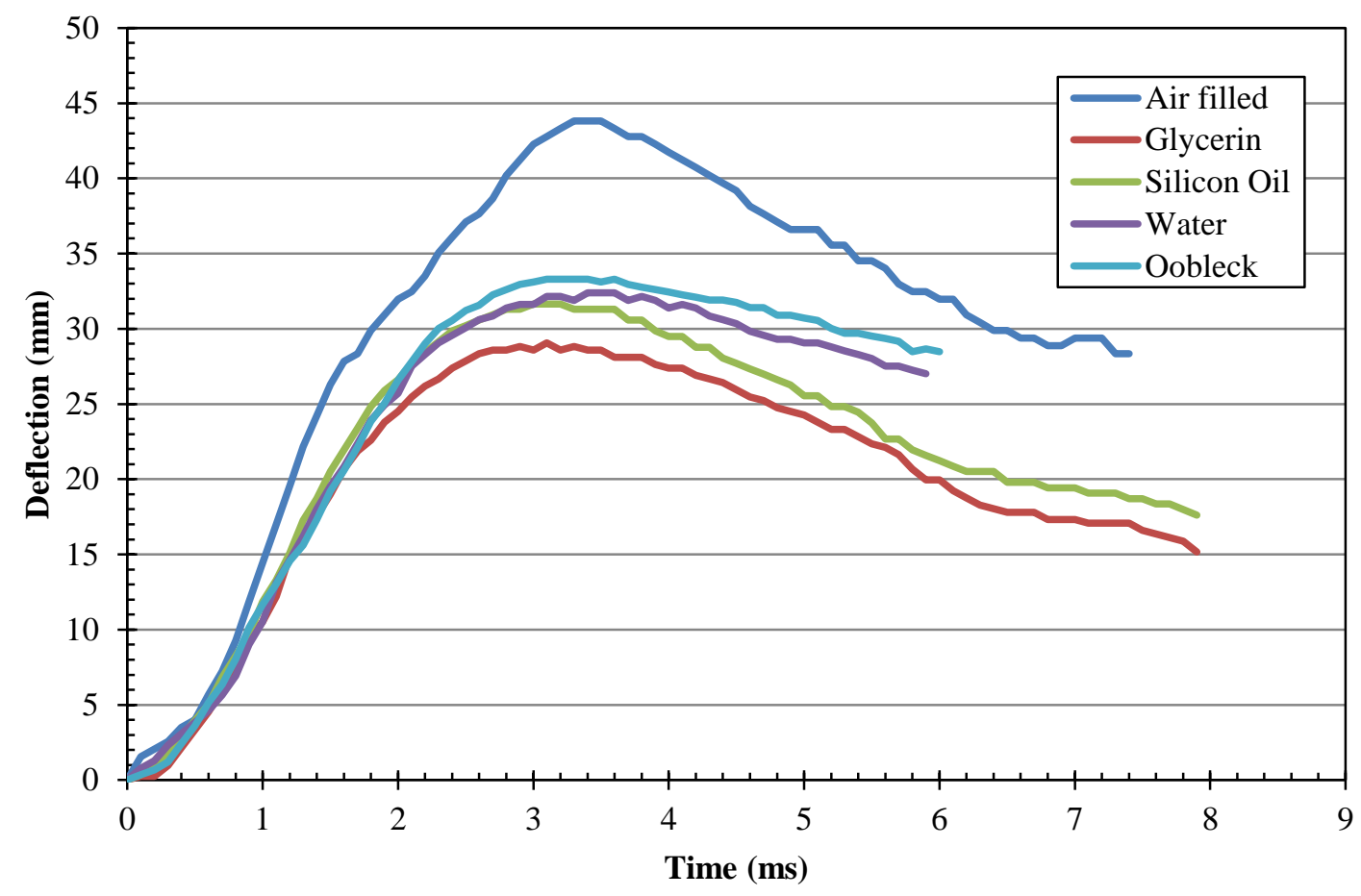

Fig. 14 FFD of sandwich panels exposed to shock wave

The air filled panels once again have the greatest deflection with a maximum of $43.8 \mathrm{~mm}$. However, in contrast to the BFDs the oobleck and water filled sandwich panels have the second and third most maximum FFD, $33.3 \mathrm{~mm}$ and $32.3 \mathrm{~mm}$, respectively. Silicon and glycerin have $31.7 \mathrm{~mm}$ and $29.0 \mathrm{~mm}$ maximum average FFD. Note that all fluid filled panels follow the same FFD history until roughly 2.0 ms with the exception of the air filled panel which diverges around $0.8 \mathrm{~ms}$. It can also be noted that the recovery rate of the water and oobleck filled panels' FFD is much slower than the others most likely due to the loss of fluid experienced by these two types of panels. 


\subsubsection{Core Compression}

As the photographs of the cameras are synchronized the compression of the core can be calculated along the midline of the panels by subtracting the FFD by the BFD as seen in Fig. 13 and Fig. 14. From this the strain and strain rate of the bulk core can be obtained from the following:

$$
\begin{gathered}
\varepsilon=\frac{\Delta l}{l_{\text {original }}} \\
\frac{d \varepsilon}{d t}=\frac{d}{d t}\left(\frac{\Delta l}{l_{\text {original }}}\right)=\frac{l}{l_{\text {original }}}\left(\frac{d(\Delta l)}{d t}\right)
\end{gathered}
$$

where, $l_{\text {original }}$ is the original thickness of the core and $\Delta l / d t$ is the rate of deformation. The FFD, BFD, core compression and strain rate of the core for each panel type is shown by Fig. 15 through Fig. 19. The air filed panels show the greatest core compression, $23.7 \mathrm{~mm}$, (roughly $93 \%$ at $1.5 \mathrm{~ms}$ ) with a peak core strain rate of approximately 1000 /s. Over the course of $7.5 \mathrm{~ms}$ the core can be seen recovering its original thickness in an oscillating manner. The glycerin filled panel reached a peak core compression of $13.0 \mathrm{~mm}(51 \%)$ at $2.0 \mathrm{~ms}$ after shock impact with a peak core strain rate of 800 /s. The silicon oil filled panel reached a peak core compression of $17.2 \mathrm{~mm}(68 \%)$ at $1.9 \mathrm{~ms}$ after shock impact with a peak core strain rate of 650 /s. The water filled panel reached a peak core compression of $18.6 \mathrm{~mm}$ $(73 \%)$ at $2.3 \mathrm{~ms}$ after shock impact with a peak core strain rate of $750 / \mathrm{s}$. The oobleck filled panel reached a peak core compression of $18.6 \mathrm{~mm}(73 \%)$ at $2.3 \mathrm{~ms}$ after shock impact with a peak core strain rate of 650 /s. Note that both the water and oobleck filled panels do not experience core recovery over the observed period most likely due to lack of restoring pressure from the enclosing silicon. The two 
liquids' similar core compression is most likely due to the liquids expulsion from the core during the shock load. The elbow in the core compression history of the oobleck filled panels, where the strain rate drops to nearly $0 / \mathrm{s}$ before rising again for an additional millisecond peaking at roughly $400 / \mathrm{s}$ gives some indication that the core may have provided some temporary increased resistance to compression.

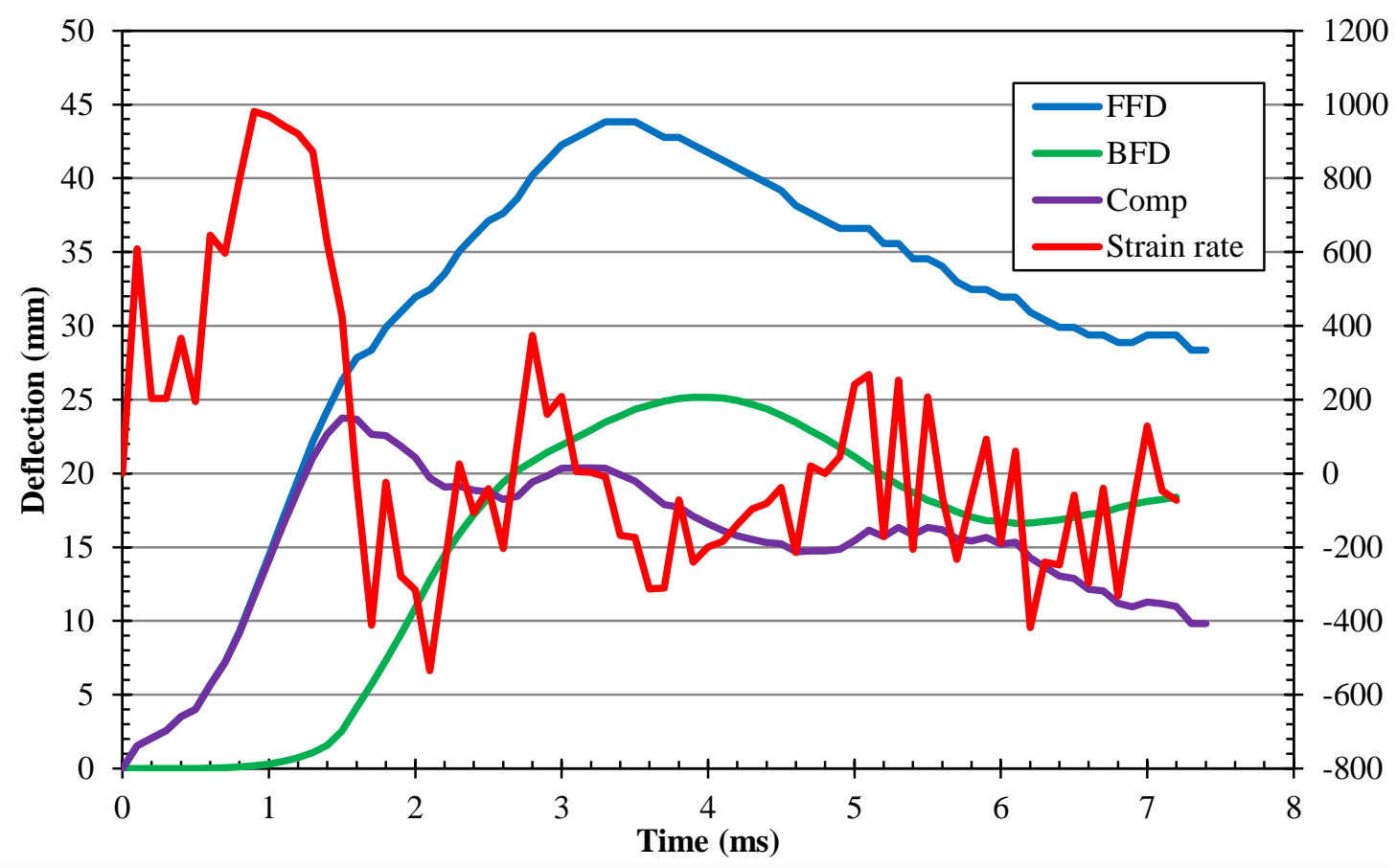

Fig. 15 Core compression of air filled sandwich panels 


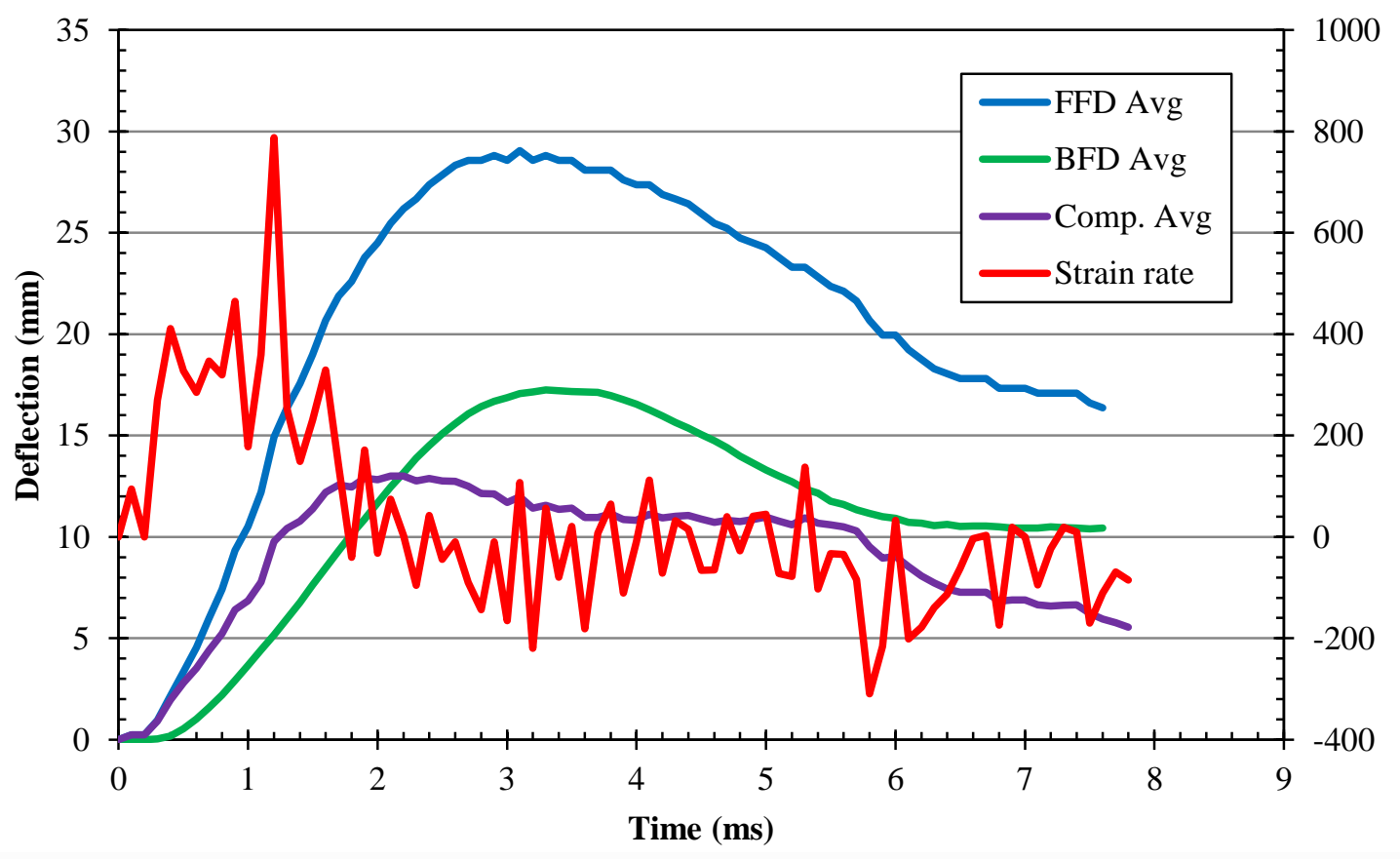

Fig. 16 Core compression of glycerin filled sandwich panels

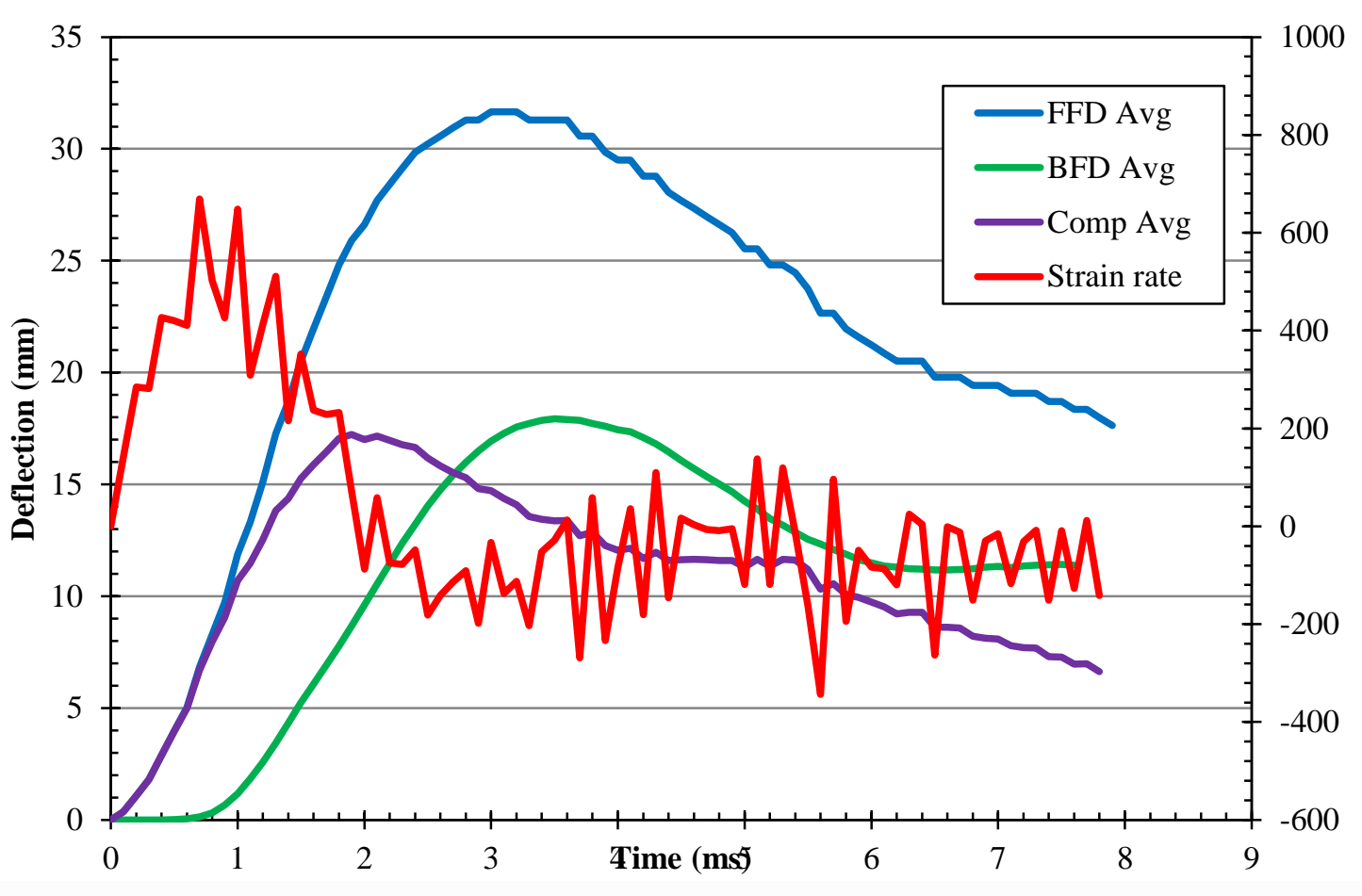

Fig. 17 Core compression of silicon oil filled sandwich panels 


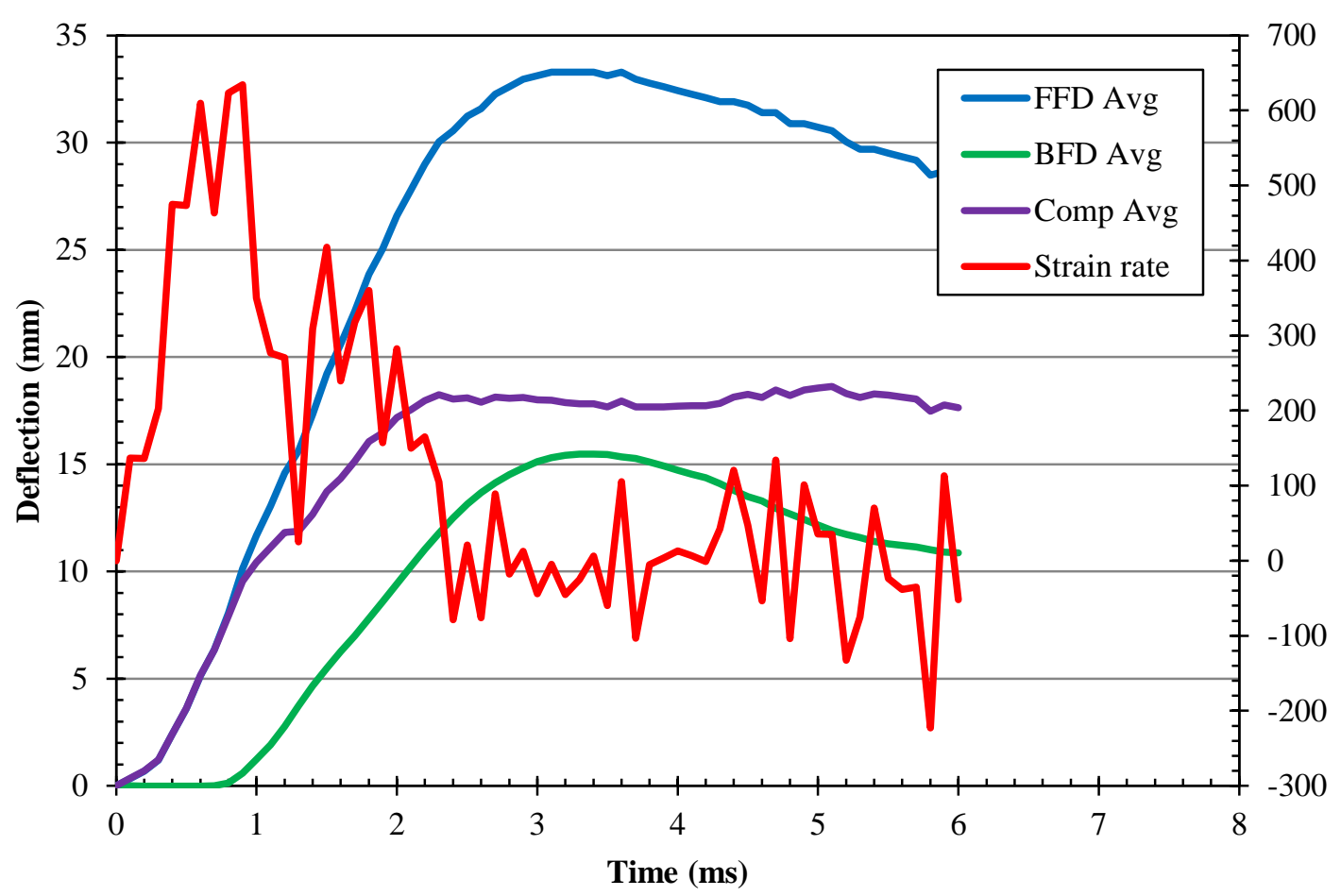

Fig. 18 Core compression of oobleck filled sandwich panels

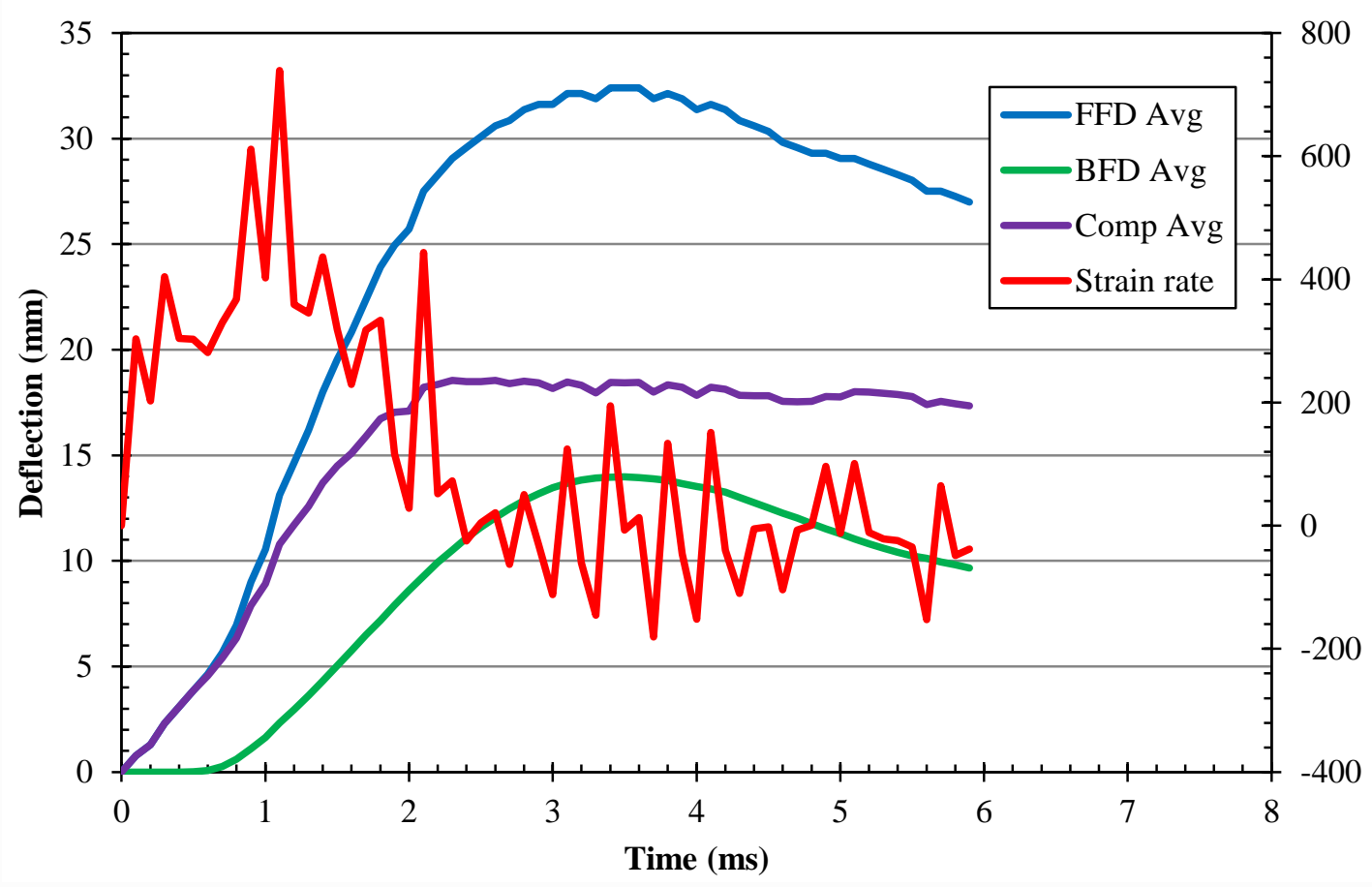

Fig. 19 Core compression of water filled sandwich panels 


\subsubsection{Post Mortem Analysis}

Two damage patterns are evident after the specimens have been shock loaded. The first is global bending of the specimen, to various degrees; with possible localized debonding (or tearing) of the silicon barrier with the metallic face sheets at the mid line of the panels (the glycerin tending to have debonding in the back while the air and silicon tend to have splits in the front) resulting in small post mortem leaking of the entrained fluid, see Fig. 20. The second pattern also displays global bending of the specimen but instead of local debonding of the silicon barrier at the face sheet interface complete debonding of one or more sides of the silicon with both the face sheets and foam occurs. In addition, shear cracking of the core and in extreme cases removal of the mid core from the panels (although this occurs post shock) and/or debonding of the foam with the face sheets occurs. This may be due to the formation of rust on the face sheets due to the presence of water within the core weakening the bonding between the materials, see Fig. 21 . 


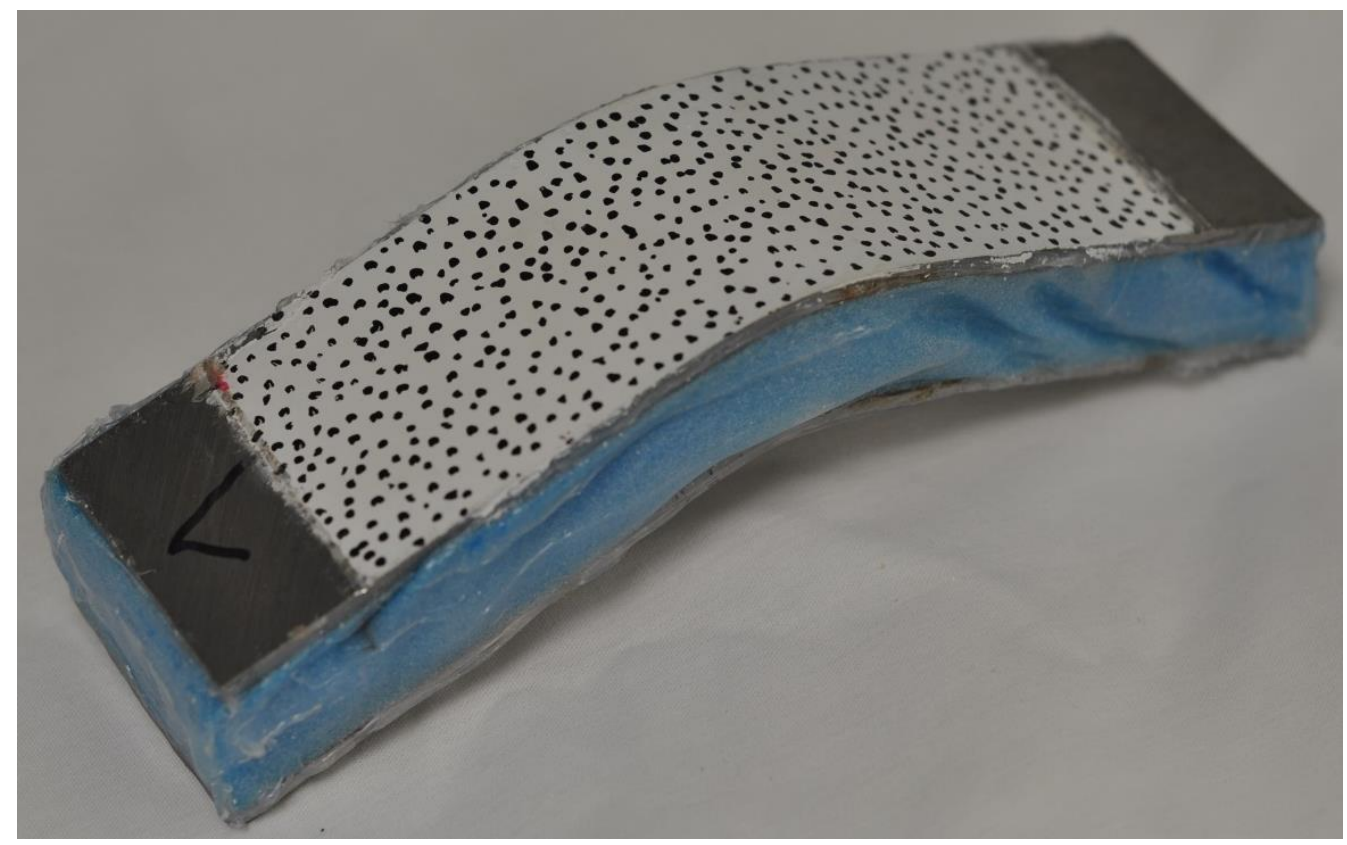

(a)

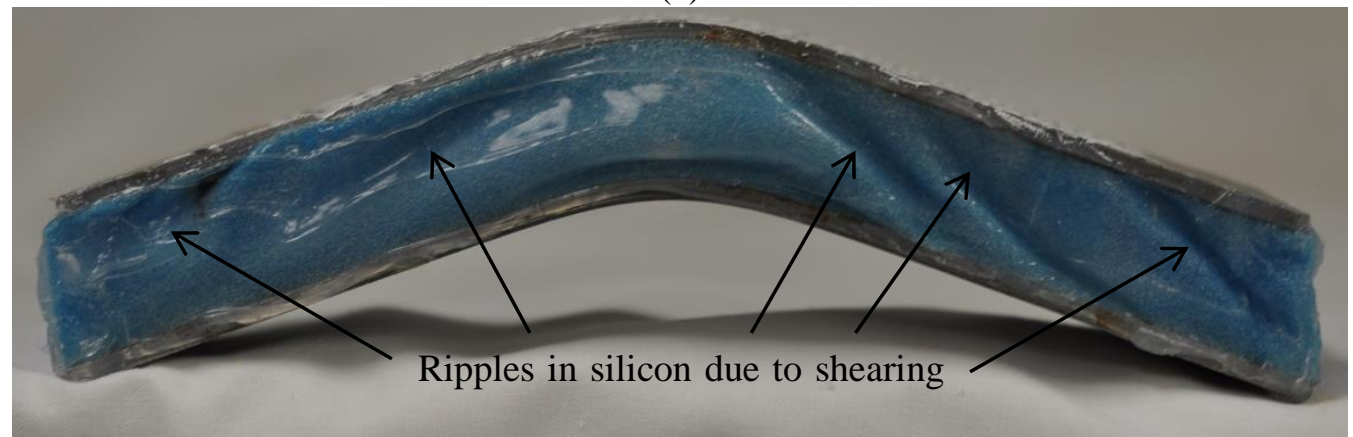

(b)

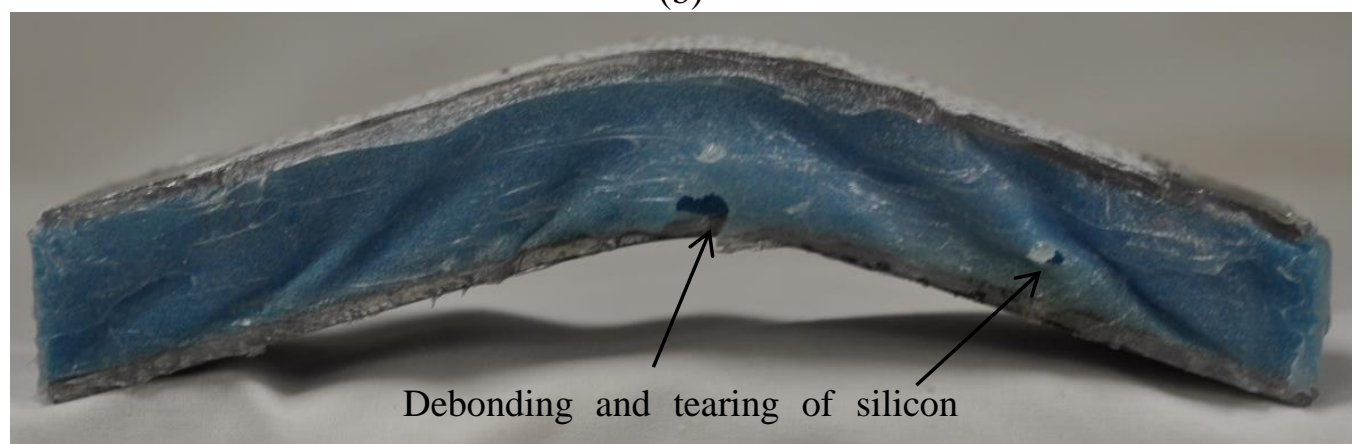

(c)

Fig. 20 Damage pattern 1 specimens (a) air filled specimen (b) side view without debonding (c) side view with debonding and tearing of silicon barrier 


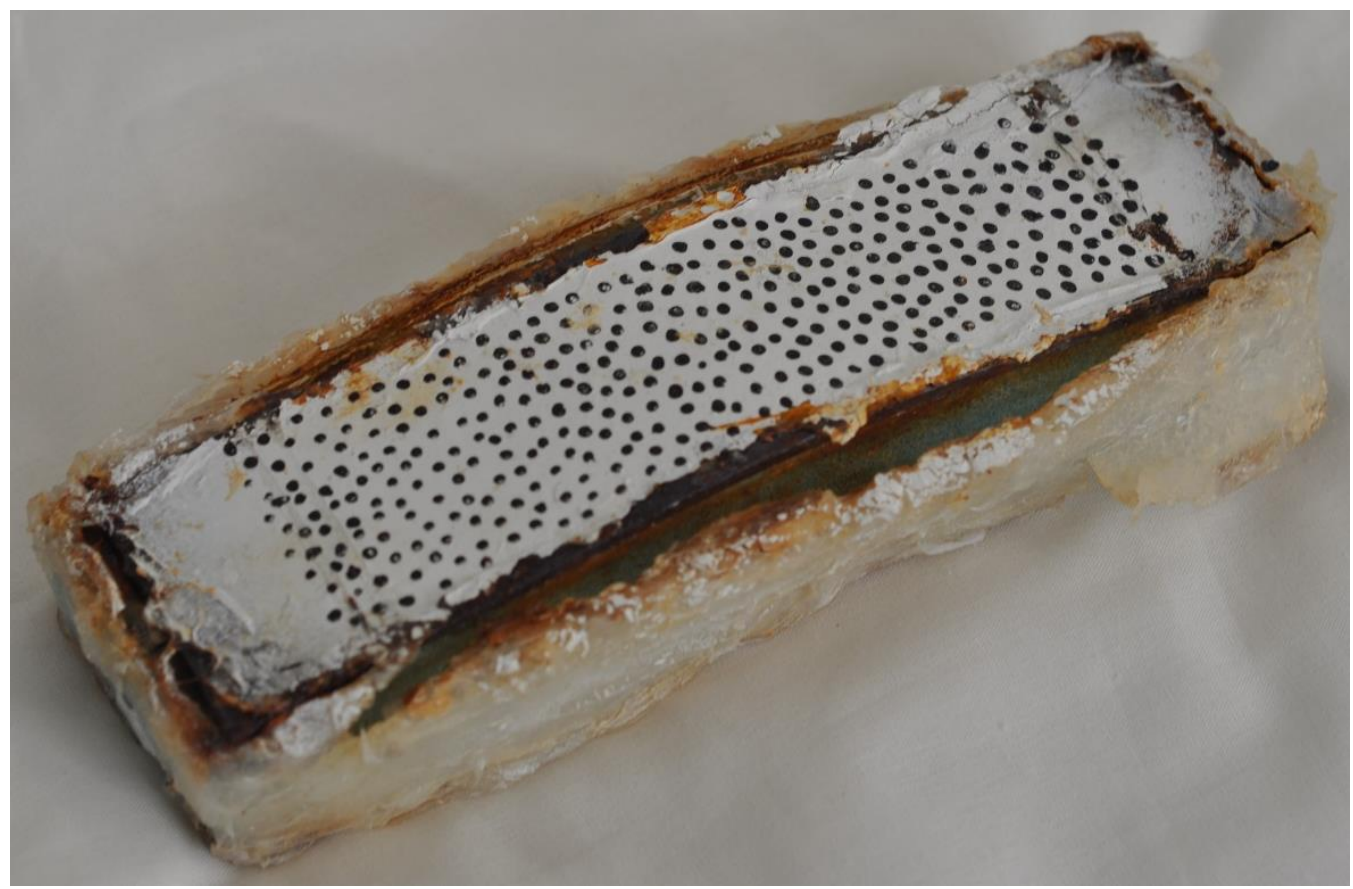

(a)

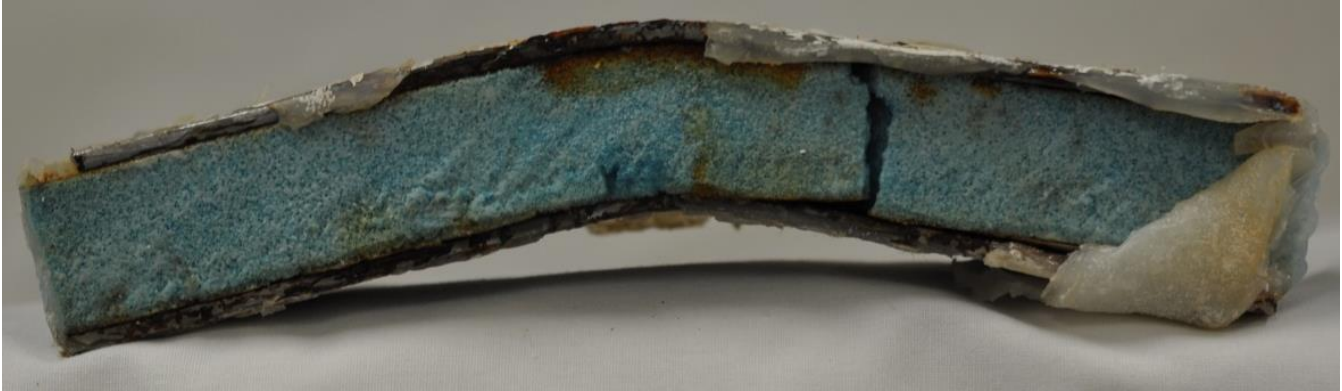

(b)

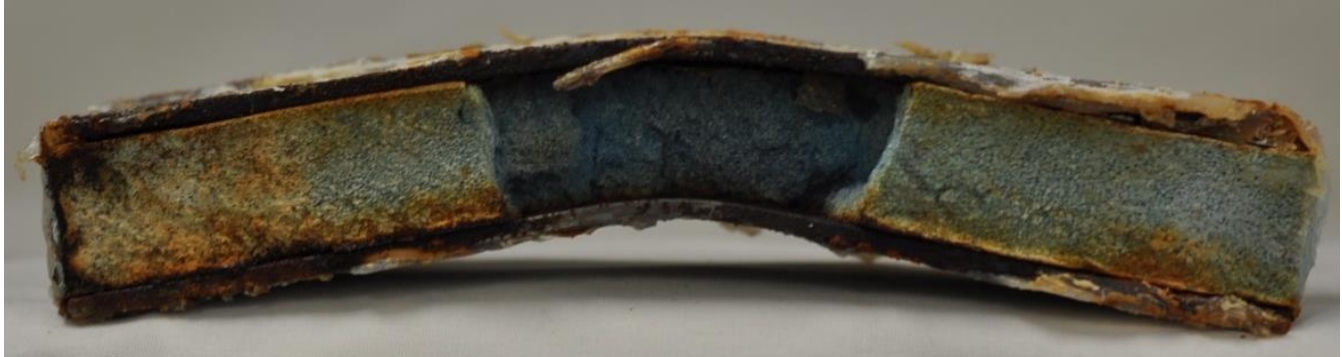

(c)

Fig. 21 Damage pattern 2 specimens (a) oobleck filled specimen (b) side view with debonding and shear cracking (c) side view with debonding and core extraction 


\section{Conclusions}

In this study, the effects of filling an open celled PU core sandwich panel with various fluids were investigated. A series of shock tube experiments and rheologic tests were performed. When comparing the various Newtonian and non-Newtonian fluids to one another, the following observations can be made:

1. Two STFs, Calcium Carbonate with PEG and silica with PEG, do not show any evidence of shear thickening in rheologic testing.

2. The polydimethylsiliconase showed characteristic viscoelasticity.

3. The air, glycerin, and silicon oil filled panels underwent different failure mechanisms (primarily global bending) than the water and oobleck filled panels which experienced large scale debonding, shear cracking, core extraction, and fluid expulsion.

4. Despite being denser than water and the other fluids the oobleck absorbed the least impulse per areal density

5. The starch and water (oobleck) filled panels experienced greater BFD than with simply water filled and slightly greater FFD.

6. The starch and water (oobleck) filled panels reached maximum BFD sooner than with simply water filled.

7. Glycerin absorbed the most impulse.

8. Glycerin (less viscous) filled panels experienced less FFD and BFD than silicon oil (more viscous) filled panels.

9. Glycerin had the least core compression of the fluids.

10. Viscoelasticity does not seem to play a role in shock mitigation 


\section{References}

[1] Bureau of Counterterrorism and Countering Violent Extremism Country Reports on Terrorism 2014 Report

[2] Bureau of Counterterrorism and Countering Violent Extremism Country Reports on Terrorism 2015 Report

[3] Tilbrook MT, Deshpande VS, Fleck NA. Underwater blast loading of sandwich beams: regimes of behaviour. Int J Solids Struct 2009; 46:3209-21.

[4] Tilbrook MT, Deshpande VS, Fleck NA. The impulsive response of sandwich beams: analytical and numerical investigation of regimes of behaviour. J Mech Phys Solids 2006; 54:2242-80.

[5] Karagiozova D, Nurick GN, Langdon GS. Behaviour of sandwich panels subject to intense air blasts - Part 2: numerical simulation. Compos Struct 2009; 91:442-50.

[6] Zhu F, Lu GA. Review of blast and impact of metallic and sandwich structures. Electron J Struct Eng 2007:92-101. Loading on structures:.

[7] Gibson LJ, Ashby MF. Cellular solids: structure and properties. 2nded.

Cambridge: Cambridge University Press; 1997.

[8] Hanssen AG, Enstock L, Langseth M. Close-range blast loading of aluminum foam panels. Int J Impact Eng 2002;27:593-618.

[9] Schimizze B, Son SF, Goel R, Vechart AP, Young L. An experimental and numerical study of blast induced shock wave mitigation in sandwich structures. Appl Acoust 2013; 74(1):1-9.

[10] Zhuang S, Ravichandran G, Grady DE. An experimental investigation of shock wave propagation in periodically layered composites. J Mech Phys Solids 2003; 51:245-65.

[11] Gardner N, Wang E, Shukla A. Performance of functionally graded sandwich composite beams under shock wave loading. Compos Struct 2012; 94:1755-70.

[12] Liu X, Tian X, Lu TJ, Zhou D, Liang B. Blast resistance of sandwich-walled hollow cylinders with graded metallic foam cores. Compos Struct 2012; 94:2485-93.

[13] Wang E, Gardner N, Shukla A. The blast resistance of sandwich composites with stepwise graded cores. Int J Solids Struct 2009; 46:3492-502.

[14] Fleck NA, Deshpande VS. The resistance of clamped sandwich beams to shock loading. J Appl Mech-T ASME 2004; 71:386-401. 
[15] Xue ZY, Hutchinson JW. A comparative study of impulse-resistant metal sandwich plates. Int J Impact Eng 2004; 30(10):1283-305.

[16] Theobald MD, Langdon GS, Nurick GN, Pillay S, Heyns A, Merrett RP. Large inelastic response of unbonded metallic foam and honeycomb core sandwich panels to blast loading. Compos Struct 2010; 92(10):2465-75.

[17] Langdon GS, von Klemperer CJ, Rowland BK, Nurick GN. The response of sandwich structures with composite face sheets and polymer foam cores to air-blast loading: preliminary experiments. Eng Struct 2012; 36:104-12.

[18] J. Wright, R. Hebert, D. Maddala, A. Shukla, Experimental Study on the Response of Graded Corrugated Steel Armor to Shock Loading. Meccanica, doi: 10.1007/s11012-014-9914-0, 2014.

[19] N. Wagner, J. E. Kirkwood, and R. G. Egres, Shear thickening fluid containment in polymer composites, US Patent 20060234572A1, 1 (2006).

[20] N. J. Wagner and F. J. Brady, Shear thickening in colloidal dispersions, Phys. Today, 27 (2009).

[21] Y. S. Lee and N. J. Wagner, Rheological properties and small angle neutron scattering of a shear thickening, nanoparticle dispersion at high shear rates, Ind. Eng. Chem. Res., 45, 7015 (2006).

[22] H. A. Barnes, Shear-thickening (dilatancy) in suspensions of non-aggregating solid particles dispersed in Newtonian liquids, J. Rheol., 33, 329 (1989).

[23] A. B. Metzner and M. Whitlock, Flow behavior of concentrated (dilatants) suspensions, Trans. Soc. Rheol., 11, 239 (1958).

[24] R. L. Hoffman, Discontinuous and dilatant viscosity in concentrated suspensions, part II. Theory and experimental tests behavior, J. Colloid Interface Sci., 46, 491 (1974).

[25] R. L. Hoffman, Explanations for the cause of shear thickening in concentrated colloidal suspensions, J. Rheol., 42, 111 (1998).

[26] R. L. Hoffman, Discontinuous and dilatant viscosity behavior in concentrated suspensions. Part I. Observation of a flow instability, Trans. Soc. Rheol., 16, 155 (1972).

[27] I. H. M. Laun, R. Bung, and F. Schmidt, Rheology of extremely shear thickening polymer dispersions (passively viscosity switching fluids), J. Rheol., 35, 999 (1991). 
[28] J. H. M. Laun, R. Bung, S. Hess, W. Loose, K. Hahn, E. Hadicke, R. Hingmann, F. Schmidt, and P. Lindner, Rheological and small angle neutron scattering investigation of shear-induced particle structures of concentrated polymer dispersions, J. Rheol., 36, 743 (1992).

[29] K. G. Bossis and J. F. Brady, The rheology of brownian suspensions, J. Chem. Phys., 91, 1866 (1989).

[30] L. W. H. Boersma, J. Laven, and H. N. Stein, Computer simulations of shear thickening of concentrated dispersions, J. Rheol., 39, 841

(1995).

[31] D. P. Kalman and N. J. Wagner, Microstructure of shear thickening concentrated Suspensions determined by flowUSANS, Rheol. Acta., 48, 897 (2009).

[32] Srivastava A, Majumdar A, Butola B. Improving the impact resistance of textile Structures by using shear thickening fluids: a review. Critical Reviews in Solid State and Materials Sciences, 2012; 37:115-129

[33] Wetzel E, Lee Y, Egres R, Kirkwood K, Kirkwood J, Wagner N. The effect of Rheological parameters on the ballistic properties of shear thickening fluid - Kevlar composites. NUMIFORM 2004;

[34] Lee B, Kim I, Kim C. The influence of the particle size of silica on the ballistic performance of fabrics impregnated with silica colloidal suspension. Journal of Composite materials, Vol. 43, No. 23/2009 2679-2698

[35] Majumdar A, Butola S, Srivastava A. An analysis of deformation and energy absorption modes of shear thickening fluid treated Kevlar fabrics as soft body armour materials. Materials and Design 2013; 51:148-153.

[36] Majumdar A, Butola S, Srivastava A. Optimal designing of soft body armour materials using shear thickening fluid. Materials and Design 2013; 46:191-198.

[37] Lee Y, Wetzel E, Egres R, Wagner N. Advanced body armor utilizing shear thickening fluids. 2002; $23^{\text {rd }}$ Army Science Conference.

[38] Majumdar A, Butola S, Srivastava A. Development of soft composite materials with improved impact resistance using Kevlar fabric and nano-silica based shear thickening fluid. Materials and Design 2014; 54:295-300.

[39] Decker M, Halbach C, Nam C, Wagner N, Wetzel E. Stab resistance of shear thickening fluid treated fabrics. Composite Science and Technology 2007; 67:565-578 
[40] Lim A, Lopatnikov, Wagner N, Gillespie J. Phenomenological modeling of the response of a dense colloidal suspension under dynamic squeezing flow. Journal of Non-Newtonian Fluid Mechanics 2011; 166:680-688

[41] Cwalina C, McCutcheon C, Dombrowski R, Wagner N. Engineering enhanced cut and puncture resistance into the thermal micrometeoroid garment using shear thickening fluid - armor ${ }^{\mathrm{tm}}$ absorber layers. Composites Science and Technology 2016; 131:31-66

[42] Haris A, Lee HP, Tay TE, Tan VBC. Shear thickening fluid impregnated ballistic fabric composites for shock wave mitigation. International Journal of Impact Engineering 2015; 80:143-151

[43] Dawson MA. Composite plates with a layer of fluid-filled, reticulated foam for blast protection of infrastructure. International Journal of Impact Engineering 2009; $36: 1288-1295$

[44] Subramaniam, K.V., Nian, W. and Andreopoulos, Y., 2009, " Blast Response Simulation of an Elastic Structure: Evaluation of the Fluid-structure Interaction Effect," International Journal of Impact Engineering 36, pp.965-974. 


\section{Chapter 5: Conclusions}

In these studies the effects of face plate thickness, corrugation thickness, preferentially foam filled cells, boundary conditions, and fluid infill of sandwich armor to shock load were investigated. Many of the insights found were possible due to an experimentally validated FEM. Foam filling proved a low density solution to increase bending rigidity, buckling resistance, as well as decreasing back face deflection (BFD) and front face deflection (FFD). The minimization of plastic deformation due to the foam also suggests that these panels would perform better for repeated loadings although this was not investigated. Increasing the stiffness of the panel through increasing the face plates, corrugation thickness, or foam infill proved effective as long as the core continued to behave in a soft-core manner. Increasing the stiffness of any of these components reduced the effectiveness of the foam as a shock mitigater however the stiffness of the foam was not varied as an additional parameter so its effectiveness may also scale as its stiffness is matched to that of the surrounding structure.

Preferentialy filling the foam within the corrugation allows for a more nuanced control of the responses of the sandwich panel to shock. Generally, increasing the amount of foam decreases the deflection of the front face of the panels but will increase the deflection of the back face (even over unfilled panels) unless some of the filling is nearest the back face in which the BFD can be greatly reduced. Filling the majority of the back face levels can provide better BFD than even entirely filled specimens although they would have increased FFD as universally the empty layers would compress, shear, and buckle before the foam filled layers would. When filling both sides, the panels behave as thickened face sheeted sandwich panels. So, foam filling can be used as a method to increase face sheet thickness behavior. 
While the investigation into filling the sandwich panels with liquids is not yet complete, with the data at hand both the Newtonian and non-Newtonian fillings provide no advantage over previous corrugation and foam filled specimens once their areal density is taken into account. Rheologic testing of shear thickening fluids (STFs) where inconsistent with published results and necessitates further investigation. The two non-Newtonian fluids (silicon oil - viscoelastic, and oobleck STF) performed worse than their Newtonian counterparts although why has not yet been definitively shown. The water and oobleck filled sandwich panels were characterized by extreme failures in bonding of their components likely due to corrosion of the mild steel by water. This in turn changed the panels from an enclosed system whose response would be dominated by the fluids energy and momentum transferal properties to more of an ablative style armor in which the manner in which these fluids and/or core are expended determine the response of the panels. Counter intuitively the specimens which absorbed more impulse, with the exception of the air filled panels, tended to perform better. Additional investigation with improved bonding or non-reactive STFs needs to be conducted for additional insight. 


\section{Appendix A}

\section{PROGRAMS: \\ Deflection Measure}

clear all;

close all;

clc

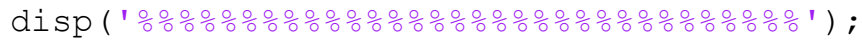

disp('Second Step: load the time series of the images.');

disp (' ');

disp('You have three ways to load the time series of the images.'); disp('1. The time between two frames is same.');

disp(' You can input total number of frames and time between two frames.')

disp(' The code will generate the time series automatically.'); $\operatorname{disp}('$ ') ;

disp('2. The time between two frames is not same.');

disp(' You can input total number of frames and input time between two frames frame by frame.')

$\operatorname{disp}('$ ') ;

disp('3. The time between two frames is not same.');

disp(' And you have saved the time series into one data file.')

disp(' Then you can just load that time series data file.');

disp (' ');

time_series_judge=true;

time series=0; \% this number can be any integer except 1, 2 and 3. while time_series_judge==true

time_series=input('Please choose which method you want to use (input the No. before the method): ');

if time_series $==1$

frames=input('Please input the total number of frames for calculating(integer): '); \% the number of images for calculating

frame_time=input('Please input the time between two frames

(unit: microsecond): ')/1000000;

for $i=1:$ frames

end

t_frame $(i, 1)=(i-1)$ *frame_time;

time_series_judge=false;

elseif time series $==2$

frames=input('Please input the total number of frames for

calculating(integer): '); $\frac{\circ}{\circ}$ the number of images for calculating sum time=0;

for $i=1$ : frames

disp('recent frame is')

i

disp ('frame. ')

disp('Please input 0 when $i=1 ;$ ');

sum time=input('Please input the time between this frame

and one frame before(unit: \mus): ')/1000000+sum_time; 


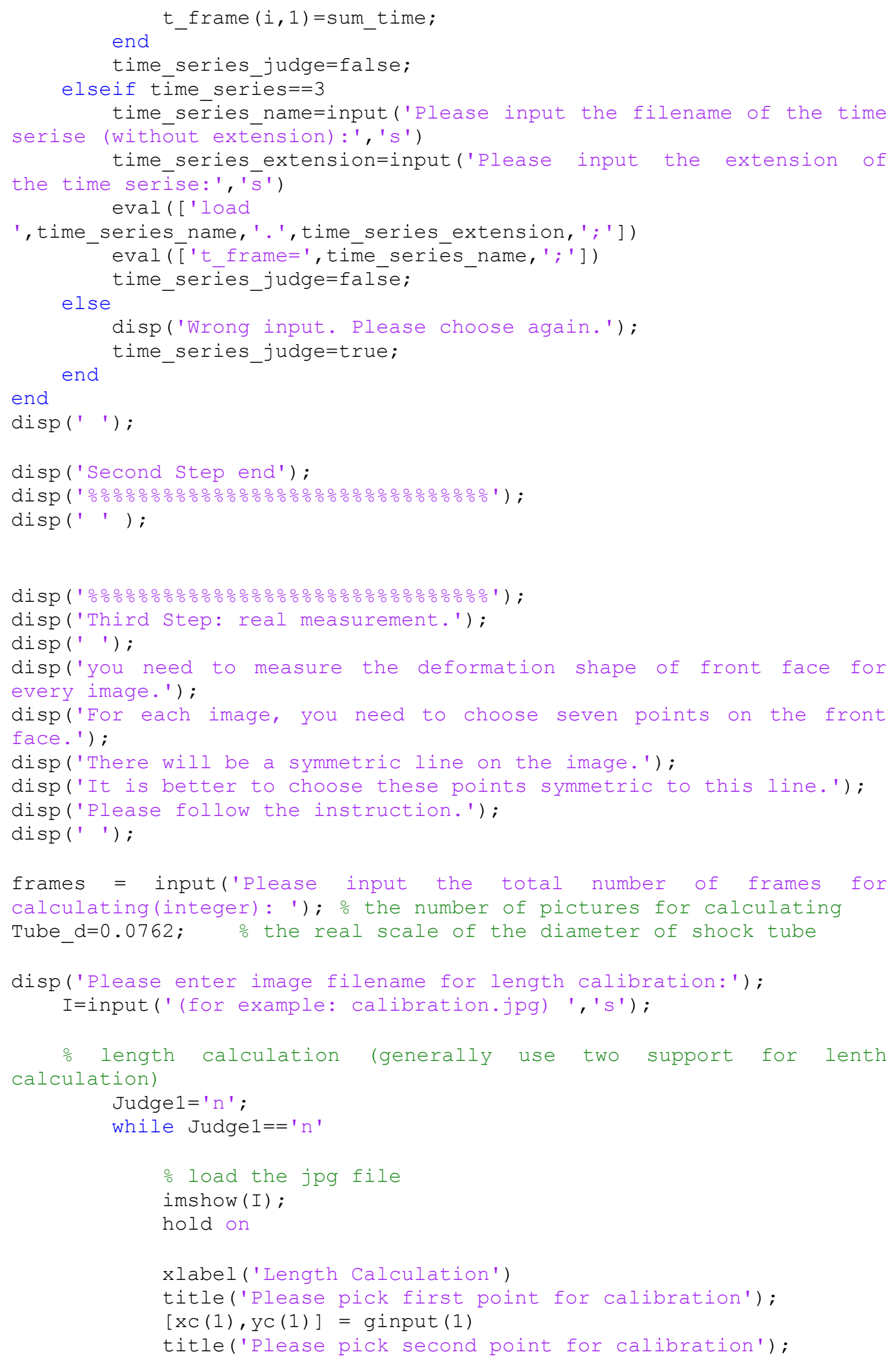




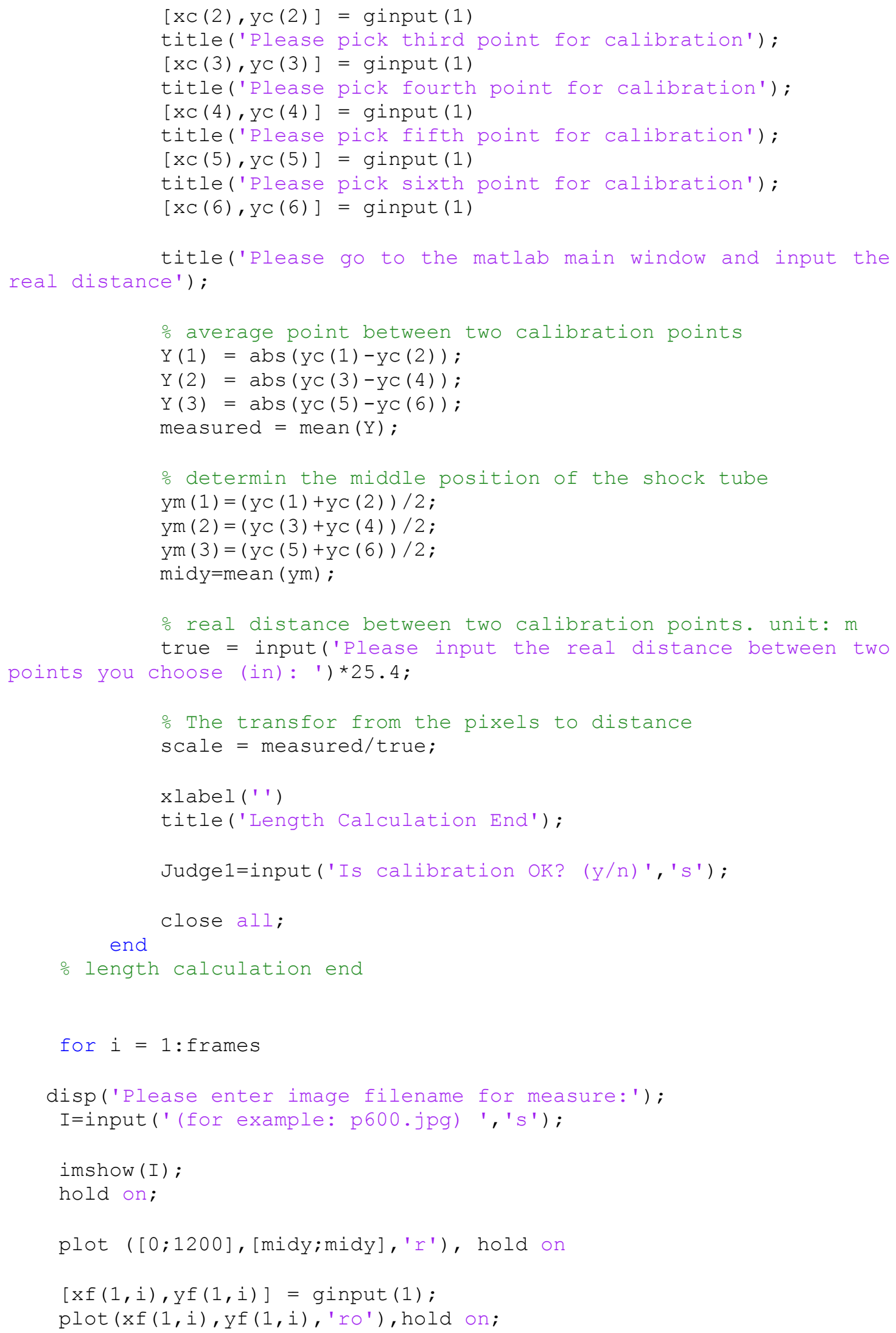




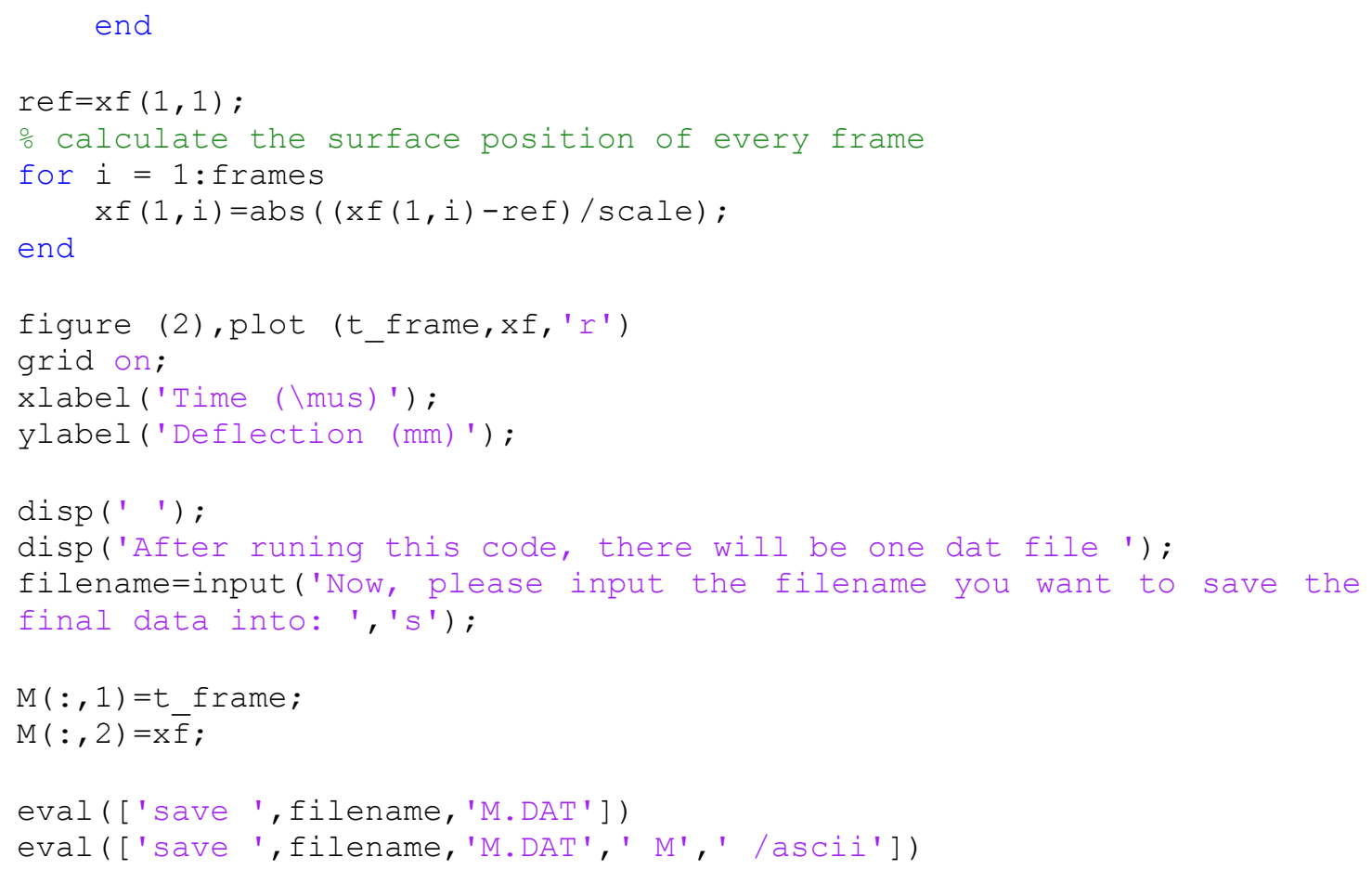




\section{SHPB Program: Verify Equilibrium}

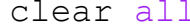




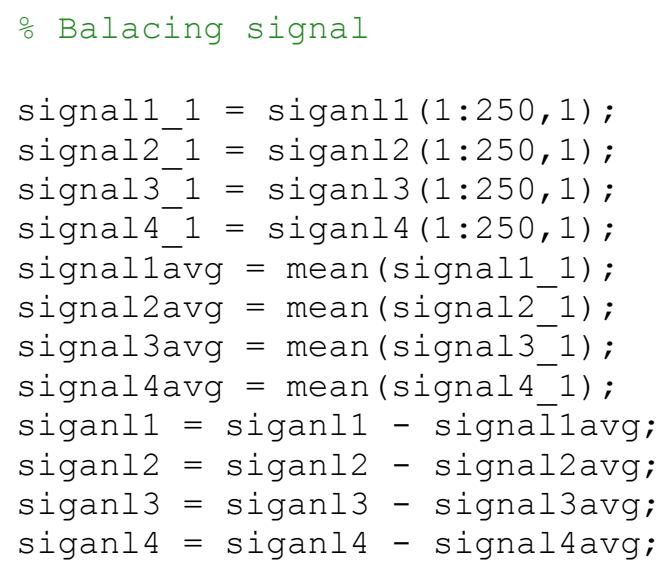




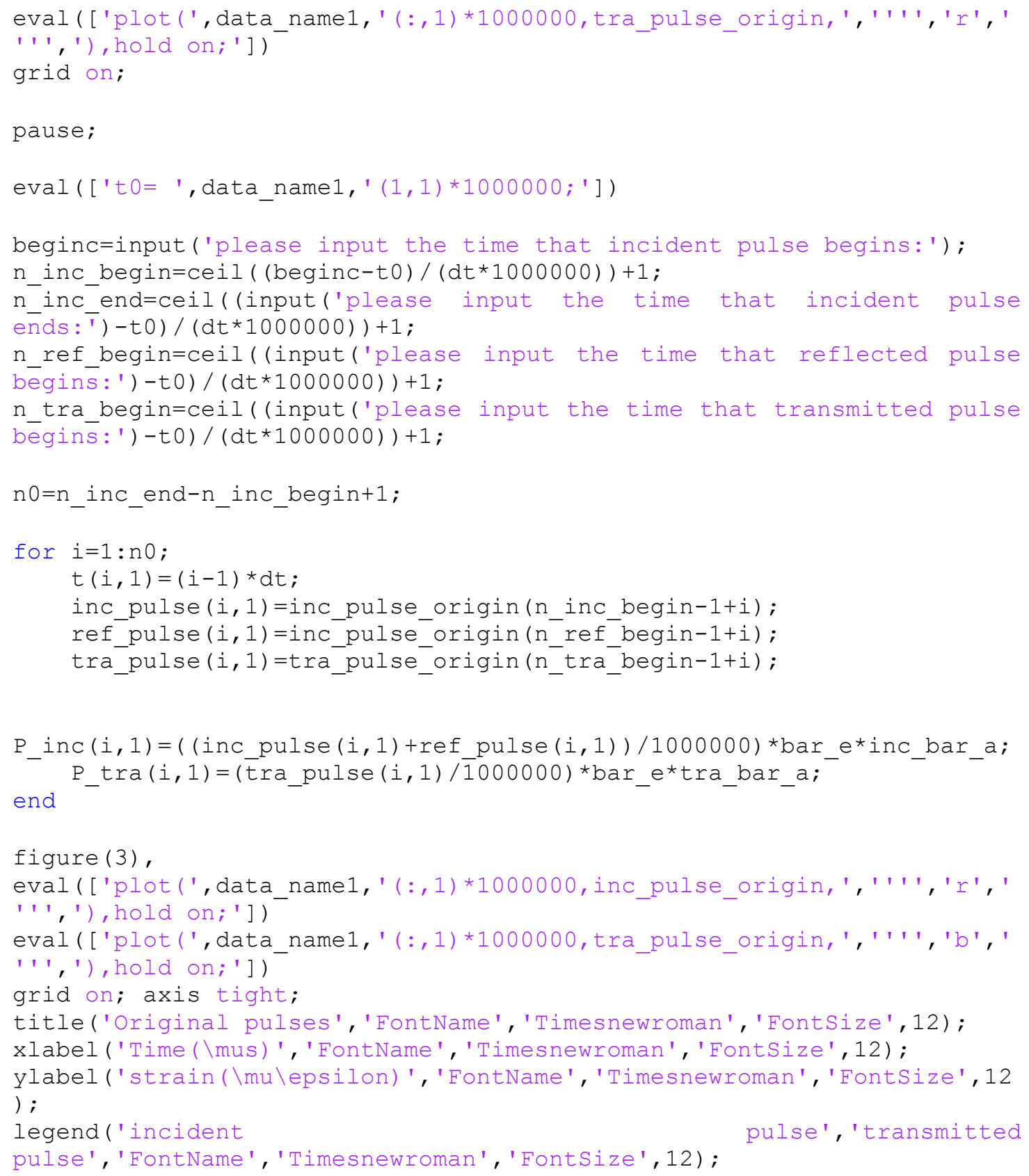


plot (t*1000000, P_inc, 'r.'), hold on;

plot (t*1000000, P_tra,'b'), hold on;

title('Force applied

on

the

specimen' ,'FontName', 'Timesnewroman', 'FontSize', 22) ;

axis tight; grid on;

xlabel ('Time (us) ', 'FontName', 'Timesnewroman', 'FontSize',22) ;

ylabel ('Force (N) ', 'FontName', 'Timesnewroman', 'FontSize', 22) ;

legend ('Front

face',' 'FontName', 'Timesnewroman', 'FontSize',22) ; 


\section{SHPB Program: Steel SHPB}

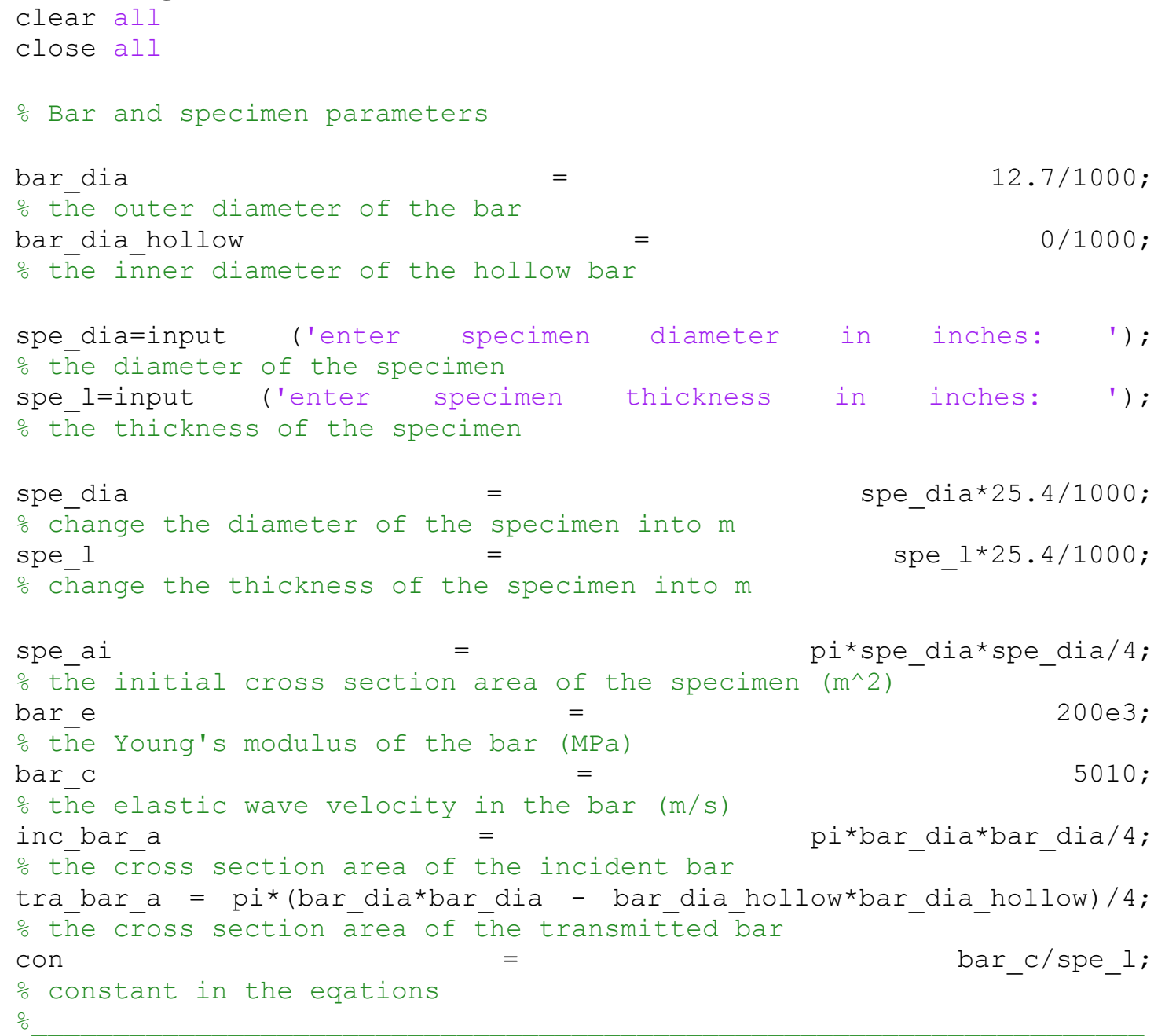




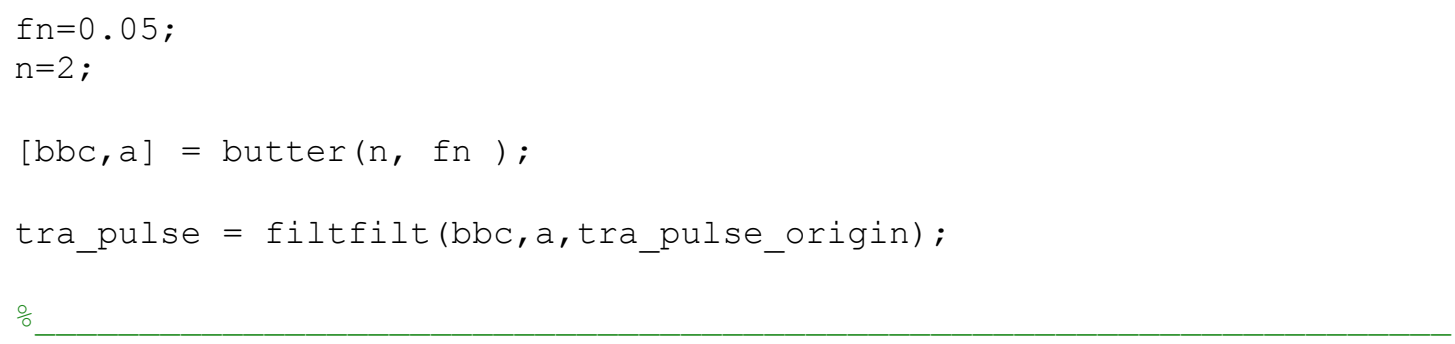

figure (1), plot(time_origin*1e6,inc_pulse_origin,'r') title('please find the time that the incident and reflected pulse begin and ends') 


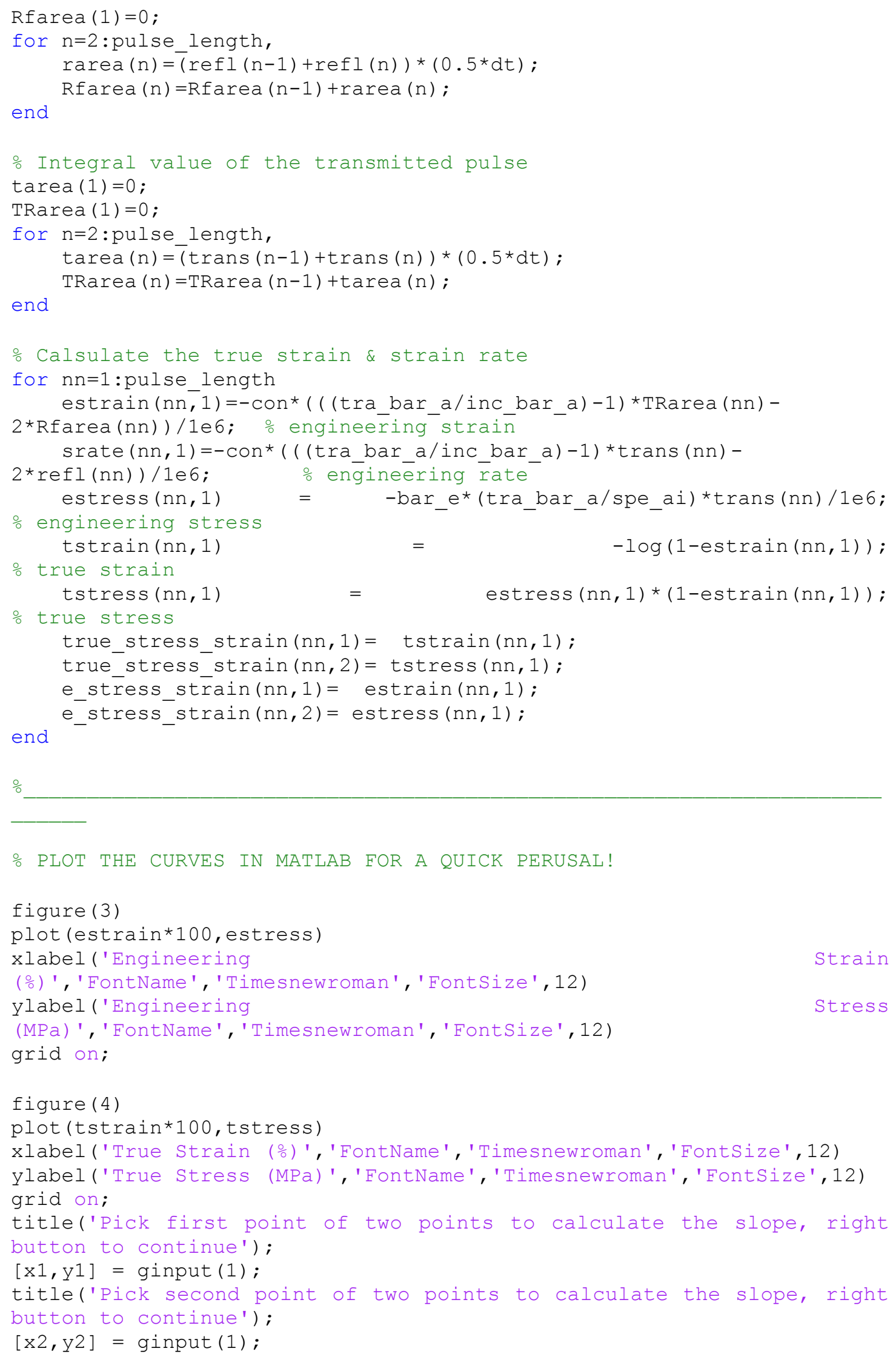




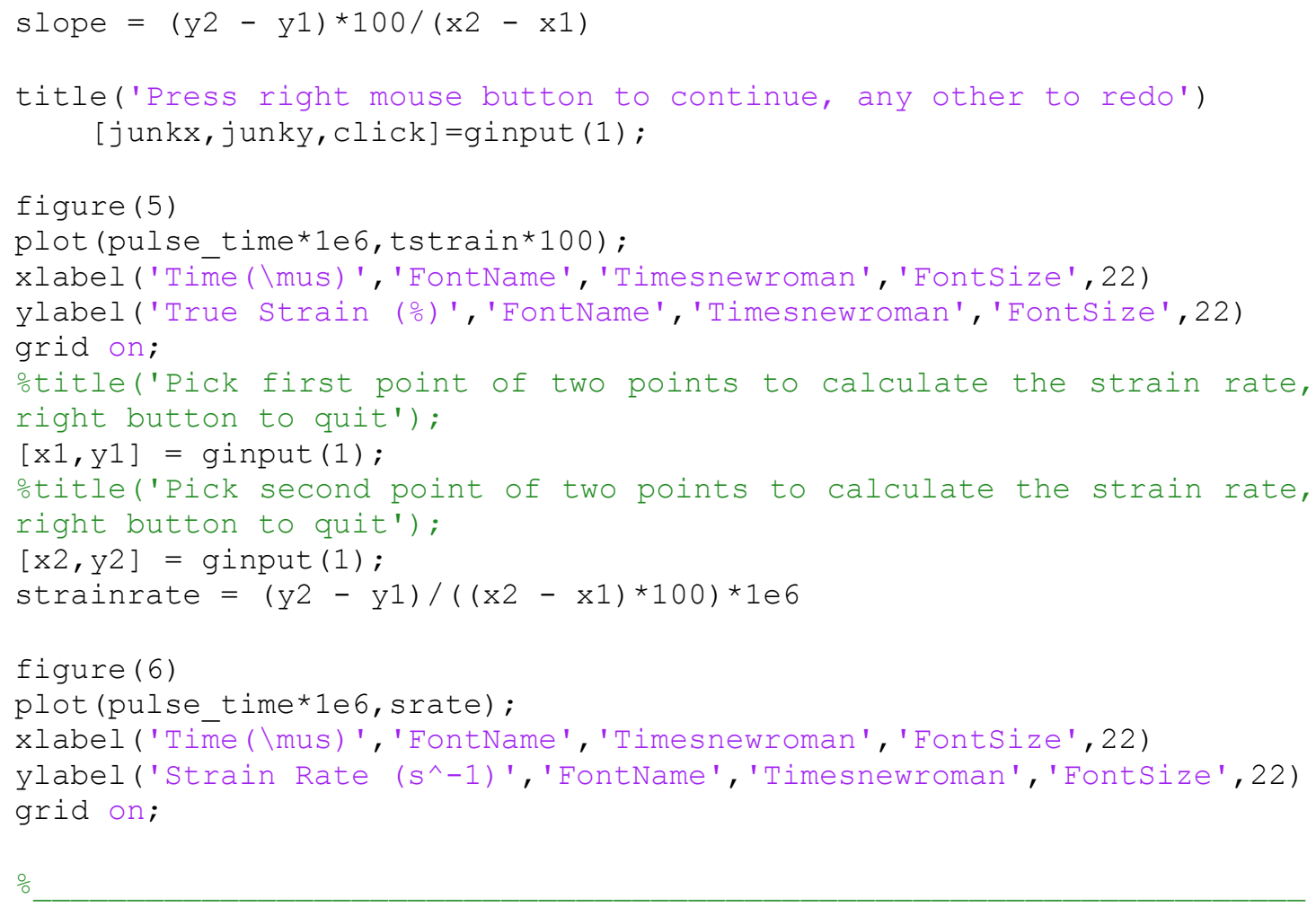

